\title{
Controlled Selectivity for Ethanol Steam Reforming Reaction over Doped CeO2 Surfaces: The Role of Gallium
}

Julia Vecchietti, Pablo Lustemberg, Esteban L. Fornero, Monica Calatayud, Sebastián E. Collins, Susanne Mohr, M. V. Ganduglia-Pirovano, Joerg Libuda, Adrian L. Bonivardi

Submitted date: 08/05/2020 - Posted date: 11/05/2020

Licence: CC BY-NC-ND 4.0

Citation information: Vecchietti, Julia; Lustemberg, Pablo; Fornero, Esteban L.; Calatayud, Monica; Collins, Sebastián E.; Mohr, Susanne; et al. (2020): Controlled Selectivity for Ethanol Steam Reforming Reaction over Doped CeO2 Surfaces: The Role of Gallium. ChemRxiv. Preprint. https://doi.org/10.26434/chemrxiv.12272192.v1

The ethanol steam reforming reaction, together with the adsorption and decomposition of ethanol was studied on $\mathrm{CeO} 2$ and gallium-doped ceria ( $\mathrm{CeGaOx}$ ) by a combined experimental and theoretical approach using infrared spectroscopy (IR), mass spectrometry (MS) and density functional theory (DFT) calculations. At $100^{\circ} \mathrm{C}$, different types of monodentate ethoxy species were identified as standing-up (SU) on Ce4+ and lying-down (LD) on Ce4+ and Ga3+, with the alkyl chain more perpendicular or parallel to the surface, respectively. It is suggested that the incorporation of $\mathrm{Ga}$ into the ceria lattice changes the decomposition pathway of LD species, which converts to acetate instead of ethylene, attributed to the increased lattice oxygen lability in the Ce-O-Ga interface upon doping and the propensity to form $\mathrm{Ga}-\mathrm{H}$ surface species. Under ethanol steam reforming conditions, Ga doping of ceria-based materials has a drastic effect by improving the $\mathrm{H} 2: \mathrm{CO} 2$ ratio, changing the product distribution and reducing coke formation.

File list (2)

manuscript_fv.pdf (1.95 MiB)

view on ChemRxiv • download file 


\section{Controlled selectivity for ethanol steam reforming}

\section{reaction over doped $\mathrm{CeO}_{2}$ surfaces: The role of}

\section{gallium}

Julia Vecchietti ${ }^{1}$, Pablo Lustemberg ${ }^{2,3^{*}}$, Esteban L. Fornero ${ }^{1}$, Mónica Calatayud ${ }^{4}$, Sebastián

E. Collins ${ }^{1}$; Susanne Mohr ${ }^{5}$, M. Verónica Ganduglia-Pirovano ${ }^{3}$, Jörg Libuda ${ }^{5}$, Adrian L. Bonivardi ${ }^{1,6^{*}}$

${ }^{1}$ Instituto de Desarrollo Tecnológico para la Industria Química, UNL-CONICET, 3000 Santa Fe, Argentina.

${ }^{2}$ Instituto de Física Rosario (IFIR), CONICET-UNR, Bv. 27 de Febrero 210bis, S2000EZP Rosario, Santa Fe, Argentina.

${ }^{3}$ Instituto de Catálisis y Petroleoquímica, CSIC, C/Marie Curie 2, 28049 Madrid, Spain.

${ }^{4}$ Sorbonne Université, CNRS, Laboratoire de Chimie Théorique, LCT, F. 75005 Paris, France

${ }^{5}$ Interface Research and Catalysis, ECRC, Friedrich-Alexander-Universität ErlangenNürnberg, Egerlandstraße 3, D-91058 Erlangen, Germany.

${ }^{6}$ Facultad de Ingeniería Química, Universidad Nacional del Litoral, Santiago del Estero 2829, 3000 Santa Fe, Argentina. 


\begin{abstract}
The ethanol steam reforming reaction, together with the adsorption and decomposition of ethanol was studied on $\mathrm{CeO}_{2}$ and gallium-doped ceria $\left(\mathrm{CeGaO}_{\mathrm{x}}\right)$ by a combined experimental and theoretical approach using infrared spectroscopy (IR), mass spectrometry (MS) and density functional theory (DFT) calculations. At $100^{\circ} \mathrm{C}$, different types of monodentate ethoxy species were identified as standing-up (SU) on $\mathrm{Ce}^{4+}$ and lying-down (LD) on $\mathrm{Ce}^{4+}$ and $\mathrm{Ga}^{3+}$, with the alkyl chain more perpendicular or parallel to the surface, respectively. It is suggested that the incorporation of Ga into the ceria lattice changes the decomposition pathway of LD species, which converts to acetate instead of ethylene, attributed to the increased lattice oxygen lability in the Ce-O-Ga interface upon doping and the propensity to form $\mathrm{Ga}-\mathrm{H}$ surface species. Under ethanol steam reforming conditions, Ga doping of ceria-based materials has a drastic effect by improving the $\mathrm{H}_{2}: \mathrm{CO}_{2}$ ratio, changing the product distribution and reducing coke formation.
\end{abstract}

Keywords: bioethanol, hydrogen production, gallia, deactivation, coke precursors 


\section{Introduction}

A few decades ago, the concern about global warming attributed to the emissions of $\mathrm{CO}_{2}$, the primary greenhouse gas originating from the burning of fossil fuels, triggered the interest in using $\mathrm{H}_{2}$ as an energy vector. For reasons of storage and transport, it is more convenient, however, that the energy vector is liquid and has low toxicity. Thus, ethanol obtained from renewable resources [1], is a suitable candidate for this purpose. It is well known that molecular hydrogen can be produced from ethanol by reforming with water vapor [2].

One of the main challenges with respect to the formulation of catalytic materials for ethanol steam reforming (ESR) lies in the development of active metal-supported catalysts that control the selectivity in order to, for example, increase the $\mathrm{H}_{2}$ yield and inhibit the undesired coke formation. The main reactions that contribute to coke production during ESR are: ethylene polymerization, the Boudouard reaction, reverse carbon gasification, and hydrocarbon decomposition [3]. As a consequence of those reactions, mainly two types of carbon deposits have been reported on the surface of ESR catalysts: amorphous and filamentous [4,5]. The nature of the carbon and the reactions involved in its formation depend on reaction conditions and the chosen catalyst, which typically consists of metal nanoparticles dispersed on a reducible oxide.

Several strategies have been applied to minimize carbon formation during ESR, such as increasing the steam to ethanol ratio, adding oxygen to the feed, co-feeding $\mathrm{CO}_{2}$ or $\mathrm{H}_{2}$, as well as catalyst modifications $[3,5]$. However, those strategies that only modify the operational conditions had limited success. Catalyst modifications have shown to be the most promising strategy to minimize coke formation during ESR in terms of yield and costs. The formulation of catalytic materials for ESR plays a crucial role in terms of minimizing carbon deposits as well as achieving complete ethanol conversion and maximizing the $\mathrm{H}_{2}$ yield. The nature of the metal, the particle size and oxidation state, and the impact of the oxide support on the stability 
and selectivity of the catalyst are fundamental aspects to be taken into account when designing an ESR catalyst [6-8]. A better understanding of the reaction mechanism, and of the aspects mentioned above, should lead to the development of new high performance catalysts for ESR. The support itself can play a major role in ESR by assisting in the removal of carbon or suppressing its formation [5]. The addition of dopants to the oxide support has been studied with the aim of modifying the acid/base properties or enhancing the oxygen storage capacity. On the one hand, neutralizing the acid sites by addition of dopants may limit ethylene polymerization, and dopants such as alkali metals [9-12], alkaline earth metals,[13-15] or rare earth oxides[16-20] have shown to be effective. However, it should be noted that doping can impact the electronic properties of the catalyst and/or block or modify specific adsorption sites. On the other hand, it has been reported that cerium oxide $\left(\mathrm{CeO}_{2}\right.$, also known as ceria) may be a suitable support for ESR metal/oxide catalysts due to its high oxygen storage capacity, and at the same time, the oxygen mobility in ceria can improve the catalytic stability by suppressing the formation of carbonaceous species $[21,22]$. The use of ceria-containing mixed oxides as a support for an ESR catalyst has been tested. Doping $\mathrm{CeO}_{2}$ with $\mathrm{Ca}, \mathrm{Pr}, \mathrm{Fe}$ and $\mathrm{Zr}$ [23-27] promoted the reducibility of pure ceria and enhanced the formation of oxygen vacancies. Also, some of us have proved that doping ceria with $\mathrm{Ga}^{3+}$ by a co-precipitation method, which allows the incorporation of gallium cations into in the fluorite structure of ceria giving place to ceriumgallium mixed oxides, significantly improves the redox property of the pure ceria material $[28,29]$. This was proven by a combination of experimental techniques such as oxygen storage capacity measurements, temperature-programmed reduction (TPR) by $\mathrm{H}_{2}$ and $\mathrm{CO}$, in situ Xray absorption spectrometry (XAS) and time-resolved X-ray diffraction (TR-XRD). Additionally, the isothermal reduction experiments with $\mathrm{H}_{2}$ followed by DRIFTS together with kinetic modeling and DFT calculations showed that in the case of the cerium-gallium mixed oxides, $\mathrm{H}_{2}$ is activated at the interface between gallia-rich and ceria-rich (nano)domains with a 
very low activation barrier, leading to $\mathrm{Ga}-\mathrm{H}$ species and the formation of $\mathrm{Ce}^{3+}$, as well as to the formation of oxygen vacancies by removal of water [30]. From the above findings, it is expected that mixed cerium-gallium oxides will be better supports for the steam reforming of ethanol than pure ceria because the higher reducibility of the mixed oxide would facilitate the oxidation of ethoxy species, preventing the formation of coke precursors. Also, the ease at which $\mathrm{H}$ would be abstracted from ethoxy species on the doped system to form $\mathrm{Ga}-\mathrm{H}$ groups, is likely to have an important effect.

In this work we investigated the ethanol steam reforming reaction, as well as the adsorption and decomposition of ethanol over bare ceria and ceria-gallia supports to characterize its surface chemical behavior. A combined experimental and theoretical approach is used to provide a comprehensive picture of the processes taking place. The adsorption and temperature programmed surface reaction (TPSR) of ethanol is measured and followed by diffuse reflectance infrared spectroscopy (TPSR-IR) and mass spectrometry (TPSR-MS). Periodic Density Functional Theory (DFT) calculations on model systems allow the characterization of the nature of some surface species and intermediates involved.

\section{Experiments}

\section{Synthesis of the materials}

Polycrystalline $\mathrm{CeO}_{2}$ and two cerium-gallium mixed oxides ( $\mathrm{Ce}$ to $\mathrm{Ga}$ atomic ratio equal to 90:10 and 80:20 at/at, hereafter labelled as $\mathrm{Ce}_{90} \mathrm{Ga}_{10} \mathrm{O}_{\mathrm{x}}$ and $\mathrm{Ce}_{80} \mathrm{Ga}_{20} \mathrm{O}_{\mathrm{x}}$, respectively), generally termed as $\mathrm{CeGaO}_{x}$, together with $\mathrm{Ga}_{2} \mathrm{O}_{3}$ as reference material, were prepared from high purity metal nitrate salts and characterized in previous studies [28-31]. In summary, $\mathrm{CeO}_{2}$, $\mathrm{Ga}_{2} \mathrm{O}_{3}$ and $\mathrm{CeGaO}_{\mathrm{x}}$ were prepared by precipitation in ammonia solution $(\mathrm{pH} 8.5$ ) of the respective nitrates dissolved in water, and ethanol in the case of $\mathrm{Ga}^{3+}$ cations alone, followed by washing, drying and calcination at $723 \mathrm{~K}$. The structural analysis by X-ray diffraction 
(XRD) of a set of $\mathrm{Ce}-\mathrm{Ga}$ materials in a wide range of compositions $(\mathrm{Ce} / \mathrm{Ga}$ atomic ratio $=95 / 5$, $90 / 10,80 / 20$, and $75 / 25)[29,31]$ together with nanostructural analysis and chemical composition by high-resolution electron microscopy (HREM) and energy dispersive spectroscopy (EDS) on the samples $\mathrm{Ce}_{95} \mathrm{Ga}_{05} \mathrm{O}_{\mathrm{x}}$ and $\mathrm{Ce}_{80} \mathrm{Ga}_{20} \mathrm{O}_{\mathrm{x}}$, allowed us to verify that it is possible to incorporate homogeneously $\mathrm{Ga}^{3+}$ cations to the fluorite-type structure of ceria [31].

Table 1 summarizes the most relevant features of those oxides for this study, that is, gallium content, surface area by Brunauer-Emmett-Teller method, oxygen storage capacity, reducibility by temperature-programmed $\mathrm{CO}$ reduction (see relative $\mathrm{CO}$ uptake) and adsorption of ethanol.

Table 1. Characterization of the oxides ${ }^{\mathrm{a}}$.

\begin{tabular}{lcccccc}
\hline Sample & $\begin{array}{c}\mathrm{Ga}^{\mathrm{b}} \\
\% \mathrm{w} / \mathrm{w}\end{array}$ & $\begin{array}{c}\mathrm{Ga}:(\mathrm{Ce}+\mathrm{Ga})^{\mathrm{c}} \\
\% \text { at } / \mathrm{at}\end{array}$ & $\begin{array}{c}\mathrm{S}_{\mathrm{BET}}{ }^{\mathrm{d}} \\
\mathrm{m}^{2} / \mathrm{g}\end{array}$ & $\begin{array}{c}\mathrm{OSC}^{\mathrm{e}} \\
\mu \mathrm{mol} \mathrm{O} / \mathrm{g}\end{array}$ & $\begin{array}{c}\text { Relative CO uptake }^{\mathrm{f}} \\
\mathrm{A}_{\text {sample}} / \mathrm{A}_{\mathrm{CeO} 2}\end{array}$ & $\begin{array}{c}\text { Ethanol uptake }^{\mathrm{g}} \\
\mu \mathrm{mol} \mathrm{C}_{2} \mathrm{H}_{5} \mathrm{OH} / \mathrm{m}^{2}\end{array}$ \\
\hline $\mathrm{CeO}_{2}$ & 0 & - & 58 & 50 & 1 & 4.0 \\
$\mathrm{Ce}_{90} \mathrm{Ga}_{10} \mathrm{O}_{\mathrm{x}}$ & 4.3 & 10 & 108 & 261 & 2.5 & 4.2 \\
$\mathrm{Ce}_{80} \mathrm{Ga}_{20} \mathrm{O}_{\mathrm{x}}$ & 8.9 & 19 & 100 & 475 & 3.7 & 4.2 \\
$\mathrm{Ga}_{2} \mathrm{O}_{3}$ & 100 & - & 76 & - & 0.3 & 3.9 \\
\hline
\end{tabular}

${ }^{a}$ The samples were previously pretreated as described in section 2 .

${ }^{\mathrm{b}}$ X-ray fluorescence spectroscopy.

${ }^{\mathrm{c}}$ Atomic surface ratio by X-ray photoelectron spectroscopy (XPS).

${ }^{\mathrm{d}}$ Brunauer-Emmett-Teller (BET) surface area.

${ }^{\mathrm{e}}$ Oxygen storage capacity (OSC), by temperature gravimetric analysis (TGA) in $\mathrm{H}_{2}$ at $200{ }^{\circ} \mathrm{C}$ (see Figure S1 in SI).

${ }^{\mathrm{f}}$ Temperature-programmed reduction (TPR) in $5 \% \mathrm{CO} / \mathrm{He}$ from 100 to $400{ }^{\circ} \mathrm{C}$ by mass spectrometry. A: integrated area of the $\mathrm{CO}$ traces (see Figure $\mathrm{S} 2$ in $\mathrm{SI}$ ).

${ }^{\mathrm{g}}$ Mass Spectrometry (MS) at $100{ }^{\circ} \mathrm{C}$ in ethanol $(2.3 \% \mathrm{v} / \mathrm{v}) / \mathrm{He}$ (see text). Estimated error: $\pm 0.1 \mu \mathrm{mol} / \mathrm{m}^{2}$ (see Figure $\mathrm{S} 3$ in SI).

The cobalt catalyst were prepared on pure $\mathrm{CeO}_{2}$ and $\mathrm{Ce}_{90} \mathrm{Ga}_{10} \mathrm{O}_{\mathrm{x}}$ by wet impregnation from an aqueous solution of $\mathrm{Co}\left(\mathrm{NO}_{3}\right)_{2} \cdot 6 \mathrm{H}_{2} \mathrm{O}$, in order to obtain a low Co loading ( 0.9 atom of $\mathrm{Co} / \mathrm{nm}^{2}$, that is, $0.5 \% \mathrm{w} / \mathrm{w} \mathrm{Co} / \mathrm{CeO}_{2}$ and $\left.1.0 \% \mathrm{w} / \mathrm{w} \mathrm{Co} / \mathrm{Ce}_{90} \mathrm{Ga}_{10} \mathrm{O}_{\mathrm{x}}\right)$. XRD patterns and $\mathrm{S}_{\mathrm{BET}}$ surface area of the catalysts were identical to those of the bare supports, indicating that Co 
particles are well dispersed and that the morphology of the support was not affected by Co incorporation.

\section{Catalytic tests}

Ceria and gallium-doped ceria samples were tested under ethanol steam reforming conditions. Each sample was diluted with quartz $(1: 4 \mathrm{w} / \mathrm{w})$, placed in a quartz microreactor and then, subjected to a cleaning pretreatment, as follows: 1) heating under pure $\mathrm{H}_{2}$ flow to $450{ }^{\circ} \mathrm{C}$ (15 min); 2) purge with $\mathrm{He}$ at $\left.450{ }^{\circ} \mathrm{C}(15 \mathrm{~min}) ; 3\right)$ oxidation with $\mathrm{O}_{2}$ at $\left.450{ }^{\circ} \mathrm{C}(15 \mathrm{~min}) ; 4\right)$ cooling under $\mathrm{O}_{2}$ flow to $100{ }^{\circ} \mathrm{C}$; and 5) purge with $\mathrm{He}$ at $100{ }^{\circ} \mathrm{C}(15 \mathrm{~min})$. The catalytic test was run with a mixture of water and ethanol diluted in $\operatorname{Ar}\left(\mathrm{H}_{2} \mathrm{O}: \mathrm{C}_{2} \mathrm{H}_{5} \mathrm{OH}: \mathrm{Ar}=8.8\right.$ :1.5:89.7 molar ratio, that is, $\mathrm{H}_{2} \mathrm{O}: \mathrm{C}_{2} \mathrm{H}_{5} \mathrm{OH}=6: 1$ ). The catalytic performance was measured from 200 to $500{ }^{\circ} \mathrm{C}\left(100{ }^{\circ} \mathrm{C}\right.$ steps, $1 \mathrm{~h}$ at each temperature $)$ using two gas chromatograph Shimadzu GC-9A equipped with a Porapack QS and Carbosieve SII, and TCD and FID detectors for the quantification of $\mathrm{C}_{2} \mathrm{H}_{5} \mathrm{OH}, \mathrm{H}_{2}, \mathrm{CO}, \mathrm{CO}_{2}, \mathrm{CH}_{4}, \mathrm{C}_{2} \mathrm{H}_{4}$ (ethylene), $\mathrm{C}_{2} \mathrm{H}_{4} \mathrm{O}$ (acetaldehyde), $\mathrm{CH}_{3} \mathrm{COCH}_{3}$ (acetone), $\mathrm{CH}_{3} \mathrm{CHOHCH}_{3}$ (2-propanol). The weight hourly space velocity was 1.7 and $3.3 \mathrm{~h}^{-1}$ for $\mathrm{CeO}_{2}$ and $\mathrm{CeGaO}_{\mathrm{x}}$, respectively, in order to keep constant the residence time normalized per surface area of the oxides $\left(1550 \mathrm{~m}^{2}\right.$ sample. $\mathrm{h} / \mathrm{mol}$ ethanol $)$. Conversion of ethanol $\left(\mathrm{X}_{\mathrm{C}_{2} \mathrm{H}_{5} \mathrm{OH}}\right)$, yield to $\mathrm{H}_{2}\left(\right.$ Yield $_{\mathrm{H}_{2}}$ ) and yield to carbon-containing compounds (Yield ${ }_{i}$ ) were calculated (for details see Supporting Information). For 100\% conversion of ethanol, the basedcarbon selectivity to the $\mathrm{i}$-product is equivalent to the Yield $\mathrm{d}_{\text {. }}$

\section{Temperature programmed surface reaction of ethanol}

Two kinds of temperature-programmed surface reaction (TPSR) studies of adsorbed ethanol were carried out to follow the adsorbed and gaseous-phase evolved species, by infrared (IR) and mass spectrometry (MS), respectively, as follows:

\subsection{TPSR by diffuse reflectance infrared Fourier Transform spectroscopy (TPSR-IR)}


$100 \mathrm{mg}$ of each oxide were loaded in a high temperature Harrick DRIFT cell with ZnSe windows mounted in a FTIR Nicolet 8700 spectrometer (MCT detector). Before the alcohol adsorption, the samples were subjected to the same cleaning procedure described above. Then, a gas stream containing $2.3 \% \mathrm{v} / \mathrm{v}$ of ethanol in He was admitted in the DRIFT cell at $100{ }^{\circ} \mathrm{C}$ (15 min), and afterwards purged with $\mathrm{He}$ to eliminate the ethanol excess $\left(15 \mathrm{~min}, 100{ }^{\circ} \mathrm{C}\right)$. Finally, the cell was heated until $450{ }^{\circ} \mathrm{C}\left(5^{\circ} \mathrm{C} / \mathrm{min}\right)$ under He flow. In all cases the gas flow was $50 \mathrm{~cm}^{3} / \mathrm{min}$. The IR spectra were taken consecutively by averaging 25 scans (acquisition time $=30 \mathrm{~s})$ and with a resolution equal to $4 \mathrm{~cm}^{-1}$.

\subsection{TPSR by mass spectrometry (TPSR-MS)}

A sample amount equivalent to $10 \mathrm{~m}^{2}$ of oxide, diluted with quartz, was loaded on a $\mathrm{U}$ shaped microreactor coupled with a mass spectrometer (Balzers QMG 112A) and the same cleaning treatment, adsorption and TPSR of ethanol protocols were carried out, as detailed in the previous TPSR-IR experiment. During the TPSR-MS, the following species were scanned at the outlet of the reactor: $\mathrm{H}_{2}, \mathrm{He}, \mathrm{N}_{2}, \mathrm{CH}_{4}, \mathrm{H}_{2} \mathrm{O}$, ethylene, $\mathrm{CO}$, acetaldehyde, ethanol, $\mathrm{O}_{2}, \mathrm{CO}_{2}$, acetone, diethyl ether, acetic acid and ethyl acetate $(\mathrm{m} / \mathrm{e}=2,4,14,16,18,27,28,29,31,32$, 44, 58, 59, 60 and $61 \mathrm{amu}$, respectively). The amount of adsorbed ethanol (ethanol uptake) on the oxides was determined at $100{ }^{\circ} \mathrm{C}$ after switching a 4-way valve from pure He to the $2.3 \%$ $\mathrm{v} / \mathrm{v}$ ethanol stream (diluted in $\mathrm{He}$ ) and $\mathrm{Ar}\left(\operatorname{tracer}, 5 \mathrm{~cm}^{3} / \mathrm{min}\right)$. The total ethanol uptake (Q) was determined by taking the integral of the difference between the trace of the adsorbate during the adsorption experiment and the trace of Ar, for a given gas molar flow rate of the adsorbate and weight of sample, from 0 to $30 \mathrm{~min}$.

Immediately after each TPSR-MS experiment, a temperature-programmed oxidation (TPO) test was run to investigate the carbonaceous species remaining after the ethanol decomposition study, as described: the TPSR-MS sample was cooled down in $\mathrm{He}$ and heated to $450{ }^{\circ} \mathrm{C}$ under 
pure $\mathrm{O}_{2}$ flow $\left(10{ }^{\circ} \mathrm{C} / \mathrm{min}\right)$; the evolution of the same MS signals as mentioned above were followed, but only $\mathrm{CO}_{2}$ was detected.

To assure that in both types of TPSR experimental setup, with IR and MS detection, both temperature and fluidodynamics were comparable, a thermocouple was inserted in the catalyst bed in order to monitor the temperature of the sample at all times and the dimensions of both sample beds were similar." Theoretical Models and Computational Methods

All electronic structure and vibrational calculations were carried out using the spin-polarized DFT approach as implemented in the Vienna ab initio simulation package (VASP) \{vasp site, http://www.vasp.at; version vasp.5.3.5\}[32]. Ce (4f, 5s, 5p, 5d, 6s), O (2s, 2p), Ga (3d, 4s, 4p), $\mathrm{C}(2 \mathrm{~s}, 2 \mathrm{p})$, and $\mathrm{H}(1 \mathrm{~s})$ electrons were explicitly treated as valence ones within the projector augmented wave (PAW) method [33], with a plane-wave cutoff energy of $600 \mathrm{eV}$, whereas the remaining electrons were considered as part of the atomic core.

The total energies, vibrational frequencies and forces were calculated with an accuracy of $10^{-8} \mathrm{eV}$ and $10^{-2} \mathrm{eV} / \AA ̊$ for electronic and force convergence, respectively, within the DFT $+\mathrm{U}$ approach by Dudarev et al. [34] ( $\mathrm{U}_{\text {eff }}=\mathrm{U}-\mathrm{J}=4.5 \mathrm{eV}$ for the Ce $4 \mathrm{f}$ electrons) with the generalized gradient approximation (GGA) proposed by Perdew, Burke, and Ernzerhof (PBE) [35]. Long-range dispersion corrections were also considered employing the so-called DFTDF2 approach (optB88-vdW) [36], as implemented in VASP by Klimeš et al. [37,38], using the algorithm of Román-Pérez and Soler [39].

The $3 \times 3$ (111) termination of the fluorite $\mathrm{CeO}_{2}$ structure was chosen as model. A six atomic layer slab (two $\mathrm{O}-\mathrm{Ce}-\mathrm{O}$ trilayers) with the calculated ceria bulk equilibrium lattice constant of $5.485 \AA$ was used, one trilayer was allowed to relax with the surface unit cell kept fixed during geometry optimization. The gallium-containing slab was modeled by replacing one surface cerium ion $\left(\mathrm{Ce}^{4+}\right)$ by a gallium one $\left(\mathrm{Ga}^{3+}\right)$ plus one hydrogen atom to keep charge neutrality. The composition of the slabs was $\mathrm{Ce}_{18} \mathrm{O}_{36}$ for pure ceria and $\mathrm{Ce}_{17} \mathrm{GaO}_{36} \mathrm{H}$ for 
gallium-doped ceria. In addition, corresponding hydroxylated surface models were also created by adding a dissociated water molecule, resulting in slabs with the $\mathrm{Ce}_{18} \mathrm{O}_{37} \mathrm{H}_{2}$ and $\mathrm{Ce}_{17} \mathrm{GaO}_{37} \mathrm{H}_{3}$ compositions. Selected calculations were performed for nine atomic layer slabs (three $\mathrm{O}-\mathrm{Ce}-\mathrm{O}$ trilayers) in order to evaluate a possible influence of the thickness of the model in the calculated properties such as the ethanol adsorption energy and its vibrational frequency (cf. Table S1 and S2).

The adsorption energy of the dissociatively chemisorbed ethanol was calculated according to the following equation for the example of the hydroxylated undoped $\mathrm{CeO}_{2}(111)$ surface:

$$
E_{\text {ads }}=\mathrm{E}\left[\left(\mathrm{C}_{2} \mathrm{H}_{5} \mathrm{O}+\mathrm{H}\right) / \mathrm{Ce}_{18} \mathrm{O}_{37} \mathrm{H}_{2}\right]-E\left[\mathrm{Ce}_{18} \mathrm{O}_{37} \mathrm{H}_{2}\right]-E\left[\mathrm{C}_{2} \mathrm{H}_{5} \mathrm{OH}_{\text {gas }}\right](1),
$$

where $E\left[\left(\mathrm{C}_{2} \mathrm{H}_{5} \mathrm{O}+\mathrm{H}\right) / \mathrm{Ce}_{18} \mathrm{O}_{37} \mathrm{H}_{2}\right]$ is the total energy of the ethoxy species and hydrogen coadsorbed on the surface, $E\left[\mathrm{Ce}_{18} \mathrm{O}_{37} \mathrm{H}_{2}\right]$ is the total energy of the surface without the adsorbate, and $E\left[\mathrm{C}_{2} \mathrm{H}_{5} \mathrm{OH}_{\text {gas }}\right]$ is the energy of the gas phase ethanol molecule. The same definition was used for the corresponding hydroxylated Ga-doped surface $\left(\mathrm{Ce}_{17} \mathrm{GaO}_{37} \mathrm{H}_{3}\right.$ slab).

Monkhorst-Pack grids with a $(2 \times 2 \times 1)$ k-point sampling were used. For the ethanol gasphase species, a $\Gamma$-point calculation in a $20 \times 19 \times 18 \AA^{3}$ box was performed.

The computed IR vibrational frequencies have been calculated by diagonalizing the Hessian matrix. The elements of the Hessian matrix were obtained from finite differences of the DFT+U forces with small displacements of all of the atoms of the chemisorbed species. The theoretical frequencies were scaled following the procedure described by Merrick et al. [40] minimizing by least-squares the residual:

$$
\Delta=\sum_{i}^{a l l}\left(\lambda \omega_{i}^{\text {theor }}-v_{i}^{\text {exp }}\right)^{2}
$$

where $\omega_{\mathrm{i}}^{\text {theor }}$ and $v_{\mathrm{i}}^{\text {exp }}$ are the $i$ th theoretical harmonic frequency and the $i$ th experimental frequency (in $\mathrm{cm}^{-1}$ ) of ethanol in gas-phase in the $800-1200 \mathrm{~cm}^{-1}$ range. The experimental data were obtained from the NIST database (https://cccbdb.nist.gov/). The minimization of equation (1) leads to: 


$$
\lambda=\sum_{i}^{\text {all }} \omega_{i}^{\text {theor }} v_{i}^{\text {exp }} / \sum_{i}^{\text {all }}\left(\omega_{i}^{\text {the }}\right)^{2}
$$

The optimized scale factor $\lambda$ was then used to calculate an overall root-mean-square error, $\mathrm{rms}_{\mathrm{ov}}$ :

$$
r m s_{o v}=\left(\sum_{1}^{n_{m o l}} \Delta_{m i n} / n_{m o l}\right)^{1 / 2}
$$

where $\mathrm{n}_{\text {mol }}$ is the number of modes and $\Delta_{\min }=\left(\lambda \omega_{i}^{\text {theor }}-v_{i}^{\text {exp }}\right)^{2}$. With this procedure the scale factor obtained and applied to the DFT frequencies values was $\lambda=1.021$ with $\mathrm{rms}_{\mathrm{ov}}=5$ $\mathrm{cm}^{-1}$ (cf. Table S3 for experimental and calculated frequencies for ethanol in the gas phase).

\section{Results and Discussion}

1. Steam reforming of ethanol on $\mathrm{CeO}_{2}$ and $\mathrm{Ce} G a \mathrm{O}_{x}$

Both $\mathrm{CeO}_{2}$ and $\mathrm{Ce}_{90} \mathrm{Ga}_{10} \mathrm{O}_{\mathrm{x}}$ were active for ethanol conversion over $300{ }^{\circ} \mathrm{C}$, reaching $100 \%$ conversion at $500{ }^{\circ} \mathrm{C}$, and being the gallium-doped oxide more active than pure ceria (Figure 1a).

The product distribution varied significantly between both samples, keeping the same features at each temperature. At $500{ }^{\circ} \mathrm{C}$, the yield to $\mathrm{H}_{2}$ was 2.5 -fold higher on $\mathrm{CeGaO}_{\mathrm{x}}$ than on $\mathrm{CeO}_{2}$, and consistently the yield to $\mathrm{CO}_{2}$ followed the same trend (Figure $1 \mathrm{~b}$ ). However, the $\mathrm{H}_{2}: \mathrm{CO}_{2}$ molar ratio at the reactor outlet was equal to 3.1 and 2.4 (see molar fractions in Supporting Information), respectively, which is a clear indication that the cerium-gallium mixed oxide is a better ESR material since that ratio is closer to the theoretical value $\left(\mathrm{H}_{2}: \mathrm{CO}_{2}\right.$ $=3)$. 

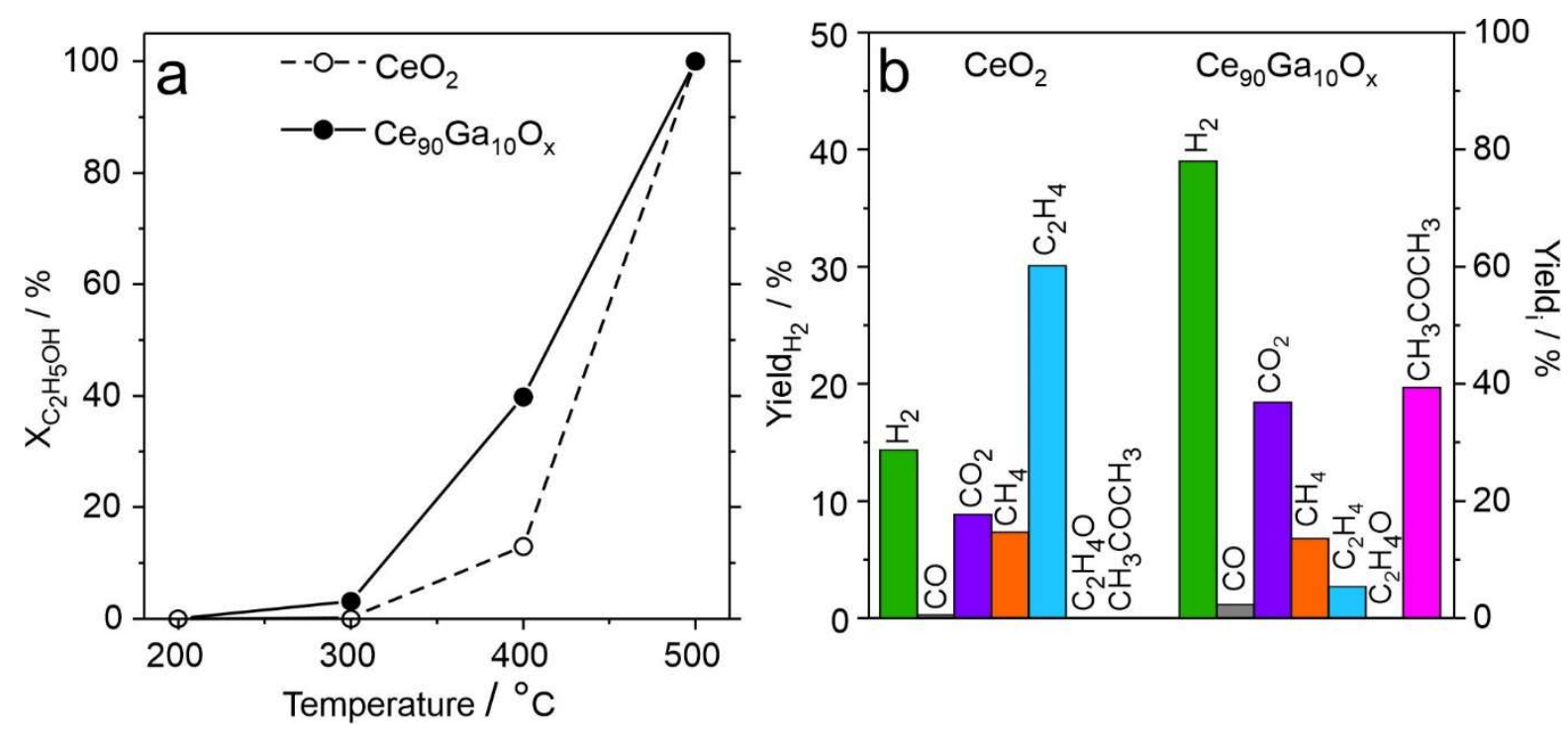

Figure 1. (a) Ethanol conversion vs. temperature $\left(200-500{ }^{\circ} \mathrm{C}\right)$ and, (b) product yield at $500{ }^{\circ} \mathrm{C}$ under ESR conditions $\left(\mathrm{H}_{2} \mathrm{O}: \mathrm{C}_{2} \mathrm{H}_{5} \mathrm{OH}=6: 1,1550 \mathrm{~m}^{2} . \mathrm{h} / \mathrm{molC}_{2} \mathrm{H}_{5} \mathrm{OH}\right)$ for $\mathrm{CeO}_{2}$ and $\mathrm{Ce}_{90} \mathrm{Ga}_{10} \mathrm{O}_{\mathrm{x}}$. Carbon balance: 93 and $97 \%$ for $\mathrm{CeO}_{2}$ andCe ${ }_{90} \mathrm{Ga}_{10} \mathrm{Ox}$, respectively at $500{ }^{\circ} \mathrm{C}$.

Also, the yields to ethylene and acetone were remarkably different: While $\mathrm{CeO}_{2}$ was able to convert the $60 \%$ of ethanol to ethylene $\left(\mathrm{C}_{2} \mathrm{H}_{4}\right)$, the $\mathrm{Ce}_{90} \mathrm{Ga}_{10} \mathrm{O}_{\mathrm{x}}$ produced less than $5 \%$ of this product. On the contrary, the yield to acetone $\left(\mathrm{CH}_{3} \mathrm{COCH}_{3}\right)$ was $40 \%$ on $\mathrm{Ce}_{90} \mathrm{Ga}_{10} \mathrm{O}_{\mathrm{x}}$ and only traces were detected on pure ceria. Some methane (approximately $14 \%$ ) and small amounts of carbon monoxide (lower than $2 \%$ ) were also produced by both oxides.

Thus, gallium addition to ceria definitely improves the ESR capacity of pure ceria, which is consistent with the higher redox capacity (OSC and relative CO uptake, see Table 1) of the cerium-gallium mixed oxides. Additionally, the noticeable production of ethylene, a coke precursor [3-5,21], was decreased by the incorporation of gallium to the pure $\mathrm{CeO}_{2}$ while the basicity of the $\mathrm{CeO}_{2}$ is slightly decreased with the addition of gallium up to $\mathrm{Ga} / \mathrm{Ce}=20 / 80$ atomic ratio $[28,41]$. To explain these disparate chemical behaviors, and to understand the plausible impact on the ERS reaction performance on both kinds of oxides, it is reasonable to study -first- the adsorption and decomposition of ethanol over the surface of pure ceria and cerium-gallium mixed oxides. 


\section{Adsorption of ethanol on $\mathrm{CeO}_{2}$ and $\mathrm{CeGaO}$}

The adsorption of ethanol gave rise to a number of bands assigned to ethoxy $\left(\mathrm{C}_{2} \mathrm{H}_{5} \mathrm{O}\right)$ species, together with the partial consumption of hydroxyl groups (negative bands at 3710, 3685 and $3660 \mathrm{~cm}^{-1}$ ) characteristic of the dissociative chemisorption of ethanol on hydroxylated oxide surfaces (Figure 2a) [42,43]. The detailed assignment of each IR bands is reported in Table 2 for all the samples studied in this work.
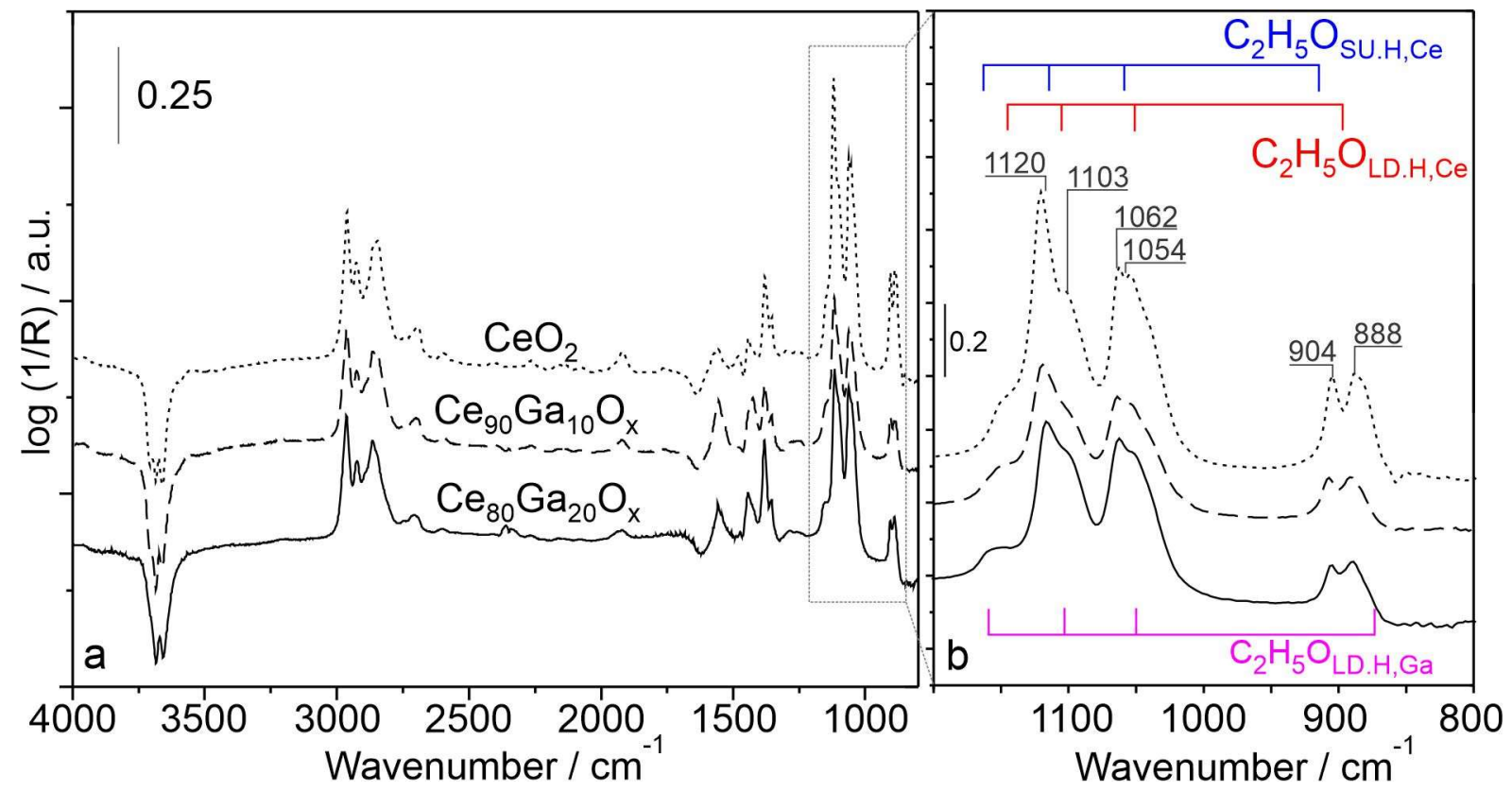

Figure 2. (a) DRIFT spectra for $\mathrm{CeO}_{2}, \mathrm{Ce}_{90} \mathrm{Ga}_{10} \mathrm{O}_{\mathrm{x}}$ and $\mathrm{Ce}_{80} \mathrm{Ga}_{20} \mathrm{O}_{\mathrm{x}}$ after ethanol adsorption at $100{ }^{\circ} \mathrm{C}$ and purging with $\mathrm{He}$ (the spectrum of the clean oxide right before the adsorption was subtracted). (b) Details of the $1200-800 \mathrm{~cm}^{-1}$ region of the spectra and the calculated scaled frequencies values for $\mathrm{C}_{2} \mathrm{H}_{5} \mathrm{O}_{\text {LD.H,Ce }}$ (red lines), $\mathrm{C}_{2} \mathrm{H}_{5} \mathrm{O}_{\text {sU.H,Ce }}$ (blue lines) and $\mathrm{C}_{2} \mathrm{H}_{5} \mathrm{O}_{\text {su.H,Ga }}$ (magenta lines), see text.

The main bands associated to $\mathrm{C}_{2} \mathrm{H}_{5} \mathrm{O}$ species on pure $\mathrm{CeO}_{2}$ can be identified in three regions of the spectra. In the region from 3000 to $2700 \mathrm{~cm}^{-1}$, a number of overlapping IR bands can be detected corresponding to the $\mathrm{C}-\mathrm{H}$ bond stretching $(v)$ modes of ethoxy species. Second, the peaks assigned to the deformation $(\delta)$ of the $\mathrm{CH}$ bonds of $\mathrm{C}_{2} \mathrm{H}_{5} \mathrm{O}$ species can be found between 
$1800-1200 \mathrm{~cm}^{-1}$. Finally, in the region from 1200 to $800 \mathrm{~cm}^{-1}$, a series of overlapping bands can be detected corresponding to the (CO) and (CCO) modes. These bands usually provide information on the coordination of alkoxy species on the surface of oxides $[44,45]$. They are decisive to explain the reactivity of the alcohols.
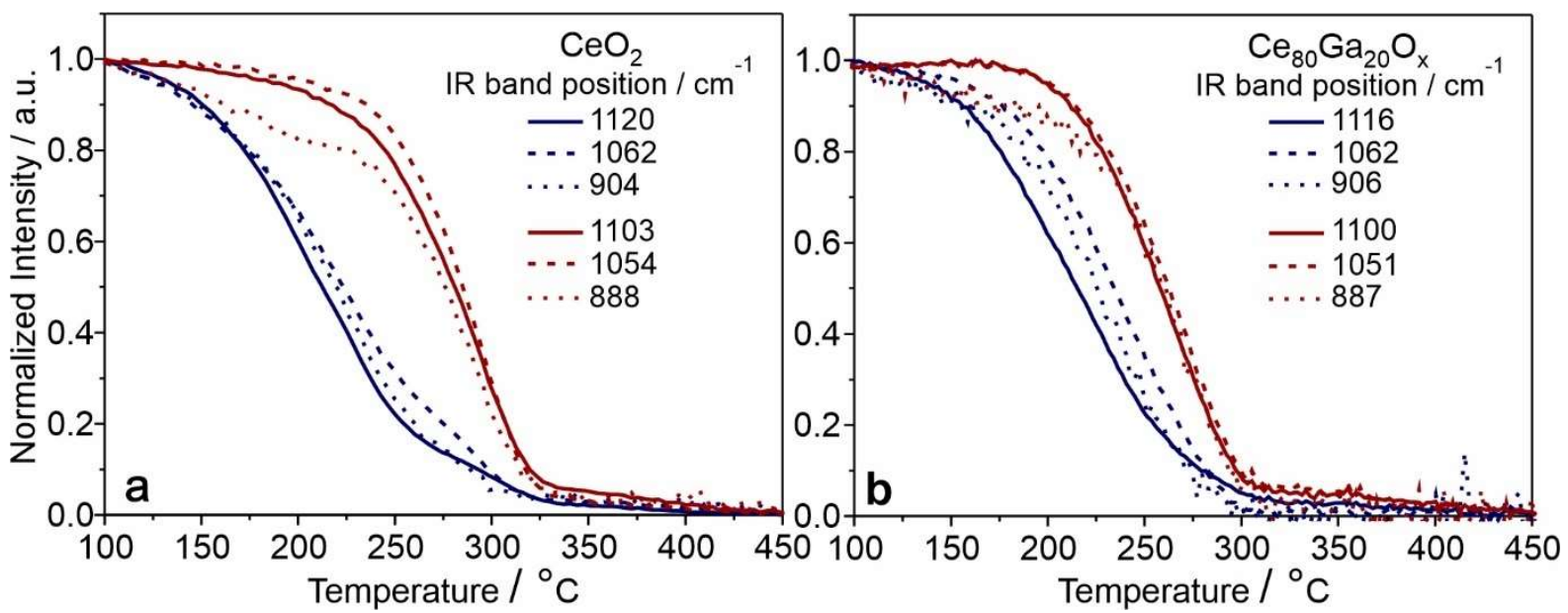

Figure 3. Normalized integrated intensity of the ethoxy DRIFT signals detected in the $1200-$ $800 \mathrm{~cm}^{-1}$ region of the spectra during the TPSR-IR for $\mathrm{CeO}_{2}$ (a) and $\mathrm{Ce}_{80} \mathrm{Ga}_{20} \mathrm{O}_{\mathrm{x}}$ (b).

It is worth mentioning that in the case of pure ceria, a number of bands were identified at $1150,1120,1103,1062,1054,904$ and $888 \mathrm{~cm}^{-1}$ which resemble doublets (with the exception of the first one, Figure 2b). The thermal evolution of these bands during the TPSR-IR experiments clearly showed that the intensities of the signals at 1103,1054 and $888 \mathrm{~cm}^{-1}$ decreases more slowly than those of the peaks at 1120, 1062 and $904 \mathrm{~cm}^{-1}$. The evolution of the normalized integrated intensity of those sets of IR signals is depicted in Figure 3a. These two sets of bands could originate from two types of ethoxy species adsorbed on the $\mathrm{CeO}_{2}$ surface (generically labeled as type 1 and 2): one more stable species (type 1) and another one more labile species (type 2). Here, it is important to point out that the adsorption and activation of ethanol was studied on a fully oxidized sample, since the final step of the cleaning pretreatment involves oxidizing the sample under pure $\mathrm{O}_{2}$ at $450^{\circ} \mathrm{C}$ (see experimental section). In other words, the ethoxy species detected by IR spectroscopy are adsorbed on $\mathrm{Ce}^{4+}$ cations. 
In agreement, the $2130 \mathrm{~cm}^{-1} \mathrm{Ce}^{3+} \mathrm{IR}$ signal was not detected before or after ethanol adsorption at $100^{\circ} \mathrm{C}$.

Due to the different thermal stability, and in line with the reactivity of surface methoxy groups [45], it is tempting to assign the first set of bands (type 1) to bidentate ethoxy species, whereas the second set (type 2) would correspond to monodentate ethoxy ones. Such an assignment would partially contradict that by Yee et al. [46], who suggested that peaks at 1107 and $1057 \mathrm{~cm}^{-1}$ may be caused by mono and bidentate ethoxy species, respectively, after the adsorption of ethanol at $25{ }^{\circ} \mathrm{C}$ on their ceria powder samples. The assignment of those vibrational frequencies is certainly more complex than it appears. Li et al. [47] studied the adsorption of ethanol on differently shaped $\mathrm{CeO}_{2}$ nanoparticles $\left(25^{\circ} \mathrm{C}\right)$ that preferentially exhibited specific crystallographic planes: (111) for nanooctahedra, (100) for nanocubes, and a mixture of facets for nanorods. The ceria nanooctahedra developed bands at 1096, 1050 and $885 \mathrm{~cm}^{-1}$, whereas in the case of the nanocubes and nanorods, two additional bands were also detected at 1120 and $905 \mathrm{~cm}^{-1}$. Also, in a recent DFT study, Beste and Overbury [48] suggested that on $\mathrm{CeO}_{2}$ (111) only monodentate ethoxy (on-top) is a stable surface species. However, two of such configurations were proposed to coexist, where ethoxy can be characterized as either standing-up (with the $\mathrm{C}-\mathrm{C}$ axis perpendicular to the surface) or lying-down (with the $\mathrm{C}-\mathrm{C}$ axis parallel to the surface). On $\mathrm{CeO}_{2}(100)$, on the other hand, ethoxy species are also predicted to be adsorbed in a bidentate form in addition to the on-top species [48]. Then, for a more accurate assignment of these bands, a combination of our experimental results with theoretical calculations is required. 
Table 2. Experimental and calculated infrared frequencies $\left(\mathrm{cm}^{-1}\right)$ together with surface species and mode assignments during the adsorption and TPSR of ethanol on $\mathrm{CeO}_{2}$ and $\mathrm{CeGaO}_{\mathrm{x}}$ samples.

\begin{tabular}{|c|c|c|c|c|c|c|c|}
\hline \multirow[t]{2}{*}{ Species } & \multirow[t]{2}{*}{ Vibrational mode } & \multicolumn{3}{|c|}{ Experimental } & \multicolumn{3}{|c|}{ Calculated } \\
\hline & & $\mathrm{CeO}_{2}$ & $\mathrm{Ce}_{90} \mathrm{Ga}_{10} \mathrm{O}_{\mathrm{x}}$ & $\mathrm{Ce}_{80} \mathrm{Ga}_{20} \mathrm{O}_{\mathrm{x}}$ & $\mathrm{C}_{2} \mathrm{H}_{5} \mathrm{O}_{\text {SU.H,Ce }}{ }^{\mathrm{a}}$ & $\mathrm{C}_{2} \mathrm{H}_{5} \mathrm{O}_{\text {LD.H,Ce }}{ }^{\mathrm{b}}$ & $\mathrm{C}_{2} \mathrm{H}_{5} \mathrm{O}_{\text {LD.H,Ga }}{ }^{\mathrm{c}}$ \\
\hline Ethoxy & $v_{\mathrm{as}}\left(\mathrm{CH}_{3}\right)$ & 2962 & 2962 & 2967 & & & \\
\hline \multirow{15}{*}{$\left(\mathrm{C}_{2} \mathrm{H}_{5} \mathrm{O}\right)$} & $v_{\mathrm{as}}\left(\mathrm{CH}_{2}\right)$ & 2926 & 2925 & 2923 & & & \\
\hline & $v_{\mathrm{s}}\left(\mathrm{CH}_{3}\right)$ & 2862 & 2864 & 2867 & & & \\
\hline & $v_{\mathrm{s}}\left(\mathrm{CH}_{2}\right)$ & 2845 & 2847 & 2848 & & & \\
\hline & $\delta\left(\mathrm{CH}_{2}\right)+\mathrm{FR}$ & 2690 & 2704 & 2696 & & & \\
\hline & $\delta\left(\mathrm{CH}_{2}\right)$ & 1480 & 1480 & 1475 & & & \\
\hline & $\delta_{\text {as }}\left(\mathrm{CH}_{3}\right)$ & 1442 & 1442 & 1443 & & & \\
\hline & $\delta_{\mathrm{s}}\left(\mathrm{CH}_{3}\right)$ & 1380 & 1380 & 1382 & & & \\
\hline & $\omega\left(\mathrm{CH}_{2}\right)$ & 1354 & 1354 & 1354 & & & \\
\hline & $\tau(\mathrm{CCO})$ & 1150 & 1152 & 1155 & 1163 & 1146 & 1158 \\
\hline & $v(\mathrm{CO})$ & 1120 & 1118 & 1116 & 1114 & & \\
\hline & & 1103 & 1100 & 1100 & & 1105 & 1103 \\
\hline & $v_{\text {as }}(\mathrm{CCO})$ & 1062 & 1063 & 1062 & 1058 & & \\
\hline & & 1054 & 1052 & 1051 & & 1051 & 1050 \\
\hline & $v_{\mathrm{s}}(\mathrm{CCO})$ & 904 & 904 & 906 & 914 & & \\
\hline & & 888 & 888 & 887 & & 896 & 874 \\
\hline Acetate & $v_{\mathrm{as}}(\mathrm{OCO})$ & 1550 & 1558 & 1557 & & & \\
\hline$\left(\mathrm{C}_{2} \mathrm{H}_{3} \mathrm{O}_{2}\right)$ & $v_{\mathrm{s}}(\mathrm{OCO})$ & 1426 & 1423 & 1430 & & & \\
\hline $\mathrm{Ce}^{3+}$ & Forbidden electronic & 2112 & 2123 & 2123 & & & \\
\hline Gallium hydride & $v(\mathrm{GaH})$ & - & $1955 \mathrm{w}$ & $1940 \mathrm{w}$ & & & \\
\hline
\end{tabular}

\footnotetext{
a "standing-up" ethoxy species stabilized by a O-Ce bond and two hydrogen bonds $\left(\mathrm{C}_{2} \mathrm{H}_{5} \mathrm{O}_{\text {su.H.Ce }}\right)$, Figure $4 \mathrm{~b}$.

b "lying-down" ethoxy species stabilized by a O-Ce bond and two hydrogen bonds $\left(\mathrm{C}_{2} \mathrm{H}_{5} \mathrm{O}_{\text {LD H,Ce }}\right)$, Figure 4a.

c "lying-down" ethoxy species stabilized by a $\mathrm{O}-\mathrm{Ga}$ bond and two hydrogen bonds $\left(\mathrm{C}_{2} \mathrm{H}_{5} \mathrm{O}_{\text {LD.H,Ga }}\right)$, Figure $4 \mathrm{c}$.
} 
As our polycrystalline $\mathrm{CeO}_{2}$ samples could exhibit a mixture of different crystallographic planes, we have run additional experiments of ethanol adsorption on $\mathrm{CeO}_{2}$ nanoctahedra and nanocubes, that preferentially exhibit the (111) and (100) planes, respectively. The results show the fingerprint of ethoxy species, in the $1200-800 \mathrm{~cm}^{-1}$ of the spectra, and the one for $\mathrm{CeO}_{2}$ nanoctahedra (dominated by (111) surfaces) resembles that of our polycrystalline $\mathrm{CeO}_{2}$ sample (Figure S5). Thus, in an effort to interpret our experimental results we have here investigated the adsorption of ethoxy species with different coordination on (111) oriented $\mathrm{CeO}_{2}$ surfaces by DFT-based calculations. Previously, some of us showed that the (111) orientation enabled the assignment of observed infrared bands upon adsorption and decomposition of methanol over ceria powders to distinct surface formate species and that the presence of hydroxyl groups could not be ignored when considering the stability of those species [49]. Thus, here we specifically consider monodentate ethoxy species with different adsorption sites for the hydrogen atom resulting from the $\mathrm{O}-\mathrm{H}$ bond cleavage of ethanol on the hydroxylated ceria surface $\left(\mathrm{Ce}_{18} \mathrm{O}_{37} \mathrm{H}_{2}\right.$ slab), for which all the positions neighboring the ethoxy groups were tested for the adsorption of the $\mathrm{OH}$ and $\mathrm{H}$ species of the added water molecule to the clean surface $\left(\mathrm{Ce}_{18} \mathrm{O}_{36} \mathrm{slab}\right)$. For the results of the dissociative adsorption of ethanol on the non-hydroxylated $\mathrm{CeO}_{2}(111)$ surface, and the vibrational frequencies of the ethoxy species, see the Supporting Information.

The DFT+U+DF2 results indicate that stable ethoxy species can have the alkyl chain parallel or perpendicular to the surface normal (Figures $4 \mathrm{a}$ and $\mathrm{b}$ ). We name these ethoxy states as "standing-up" (SU), $\mathrm{C}_{2} \mathrm{H}_{5} \mathrm{O}_{\text {SU.H, }}$ and "lying-down" (LD), $\mathrm{C}_{2} \mathrm{H}_{5} \mathrm{O}_{\text {LD.H, }}$, respectively. They are stabilized on the surface by the $\mathrm{O}-\mathrm{Ce}$ bond and two hydrogen bonds. The two states have similar chemisorption energies $\left(-1.12\right.$ and $-1.08 \mathrm{eV}$ for the $\mathrm{C}_{2} \mathrm{H}_{5} \mathrm{O}_{\text {LD.H,Ce }}$ and $\mathrm{C}_{2} \mathrm{H}_{5} \mathrm{O}_{\text {SU.H,Ce }}$ species, respectively, with respect to ethanol and the hydroxylated $\mathrm{CeO}_{2}$ surface), but the

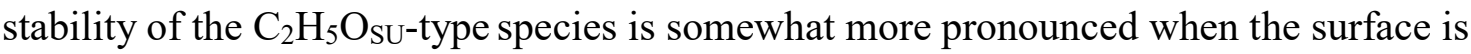



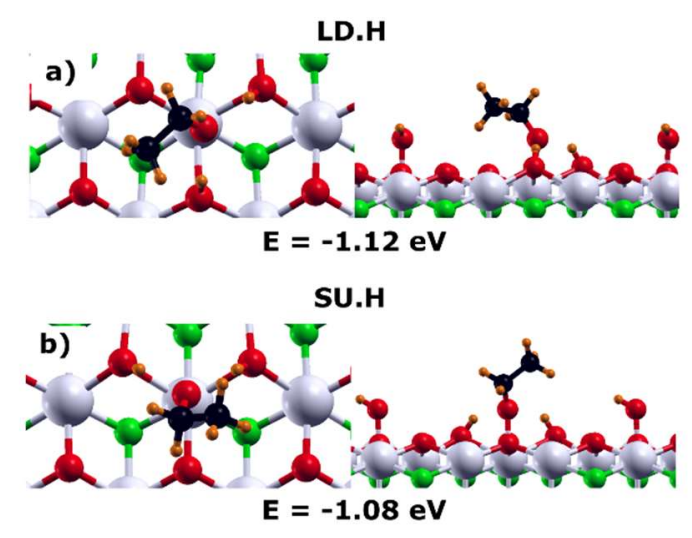

LD.H.Ga

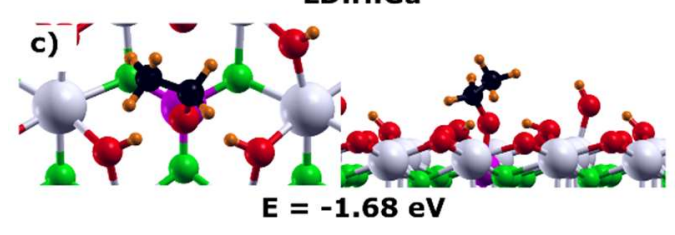

Figure 4. Top and side views of adsorbed ethoxy species with a co-adsorbed dissociated water molecule: a) monodentate $\mathrm{C}_{2} \mathrm{H}_{5} \mathrm{O}_{\text {LD.H, }}$ b) monodentate $\mathrm{C}_{2} \mathrm{H}_{5} \mathrm{O}_{\text {SU.H }}$ and c) monodentate $\mathrm{C}_{2} \mathrm{H}_{5} \mathrm{O}_{\mathrm{LD}, \mathrm{Ga}}$, for the $\mathrm{Ce}_{18} \mathrm{O}_{37} \mathrm{H}_{2}$ (a-b) and $\mathrm{Ce}_{17} \mathrm{GaO}_{37} \mathrm{H}_{3}$ (c) slabs. Color code: Ce atoms, white; $\mathrm{O}$ atoms of the first $\mathrm{CeO}_{2}$ layer and belonging to the ethoxy species, red; $\mathrm{O}$ atoms of the second $\mathrm{CeO}_{2}$ layer, green; $\mathrm{C}$ atoms, black, $\mathrm{H}$ atoms, orange and $\mathrm{Ga}$ atom in purple. The ethanol adsorption energies are calculated with respect to ethanol in the gas-phase and the hydroxylated surfaces (cf. Eq. 1).

hydroxylated than when is not (cf. Table S1). The calculation of the scaled frequencies for these species gives the following values: $v(\mathrm{CO})_{\mathrm{LD} . \mathrm{H}, \mathrm{Ce}} 1105 \mathrm{~cm}^{-1}<v(\mathrm{CO})_{\mathrm{SU} . \mathrm{H}, \mathrm{Ce}} 1114 \mathrm{~cm}^{-1}$, $v_{\text {as }}(\mathrm{CCO})_{\text {LD.H,Ce }} 1051 \mathrm{~cm}^{-1}<v_{\text {as }}(\mathrm{CCO})_{\text {SU.H,Ce }} 1058 \mathrm{~cm}^{-1}$, and $v_{\mathrm{s}}(\mathrm{CCO})_{\mathrm{LD} . \mathrm{H}, \mathrm{Ce}} 896 \mathrm{~cm}^{-1}<$ $v_{\mathrm{s}}(\mathrm{CCO})_{\mathrm{SU} . \mathrm{H}, \mathrm{Ce}} 914 \mathrm{~cm}^{-1}$, which are superimposed to the IR spectrum for $\mathrm{CeO}_{2}$ at $100{ }^{\circ} \mathrm{C}$ in Figure $2 \mathrm{~b}$. As can be seen, the calculated frequencies not only describe the splitting of the bands corresponding to the $\mathrm{CO}$, asymmetric and symmetric $\mathrm{CCO}$ stretching vibrations, but also predict that the frequencies of the somewhat more stable $\mathrm{C}_{2} \mathrm{H}_{5} \mathrm{O}_{\text {LD.H,Ce }}$ species appear at lower wavenumbers than the corresponding ones for the less stable $\mathrm{C}_{2} \mathrm{H}_{5} \mathrm{O}_{\text {SU.H,Ce }}$ groups, for all three stretching modes [that is, $v(\mathrm{j} \text {-mode })_{\text {LD.H,Ce }}<v(\mathrm{j} \text {-mode })_{\text {SU.H,Ce}}$. The results of the selected test 
calculations performed employing a thicker (three $\mathrm{O}-\mathrm{Ce}-\mathrm{O}$ trilayers) slab (cf. Table $\mathrm{S} 1$ and S2), show a variation of the $\mathrm{C}_{2} \mathrm{H}_{5} \mathrm{O}_{\text {LD.H,Ce }}$ and $\mathrm{C}_{2} \mathrm{H}_{5} \mathrm{O}_{\text {SU.H,Ce }}$ binding energies of less than 4 $\mathrm{meV}$, and of the vibrational frequencies of less than $5 \mathrm{~cm}^{-1}$, where the relative stabilities and the $v_{\mathrm{LD} . \mathrm{H}, \mathrm{Ce}}<v_{\mathrm{SU} . \mathrm{H}, \mathrm{Ce}}$ ordering of the $v(\mathrm{CO}), v_{\mathrm{as}}(\mathrm{CCO})$, and $v_{\mathrm{s}}(\mathrm{CCO})$ frequencies are preserved.

Given the agreement between the theoretical predictions and the experimental results, we propose that the "lying-down" ethoxy $\left(\mathrm{C}_{2} \mathrm{H}_{5} \mathrm{O}_{\text {LD.H,Ce }}\right)$ is the one that decomposes more slowly than the "standing-up" one $\left(\mathrm{C}_{2} \mathrm{H}_{5} \mathrm{O}_{\mathrm{SU} . \mathrm{H}, \mathrm{Ce}}\right)$, that is, those formerly labeled as type 1 and 2 , respectively. It is important to note that theoretical calculations predict $\mathrm{OH}$ groups to have a decisive impact on the adsorbed ethoxy species (see Supporting Information), similar as previously reported for formate on ceria [49].

For the ceria-gallia $\mathrm{Ce}_{90} \mathrm{Ga}_{10} \mathrm{O}_{\mathrm{x}}$ and $\mathrm{Ce}_{80} \mathrm{Ga}_{20} \mathrm{O}_{\mathrm{x}}$ systems, similar DRIFT spectra to those of pure ceria after adsorption of ethanol at $100{ }^{\circ} \mathrm{C}$ were observed (Figure 2), with three double peaks in the $1200-800 \mathrm{~cm}^{-1}$ region of the spectra. Specifically, the same types of IR bands associated with ethoxy species were detected as in the case of $\mathrm{CeO}_{2}$ (Table 2), and the ethanol uptake calculated from the adsorption curves acquired by mass spectrometry was approximately $4 \mu \mathrm{mol} \mathrm{EtOH} / \mathrm{m}^{2}$ for the whole set of $\mathrm{Ce}(\mathrm{Ga}) \mathrm{O}_{\mathrm{x}}$ samples (Table 1$)$. Again, two types of ethoxy species can be anticipated from the normalized integrated intensity of the ethoxy bands collected during the TPSR-IR (Figure 3b). The evolution of the two sets of ethoxy bands were practically identical for $\mathrm{Ce}_{90} \mathrm{Ga}_{10} \mathrm{O}_{\mathrm{x}}$ and $\mathrm{Ce}_{80} \mathrm{Ga}_{20} \mathrm{O}_{\mathrm{x}}$ (cf. Figure $3 \mathrm{~b}$ and Figure $\mathrm{S} 8$, for $\mathrm{Ce}_{80} \mathrm{Ga}_{20} \mathrm{O}_{\mathrm{x}}$ and $\mathrm{Ce}_{90} \mathrm{Ga}_{10} \mathrm{O}_{\mathrm{x}}$, respectively). However, the rate of decomposition of the "more labile" type of ethoxy species is faster in the gallium-doped materials compared to pure ceria (cf. Figure $3 a$ and $3 b$ ).

In order to gain insight into the effects of gallium incorporation on the IR bands associated with ethoxy species, we have investigated the $\mathrm{Ce}_{17} \mathrm{GaO}_{37} \mathrm{H}_{3}$ slab model. On this gallium-doped ceria surface, ethanol still dissociates upon adsorption with the ethoxy species in monodentate 
form on top of the Ga atom, either "standing-up" or "lying-down" species (namely, $\mathrm{C}_{2} \mathrm{H}_{5} \mathrm{O}_{\text {SU.H,Ga }}$ or $\mathrm{C}_{2} \mathrm{H}_{5} \mathrm{O}_{\text {LD.H,Ga, }}$, respectively, see Figure S9). However, the "lying-down" state is by $0.17 \mathrm{eV}$ more stable than the "standing-up" one (Figure S9 and Table S1), and thus, a strongly preferred population of surface Ga sites by lying down ethoxy species is expected. For the remaining surface Ce sites, since the $\mathrm{C}_{2} \mathrm{H}_{5} \mathrm{O}_{\text {LD.H,Ce }}$ state is only by $0.04 \mathrm{eV}$ more stable than the $\mathrm{C}_{2} \mathrm{H}_{5} \mathrm{O}_{\text {su.H,Ce }}$ one (Table S1), as mentioned above, the presence of both types of ethoxy species is likely to occur. Thus, upon gallium-doping, Ga sites will be occupied by $\mathrm{C}_{2} \mathrm{H}_{5} \mathrm{O}_{\text {LD.H,Ga }}$ species and the remaining $\mathrm{Ce}$ sites with $\mathrm{C}_{2} \mathrm{H}_{5} \mathrm{O}_{\text {LD.H,Ce }}$ and $\mathrm{C}_{2} \mathrm{H}_{5} \mathrm{O}_{\text {sU.H,Ce }}$ ones.

The calculated (scaled) frequency values for $\mathrm{C}_{2} \mathrm{H}_{5} \mathrm{O}_{\text {LD.H,Ga }}$ are: $\tau(\mathrm{CCO})=1158 \mathrm{~cm}^{-1}, v(\mathrm{CO})$ $=1103 \mathrm{~cm}^{-1}, v_{\mathrm{as}}(\mathrm{CCO})=1050 \mathrm{~cm}^{-1}$, and $v_{\mathrm{s}}(\mathrm{CCO})=874 \mathrm{~cm}^{-1}$. Figure $2 \mathrm{~b}$ shows the calculated frequencies for the $\mathrm{C}_{2} \mathrm{H}_{5} \mathrm{O}_{\text {LD.H,Ce, }} \mathrm{C}_{2} \mathrm{H}_{5} \mathrm{O}_{\text {SU.H,Ce }}$ and $\mathrm{C}_{2} \mathrm{H}_{5} \mathrm{O}_{\text {LD.H,Ga }}$ superimposed with the IR spectra of chemisorbed ethanol on $\mathrm{Ce}_{80} \mathrm{Ga}_{20} \mathrm{O}_{\mathrm{x}}$ at $100{ }^{\circ} \mathrm{C}$. After $\mathrm{Ga}$ doping, the DRIFT spectra show vibrations at frequencies which are either blue or red shifted with respect to those observed for the pure ceria by at most $5 \mathrm{~cm}^{-1}$ (Table 2). In the $1120-1100 \mathrm{~cm}^{-1}$ region, a double peak is again observed (Figure $2 b$ ) where, according to the calculations (Table 2), the peak at $1116 \mathrm{~cm}^{-1}$ is attributed to the $\mathrm{CO}$ stretching mode $[(\mathrm{CO})]$ of the $\mathrm{C}_{2} \mathrm{H}_{5} \mathrm{O}_{\text {SU.H,Ce }}$ species $\left(1114 \mathrm{~cm}^{-1}\right)$ and that at $1100 \mathrm{~cm}^{-1}$ to the same mode of the $\mathrm{C}_{2} \mathrm{H}_{5} \mathrm{O}_{\text {LD.H,Ce }}$ plus $\mathrm{C}_{2} \mathrm{H}_{5} \mathrm{O}_{\text {LD.H,Ga }}$ species (1105 and $1103 \mathrm{~cm}^{-1}$, respectively).

Furthermore, three bands contribute to the $1060-1050 \mathrm{~cm}^{-1}$ region, two are assigned to the asymmetric CCO mode $\left[v_{\mathrm{as}}(\mathrm{CCO})\right]$ of the $\mathrm{C}_{2} \mathrm{H}_{5} \mathrm{O}_{\text {SU.H,Ce }}$ and $\mathrm{C}_{2} \mathrm{H}_{5} \mathrm{O}_{\text {LD.H,Ce }}$ species, calculated at 1058 and $1051 \mathrm{~cm}^{-1}$, respectively, and the third one at $1050 \mathrm{~cm}^{-1}$ is due to the same mode but of the $\mathrm{C}_{2} \mathrm{H}_{5} \mathrm{O}_{\text {LD.H,Ga }}$ species. The appearance of such an additional band may explain the observed widening of the lower energy band of the double peak in the $1060-1050 \mathrm{~cm}^{-1}$ range upon gallium doping (Figures $2 \mathrm{~b}$ ). 
Finally, in the $900-880 \mathrm{~cm}^{-1}$ range, the observed peak at $906 \mathrm{~cm}^{-1}$ corresponds to the symmetric CCO stretching $\left[\nu_{\mathrm{s}}(\mathrm{CCO})\right]$ of the $\mathrm{C}_{2} \mathrm{H}_{5} \mathrm{O}_{\mathrm{SU} . \mathrm{H}, \mathrm{Ce}}\left(\right.$ calculated at $\left.914 \mathrm{~cm}^{-1}\right)$, and that at $887 \mathrm{~cm}^{-1}$ to the $\mathrm{C}_{2} \mathrm{H}_{5} \mathrm{O}_{\text {LD.H,Ce }}$ plus $\mathrm{C}_{2} \mathrm{H}_{5} \mathrm{O}_{\text {LD.H,Ga }}$ species (calculated at 896 and $874 \mathrm{~cm}^{-1}$, respectively (Table 2).

\section{Decomposition of ethanol on $\mathrm{CeO}_{2}$ and $\mathrm{CeGaO}$}

As discussed in the previous section, in the case of pure ceria, ethanol is dissociatively adsorbed at $100{ }^{\circ} \mathrm{C}$ to form monodentate ethoxy species, in "standing up" $\left(\mathrm{C}_{2} \mathrm{H}_{5} \mathrm{O}_{\mathrm{SU} . \mathrm{H}, \mathrm{Ce}}\right)$ and "lying down" $\left(\mathrm{C}_{2} \mathrm{H}_{5} \mathrm{O}_{\text {LD.H,Ce }}\right)$ configurations, leaving $\mathrm{H}$ available on the surface that reacts with surface hydroxyl groups to yield water (Scheme 1, r1). In the case of the $\mathrm{CeGaO}_{\mathrm{x}}$ samples, in

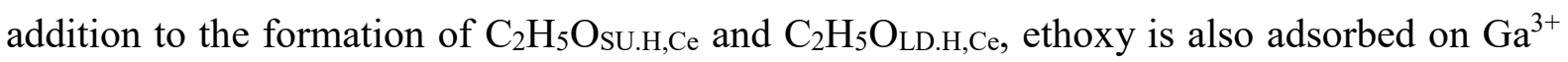
cations in its lying-down configuration (Scheme 2, r1 and r2). This dissociative chemisorption of ethanol, followed by water release, is generally accepted as the first step of the mechanism for lineal alcohol chemisorption on oxides $[42,43]$.

After the adsorption of ethanol, the samples were heated under He flow to study the thermal evolution of the species adsorbed on the surface (TPSR-IR) and their gaseous products at the outlet of the reactor (TPSR-MS). The correlation of the TPSR results by DRIFTS and MS allowed us to propose a mechanism for the reaction of ethanol with the surface of the supports studied in this work (Schemes 1 and 2).

$$
\begin{aligned}
& \mathrm{C}_{2} \mathrm{H}_{5} \mathrm{OH}+\mathrm{Ce}^{4+}+\mathrm{OH} \rightarrow \mathrm{C}_{2} \mathrm{H}_{5} \mathrm{O}_{\text {SU.H,Ce }}\left(\text { or } \mathrm{C}_{2} \mathrm{H}_{5} \mathrm{O}_{\text {LD.H,Ce }}\right)+\mathrm{H}_{2} \mathrm{O} \\
& \mathrm{C}_{2} \mathrm{H}_{5} \mathrm{O}_{\text {SU.H,Ce }}+3 \mathrm{O}_{\text {lattice }} \rightarrow \mathrm{CH}_{3} \mathrm{COO}+2 \mathrm{OH} \\
& \mathrm{CH}_{3} \mathrm{COO}+\mathrm{OH} \rightarrow \mathrm{CO}_{2}+\mathrm{CH}_{4}+\square+\mathrm{O} \\
& \mathrm{C}_{2} \mathrm{H}_{5} \mathrm{O}_{\text {LD.H,Ce }} \rightarrow \mathrm{C}_{2} \mathrm{H}_{4}+\mathrm{OH} \\
& \mathrm{C}_{2} \mathrm{H}_{4} \rightarrow \mathrm{CH}_{\mathrm{x}}+\mathrm{C}_{\text {amorphous }}+\mathrm{H}_{2} \\
& \mathrm{CH}_{\mathrm{x}}+\mathrm{n} \mathrm{H}_{2} \rightarrow \mathrm{CH}_{4} \\
& 2 \mathrm{OH} \rightarrow \mathrm{H}_{2}+2 \mathrm{O}_{\text {lattice }}
\end{aligned}
$$


Scheme 1. Mechanism for ethanol adsorption and decomposition on pure $\mathrm{CeO}_{2}$.

$$
\begin{aligned}
& \mathrm{C}_{2} \mathrm{H}_{5} \mathrm{OH}+\mathrm{Ce}^{4+}+\mathrm{OH} \rightarrow \mathrm{C}_{2} \mathrm{H}_{5} \mathrm{O}_{\text {SU.H,Ce }}\left(\text { or } \mathrm{C}_{2} \mathrm{H}_{5} \mathrm{O}_{\text {LD.H,Ce }}\right)+\mathrm{H}_{2} \mathrm{O} \\
& \mathrm{C}_{2} \mathrm{H}_{5} \mathrm{OH}+\mathrm{Ga}^{3+}+\mathrm{OH} \rightarrow \mathrm{C}_{2} \mathrm{H}_{5} \mathrm{O}_{\text {LD.H,Ga }}+\mathrm{H}_{2} \mathrm{O} \\
& \mathrm{C}_{2} \mathrm{H}_{5} \mathrm{O}_{\text {SU.H,Ce }}+3 \mathrm{O}_{\text {lattice }} \rightarrow \mathrm{CH}_{3} \mathrm{COO}+2 \mathrm{OH} \\
& \mathrm{C}_{2} \mathrm{H}_{5} \mathrm{O}_{\text {LD.H,Ce or Ga }}+\mathrm{O}_{\text {interface }}+\mathrm{Ga}^{3+}+\mathrm{O}_{\text {lattice }} \rightarrow \mathrm{CH}_{3} \mathrm{COO}_{\text {interface }}+\mathrm{Ga}-\mathrm{H}+\mathrm{O}_{\text {latticeH }} \mathrm{H} \\
& \mathrm{CH}_{3} \mathrm{COO}_{\text {interface }}+\mathrm{Ga}-\mathrm{H} \rightarrow \mathrm{CO}_{2}+\mathrm{CH}_{4}+\square+\mathrm{Ga}^{3+} \\
& \mathrm{Ga}-\mathrm{H}+\mathrm{OH} \rightarrow \mathrm{Ga}^{3+}+\mathrm{O}_{\text {surface }}+\mathrm{H}_{2}
\end{aligned}
$$

Scheme 2. Mechanism for ethanol adsorption and decomposition on $\mathrm{CeGaO}_{\mathrm{x}}$.

Figure 5 shows the thermal evolution of the IR spectra and the two-dimensional iso-intensity maps, arising from the decomposition of adsorbed ethoxy species on pure $\mathrm{CeO}_{2}$ and $\mathrm{Ce}_{80} \mathrm{Ga}_{20} \mathrm{O}_{\mathrm{x}}$ with increasing temperature (TPSR-IR). The normalized integrated intensity of the most appropriate IR signal (more intense and less overlapped) for each surface species identified during the ethanol TPSR-IR experiments, together with the normalized intensity of the most important products detected during the TPSR-MS are shown in Figure 6 for both samples. Similar results were found for $\mathrm{Ce}_{90} \mathrm{Ga}_{10} \mathrm{O}_{\mathrm{x}}$ (Figure $\mathrm{S} 10$ ). IR traces for both the SU and LD ethoxy species were plotted on all three panels of Figure 6I and 6II, to facilitate comparison of their rate of decomposition with the thermal evolution of other surface species and products.

\subsection{Acetate formation}

A clear evidence of the formation of acetate species on $\mathrm{CeO}_{2}$ above $150{ }^{\circ} \mathrm{C}$ is found by the appearance of two bands at 1550 and $1425 \mathrm{~cm}^{-1}$ during the TPSR-IR (Figure 5 Ic, see Table 2). This can be easily observed by the emergence of two red areas in the two-dimensional isointensity maps (Figure $5 \mathrm{Ig}$ ). The curves of the normalized integrated intensity of the signals at $1120\left(\mathrm{C}_{2} \mathrm{H}_{5} \mathrm{O}_{\mathrm{SU} . \mathrm{H}, \mathrm{Ce}}\right)$ and $1550\left(\mathrm{CH}_{3} \mathrm{COO}\right) \mathrm{cm}^{-1}$ as a function of temperature plotted in Figure 
6 Ia, intersect at approximately $50 \%$ of conversion $\left(\mathrm{T}_{50 \%}=215^{\circ} \mathrm{C}\right)$. This is a strong suggestion that $\mathrm{C}_{2} \mathrm{H}_{5} \mathrm{O}_{\text {SU.H,Ce }}$ species react with surface lattice oxygen of ceria to yield acetate species according to $\mathrm{r} 2$ (Scheme 1).

The thermal evolution of $\mathrm{C}_{2} \mathrm{H}_{5} \mathrm{O}_{\text {SU.H,Ce }}$ in the $\mathrm{CeGaO}_{\mathrm{x}}$ samples is identical to pure ceria, suggesting that this type of ethoxy is not affected by the presence of $\mathrm{Ga}^{3+}$ and it decomposes according to $\mathrm{r} 3$ in Scheme 2 (cf. Figure 6 Ia and IIa). Although a correlation between the decomposition of $\mathrm{C}_{2} \mathrm{H}_{5} \mathrm{O}_{\text {sU.H,Ce }}$ and the formation of acetate species is also observed on $\mathrm{CeGaO}_{\mathrm{x}}$, the intersection between the thermal evolution of the $\mathrm{C}_{2} \mathrm{H}_{5} \mathrm{O}_{\text {SU.H,Ce }}$ and acetate species does not take place at $50 \%$ of $\mathrm{C}_{2} \mathrm{H}_{5} \mathrm{O}_{\text {SU.H,Ce }}$ decomposition, but at a lower value, $\sim 40 \%$ (Figure 6 IIa). Then, there must be another source, besides $\mathrm{C}_{2} \mathrm{H}_{5} \mathrm{O}_{\text {SU.H,Ce }}$ species, contributing to the formation of acetate species, as explained below. 

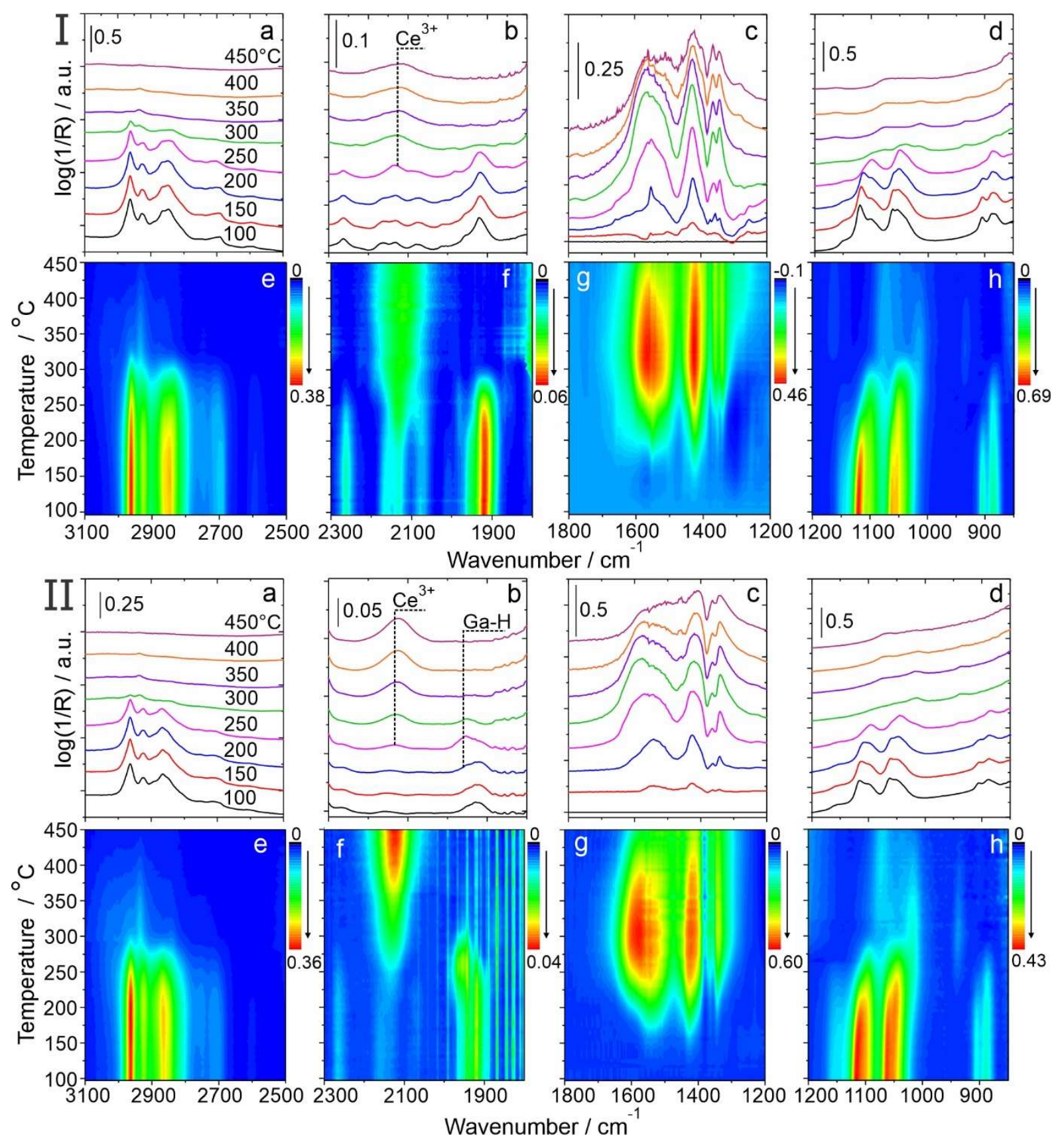

Figure 5. DRIFT spectra (a-d), together with the two-dimensional iso-intensity maps (e-h, bottom panel) collected during the TPSR-IR of ethanol on: I) pure $\mathrm{CeO}_{2}$, and II) $\mathrm{Ce}_{80} \mathrm{Ga}_{20} \mathrm{O}_{\mathrm{x}}$ samples. 

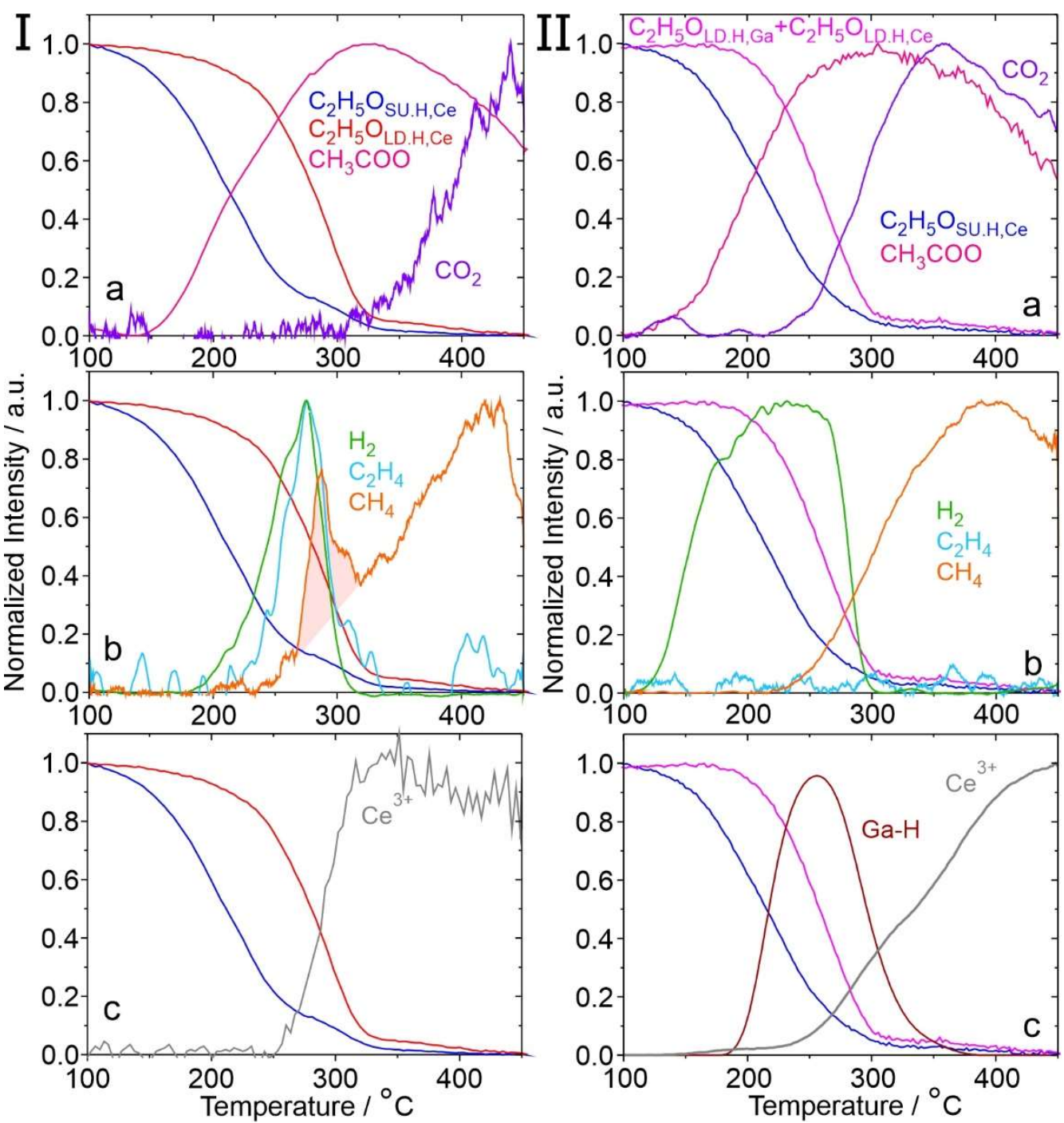

Figure 6. Normalized integrated intensity of the most important DRIFT signals detected during the TPSR-IR and normalized intensity of the gaseous products detected during the TPSR-MS on: I) $\mathrm{CeO}_{2}$ and II) $\mathrm{Ce}_{80} \mathrm{Ga}_{20} \mathrm{O}_{\mathrm{x}}$ samples.

The evolution of the $v_{\mathrm{as}}(\mathrm{CCO})$ band at about $1100 \mathrm{~cm}^{-1}$ on $\mathrm{CeGaO}_{\mathrm{x}}$, that is, the simultaneous decomposition of the $\mathrm{C}_{2} \mathrm{H}_{5} \mathrm{O}_{\text {LD.H,Ga }}$ and $\mathrm{C}_{2} \mathrm{H}_{5} \mathrm{O}_{\text {LD.H,Ce}}$, is faster with respect to that on $\mathrm{CeO}_{2}$ (which is only due to $\mathrm{C}_{2} \mathrm{H}_{5} \mathrm{O}_{\text {LD.H,Ce}}$ ): $50 \%$ of the intensity drop occurs at 258 and $284{ }^{\circ} \mathrm{C}$ (temperature shift of $-26^{\circ} \mathrm{C}$ ), respectively (cf. Figure 6 Ia and IIa). Additionally, the formation of acetate species on $\mathrm{Ce}_{80} \mathrm{Ga}_{20} \mathrm{O}_{x}$, which implies the dehydrogenation/oxidation of ethoxy species, occurs at a higher rate compared to pure ceria $\left(\mathrm{T}_{50 \%}=200{ }^{\circ} \mathrm{C}\right.$ vs. $215^{\circ} \mathrm{C}$, respectively -see also Figure 6 Ia and IIa). Thus, it is suggested that both LD ethoxy species, $\mathrm{C}_{2} \mathrm{H}_{5} \mathrm{O}_{\mathrm{LD} . \mathrm{H}, \mathrm{Ga}}$ 
and $\mathrm{C}_{2} \mathrm{H}_{5} \mathrm{O}_{\mathrm{LD} . \mathrm{H}, \mathrm{Ce}}$, on the surface of $\mathrm{CeGaO}_{\mathrm{x}}$ would convert by dehydrogenation/oxidation into acetate species, assisted by both the pronounced oxidative capacity of the Ce-O-Ga interface and the ability to form gallium hydride (Scheme 2, r4), as compare to the undoped surface. The observed more facile removal of oxygen from the cerium-gallium mixed oxide with respect to pure ceria (see Table 1) is consistent with the results of DFT calculations [29] and it has been attributed to an important relaxation (an umbrella type displacement of the gallium atom) that takes place after the removal of an oxygen atom at the Ce-O-Ga interface. Moreover, some of us have reported that at the boundary of gallium nanodomains on $\mathrm{CeGaO}_{\mathrm{x}}$ samples, $\mathrm{H}_{2}$ easily dissociates, being the driving-force the formation of surface gallium hydride [30]. Another piece of experimental evidence is the absence of ethylene during the TPSR-MS on the $\mathrm{CeGaO}_{\mathrm{x}}$ samples (see for example Figure $6 \mathrm{IIb}$ ), which is a clear suggestion that both ethoxy $\mathrm{C}_{2} \mathrm{H}_{5} \mathrm{O}_{\text {LD.H,Ga }}$ and $\mathrm{C}_{2} \mathrm{H}_{5} \mathrm{O}_{\text {LD.H,Ce }}$ must lead to the formation of a product other than $\mathrm{C}_{2} \mathrm{H}_{4}$ (as observed on pure ceria and it is clarified below), that is, acetate species. In line with this suggestion, the evolution of the non-normalized integrated intensity of acetate species during the TPSR-IR (see last panel of Figure S11 in SI) shows that the concentration of acetate species is higher with increasing Ga loading.

\subsection{Methane and carbon dioxide formation}

On pure $\mathrm{CeO}_{2}$, the trace of methane plotted in Figure $6 \mathrm{Ib}$ displays a sharp peak at $287^{\circ} \mathrm{C}$, which is overlapped to a broad desorption peak with a maximum at around $420{ }^{\circ} \mathrm{C}$. This observation suggests that there are at least two sources of methane production. The broad desorption peak of $\mathrm{CH}_{4}$ at higher temperatures, which somehow parallels the evolution of $\mathrm{CO}_{2}$, resembles the opposite trend of acetate decomposition above $250{ }^{\circ} \mathrm{C}$ (Figure 6 Ia). This previous observation is an indication that $\mathrm{CH}_{4}$ together with $\mathrm{CO}_{2}$ are the main final gaseous products of $\mathrm{C}-\mathrm{C}$ bond cleavage of acetate species (Scheme 1,r3). The origin of the sharp peak of methane will be explained later. 
Evidence of the reduction of ceria as a consequence of the decomposition of acetate species can be found in Figure $5 \mathrm{Ib}$ and 5 If: a band at $2130 \mathrm{~cm}^{-1}$, assigned to the forbidden electronic transition ${ }^{2} \mathrm{~F}_{5 / 2} \rightarrow{ }^{2} \mathrm{~F}_{7 / 2}$ of $\mathrm{Ce}^{3+}$ cations [29,30,50], was observed above $250{ }^{\circ} \mathrm{C}$. Its intensity increases as the temperature raises to finally level off at $\mathrm{T}>340{ }^{\circ} \mathrm{C}$ (Figure 6 Ic). Thus, the formation of $\mathrm{Ce}^{3+}$ is correlated to the decomposition of acetate species: as soon as $\mathrm{CH}_{4}$ is released, the ceria surface is reduced with the concomitant formation of carbonate species (evidenced by the broadening of the peaks in the region from 1800 to $1200 \mathrm{~cm}^{-1}$, see Figure 5 Ic) [41], which decompose to $\mathrm{CO}_{2}$ after further heating. The formation of $\mathrm{Ce}^{3+}$ cations during acetate decomposition is represented by the oxygen vacancy formation in reaction 3 (Scheme 1). Although some of the oxygen vacancies could be re-filled by the near-by oxygen species, the detection of the $2130 \mathrm{~cm}^{-1} \mathrm{IR}$ band from $250^{\circ} \mathrm{C}$ to $450^{\circ} \mathrm{C}$ is a clear indication that the support remains reduced.

On the gallium doped oxides, the decomposition of acetate species begins at lower temperature than on pure ceria. The maximum intensity of acetate traces on $\mathrm{Ce}_{80} \mathrm{Ga}_{20} \mathrm{O}_{\mathrm{x}}$, which also includes the formation of some carbonate species, is reached at $295{ }^{\circ} \mathrm{C}$, that is, $30{ }^{\circ} \mathrm{C}$ lower compared to ceria (cf. Figure 6 Ia and IIa). The decomposition of those acetate species is again clearly related to the formation of $\mathrm{CO}_{2}, \mathrm{CH}_{4}$ and $\mathrm{Ce}^{3+}$ (Figure 6 IIa-c). However, $\mathrm{CO}_{2}$ desorbed $100{ }^{\circ} \mathrm{C}$ earlier than in $\mathrm{CeO}_{2}$, showing a maximum at $350{ }^{\circ} \mathrm{C}$ (cf. Figures 6 Ia and IIa). Additionally, the ratio of the maximum integrated intensity of the $2130 \mathrm{~cm}^{-1} \mathrm{IR}$ signal ( $\left.\mathrm{I}_{\mathrm{Ce} 3+}\right)$, reached at $450^{\circ} \mathrm{C}$, between $\mathrm{CeGaO}_{\mathrm{x}}$ and $\mathrm{CeO}_{2}$ (that is, $\mathrm{I}_{\mathrm{Ce} 3+}+\left(\mathrm{CeGaO}_{\mathrm{x}}, 450^{\circ} \mathrm{C}\right) / \mathrm{I}_{\mathrm{Ce} 3}+\left(\mathrm{CeO}_{2}\right.$, $450^{\circ} \mathrm{C}$ )) shows that the relative amount of $\mathrm{Ce}^{3+}$ is 20 and $30 \%$ higher on $\mathrm{Ce}_{90} \mathrm{Ga}_{10} \mathrm{O}_{\mathrm{x}}$ and $\mathrm{Ce}_{80} \mathrm{Ga}_{20} \mathrm{O}_{\mathrm{x}}$, respectively. Congruent with this last observation, both OSC and relative CO uptake results (Table 1) show that Ce-Ga mixed oxides are more reducible than pure ceria, the higher the Ga content, the higher the relative $\mathrm{CO}$ uptake, that is, the reducibility of the mixed oxide increases with gallium loading [29]. In agreement, $\mathrm{CO}_{2}$ release during the TPSR-MS 
begins at lower temperature on the sample with higher gallium loading $\left(\mathrm{T}_{50}=300 \mathrm{vs} .340{ }^{\circ} \mathrm{C}\right.$ on $\mathrm{Ce}_{80} \mathrm{Ga}_{20} \mathrm{O}_{\mathrm{x}}$ and $\mathrm{Ce}_{90} \mathrm{Ga}_{10} \mathrm{O}_{\mathrm{x}}$, respectively). Furthermore, the amount of $\mathrm{CO}_{2}$ released in the gas phase is also higher as the Ga loading, that is, the acidity of the mixed oxides [41], increases (Figure S11). This observation is consistent with the higher acetate surface concentration mentioned in the previous section.

Thus, it can be concluded that ethoxy oxidation to acetate species near the Ce-O-Ga interface is favored by the higher oxygen mobility of the mixed oxides, leading to $\mathrm{CO}_{2}$ release at much lower temperature $\left(\sim 50\right.$ and $100{ }^{\circ} \mathrm{C}$ earlier on $\mathrm{Ce}_{90} \mathrm{Ga}_{10} \mathrm{O}_{\mathrm{x}}$ and $\mathrm{Ce}_{80} \mathrm{Ga}_{20} \mathrm{O}_{\mathrm{x}}$, respectively, and congruent with the increase in redox properties with increasing gallium loading) compared to pure ceria (Scheme 2,r5). On the other hand, and most likely, acetate species that are far away from the nanodomains of Ga behave as in the case of pure ceria (Scheme1, r3), decomposing at higher temperatures.

\subsection{Ethylene and carbon formation}

Figure $6 \mathrm{Ib}$ shows that on pure $\mathrm{CeO}_{2}$, ethylene release was detected between 200 and $330{ }^{\circ} \mathrm{C}$, with a maximum at $275^{\circ} \mathrm{C}$. In the same temperature range, the decrease of LD ethoxy species concentration is observed. In fact, the maximum of ethylene desorption peak matches the $50 \%$ depletion of $\mathrm{C}_{2} \mathrm{H}_{5} \mathrm{O}_{\text {LD.H,Ce }}$ species. Thus, it is proposed that the ethoxy species in LD configuration on pure ceria decompose to yield ethylene in the gas phase and $\mathrm{OH}$ species a $\mathrm{T}$ $>200{ }^{\circ} \mathrm{C}$ ( Scheme 1, r4). However, ethylene was not detected on the Ce-Ga mixed oxides (Figure $6 \mathrm{IIb}$ and Figure S10 b) and, as suggested before, the LD ethoxy were converted to acetate instead.

A concerted elimination pathway was identified as a plausible pathway that can produce ethylene when ethanol is adsorbed on Lewis acidic sites adjacent to a surface O basic site. Overbury and coworkers [47] suggested that ethylene is produced on $\mathrm{CeO}_{2}$ nanoshapes (octahedra, cubes, and rods) from a concerted cleavage of $\beta-\mathrm{CH}$ and $\mathrm{C}-\mathrm{O}$ of ethoxy species 
(bimolecular elimination, E2). Our TPSR-MS results on $\mathrm{CeO}_{2}$ are in agreement with this mechanism. Water is the co-product of this reaction, although during our TPRS experiments the background signal from water $(\mathrm{m} / \mathrm{e}=18)$ was high and variable and interfered with determination of the water desorption peak. Under this mechanism, $\beta-\mathrm{CH}$ cleavage is related with the basicity of the adjacent $\mathrm{O}^{-2}$ site. Conversely, desorption of ethylene was not observed on the $\mathrm{CeGaO}_{\mathrm{x}}$. It was previously shown that the basicity of $\mathrm{CeGaO}_{\mathrm{x}}$ mixed oxide is lower than pure $\mathrm{CeO}_{2}$, as measured by $\mathrm{CO}_{2}$ uptake at $298 \mathrm{~K}$ [41]. Then, the lower basicity of the mixed oxide can favor the $\alpha-\mathrm{CH}$ scission vs. $\beta-\mathrm{CH}$ scission. Additionally, it can be hypothesized that $\alpha-\mathrm{CH}$ scission can be performed by $\mathrm{Ga}$ sites, forming $\mathrm{Ga}-\mathrm{H}$, and then enhancing the transformation of ethoxy to acetate rather than ethylene.

Finally, polymerization of ethylene may lead to the formation of amorphous carbonaceous deposits $[3,21]$ (some of them are partially hydrogenated, $\mathrm{CH}_{\mathrm{x}}$ ) on the surface of ceria. Thus, the sharp $\mathrm{CH}_{4}$ peak detected in the case of pure ceria, which is shifted to higher temperature than the one of $\mathrm{C}_{2} \mathrm{H}_{4}$ (Figure $6 \mathrm{IIb}$ ), could be the product of the hydrogenation of carbon deposited (probably partially hydrogenated) at the surface of ceria by polymerization of ethylene (Scheme 1, r5 and r6). This hypothesis is supported by the absence of the sharp methane peak in the gallium-doped oxides, which is in agreement with the non-detection of ethylene (Figure $6 \mathrm{IIb}$ and Figure S10 b).

But still it is feasible to think that the reason we do not detect ethylene in the case of the CeGa mixed oxides is because polymerization could be favored, converting all the ethylene into a carbonaceous deposit. However, the evolution of the $\mathrm{CO}_{2}$ trace during the TPO experiments on previously treated oxides samples by the TPRS-MS of ethanol, shown in Figure 7, allow us to discard this last hypothesis because the nature of carbonaceous deposit is similar on both cerium and cerium-gallium oxides and the total amount of carbon burned during the TPO is at least 3-fold higher on $\mathrm{CeO}_{2}$ than on $\mathrm{CeGaO}_{x}$. 
At least three peaks evolved during oxidation at 165,255 and $340{ }^{\circ} \mathrm{C}$ on pure $\mathrm{CeO}_{2}$ and at 145, 230 and $300{ }^{\circ} \mathrm{C}$ on $\mathrm{CeGaO}_{\mathrm{x}}$ samples, suggesting the formation of different types of carbonaceous deposits. It has been proposed that $\mathrm{C}_{2} \mathrm{H}_{4}$ is able to polymerize to finally yield coke over the surface of ethanol reforming catalysts [3,5], and this idea is based on the wellknown phenomena of olefin polymerization in different industrial processes [51,52]. Usually, the different types of coke are characterized by TPO according to the temperature of $\mathrm{CO}_{2}$ release: the higher the temperature the most stable the type of carbon deposit [53-55]. In our case, it might be postulated that the first two peaks of $\mathrm{CO}_{2}\left(\mathrm{~T}<300{ }^{\circ} \mathrm{C}\right)$ are due to partially hydrogenated carbon deposits, whereas the one at $\mathrm{T}>300^{\circ} \mathrm{C}$ would correspond to amorphous carbon. However, at least 3 to 4 -fold more $\mathrm{CO}_{2}$ was released from $\mathrm{CeO}_{2}$ with respect to $\mathrm{Ce}_{90} \mathrm{Ga}_{10} \mathrm{O}_{\mathrm{x}}$ and $\mathrm{Ce}_{80} \mathrm{Ga}_{20} \mathrm{O}_{\mathrm{x}}$, respectively. Then, if the source of those carbonaceous deposits were the polymerization of ethylene over any of the oxides employed in this work, it is possible to affirm that gallium-doping to the ceria significantly reduces the formation of ethylene to a level that we were unable to detect. In other terms, the lower amount of carbonaceous deposit in $\mathrm{CeGaO}_{\mathrm{x}}$ cannot be attributed to the higher concentration of surface $\mathrm{H}$ on the gallium doped samples (due to de formation of $\mathrm{Ga}-\mathrm{H}$ species), which would prevent $\mathrm{C}_{2} \mathrm{H}_{4}$ polymerization [51], because the production of ethylene was undetectable for the $\mathrm{CeGaO}_{\mathrm{x}}$ samples. Therefore, and again, the most reasonable explanation is that the acetate route for LD ethoxy decomposition is favored by the greater oxidative power of the Ce-O-Ga interface and $\mathrm{Ga}-\mathrm{H}$ formation. 


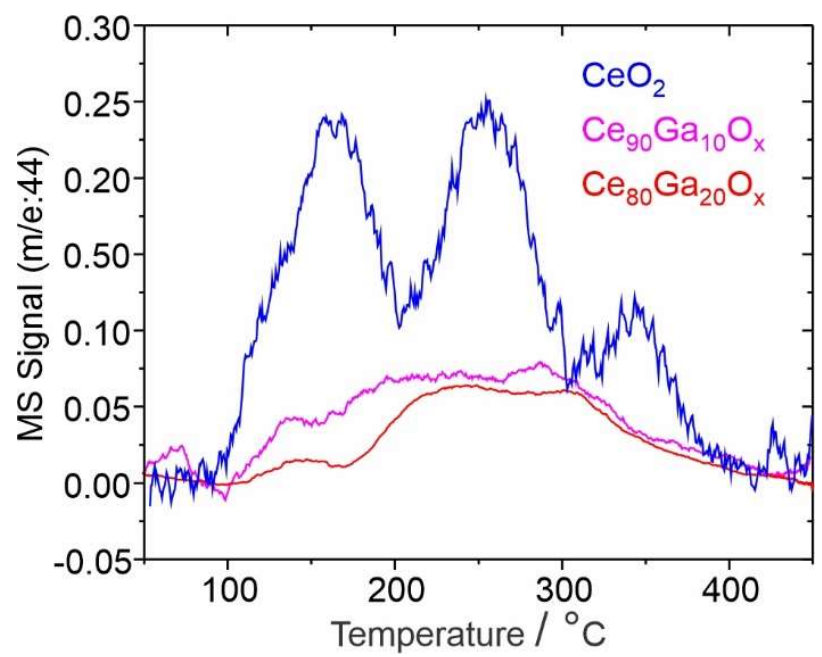

Figure 7. TPO traces on $\mathrm{CeO}_{2}, \mathrm{Ce}_{90} \mathrm{Ga}_{10} \mathrm{O}_{\mathrm{x}}$ and $\mathrm{Ce}_{80} \mathrm{Ga}_{20} \mathrm{O}_{\mathrm{x}}$, followed by mass spectrometry.

\subsection{Hydrogen formation}

$\mathrm{H}_{2}$ desorption on ceria was detected between 180 and $330^{\circ} \mathrm{C}$, with a parallel evolution to that of the ethylene (Figure $6 \mathrm{Ib}$ ). This observation could be the result of the recombination of $\mathrm{H}$ and/or $\mathrm{OH}$ species (Scheme 1, r7) resulting from both the dehydrogenation of ethoxy LD to ethylene (Scheme 1, r4) and the formation of acetate species from ethoxy SU (Scheme 1, r2).

However, $\mathrm{H}_{2}$ begins to be detected at the outlet of the TPSR-MS reactor from $120{ }^{\circ} \mathrm{C}$ on the $\mathrm{Ce}_{80} \mathrm{Ga}_{20} \mathrm{O}_{\mathrm{x}}$ sample, that is, at a lower temperature than on pure ceria (cf. Figures $6 \mathrm{Ib}$ and IIb), and as soon as ethoxy SU begins to decompose. This result would imply that the H species

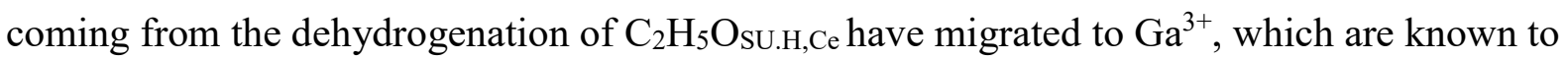
be active sites for $\mathrm{H}_{2}$ dissociation and/or $\mathrm{H}$ recombination [30], rapidly recombined and left the surface as $\mathrm{H}_{2}$ (Scheme 2, r6). In other words, the recombination of $\mathrm{OH}$ species to give $\mathrm{H}_{2}$ in pure ceria (Scheme $1, \mathrm{r} 7$ ) is a slower step than the proposed migration of $\mathrm{H}$ species to $\mathrm{Ga}^{3+}$ surface sites and the hydrogen release according to r6 in Scheme 2. The hydrogen evolution of the $\mathrm{Ce}_{90} \mathrm{Ga}_{10} \mathrm{O}_{\mathrm{x}}$ sample (Figure $\mathrm{S} 10$ ) shows an intermediate behavior between pure ceria and $\mathrm{Ce}_{80} \mathrm{Ga}_{20} \mathrm{O}_{\mathrm{x}}$, with a maximum at $252^{\circ} \mathrm{C}$.

In line with the expected facile formation of gallium hydrides, an IR band of Ga-H species at $1955 \mathrm{~cm}^{-1}$ was detected above $180{ }^{\circ} \mathrm{C}$ reaching a maximum at $250{ }^{\circ} \mathrm{C}$ (Figures $5 \mathrm{IIb}, 5 \mathrm{IIf}$ 
and 6 IIc). The normalized integrated intensity of the Ga-H signal (plotted in Figure 6 IIc) suggests that the Ga-H species develop along with the decomposition of the ethoxy species in LD configuration, and when $\mathrm{H}_{2}$ has almost reached a maximum (due to $\mathrm{C}_{2} \mathrm{H}_{5} \mathrm{O}_{\text {SU.H,Ce }}$ decomposition, as explained above). These results indicate that below $180{ }^{\circ} \mathrm{C}$, the rate of recombination of $\mathrm{Ga}-\mathrm{H}$ and $\mathrm{OH}$ species to yield $\mathrm{H}_{2}(\mathrm{r} 6)$ is faster than the rate of formation of $\mathrm{Ga}-\mathrm{H}$ species. Moreover, when the temperature increases above $180{ }^{\circ} \mathrm{C}$ the decomposition of LD ethoxy species, to acetate, near the gallium nanodomains begins to dominate and $\mathrm{Ga}-\mathrm{H}$ species begin to be detected (Figure 6 IIc). The consumption of $\mathrm{Ga}-\mathrm{H}$ observed above $250{ }^{\circ} \mathrm{C}$ could be a consequence of the decomposition of some of the acetate species, originated from LD and/or SU ethoxy species, leading to the formation of $\mathrm{Ce}^{3+}$ (Scheme 2, r5).

Another point to mention is that neither ethanol nor acetaldehyde were detected in the gas phase by MS over any of our ceria-based samples. Conversely, Li et al. [47] found a broad desorption peak of ethanol and acetaldehyde in the low temperature range (between 70 to 250 ${ }^{\circ} \mathrm{C}$ ) with a maximum between 100 and $150^{\circ} \mathrm{C}$ on nanoshaped ceria samples, but after adsorption of ethanol at room temperature with further He purging. Since physisorbed ethanol can still remain on the surface of ceria in those conditions, we run an extra TPRS-MS experiment after exposing our polycrystalline $\mathrm{CeO}_{2}$ powder to ethanol at $25{ }^{\circ} \mathrm{C}$. Our results showed broad peaks, between RT and $150{ }^{\circ} \mathrm{C}$, due to the desorption of ethanol and acetaldehyde (Figure S12). This last result, along with the no-detection of acetaldehyde during the ethanol adsorption at $100{ }^{\circ} \mathrm{C}$, suggest that acetaldehyde could be related to the presence of physisorbed ethanol rather than to ethoxy species.

In summary, and along the section 3 , we have shown that doping of ceria with gallia: (i) allows the recombination of $\mathrm{H}$ species coming from the dehydrogenation of ethoxy $\mathrm{SU}$, favored by the formation of $\mathrm{Ga}-\mathrm{H}$ species, which release $\mathrm{H}_{2}$ to the gas phase at much lower temperature compared to pure ceria, (ii) facilitates the dehydrogenation/oxidation of LD ethoxy species to 
acetate species due to both, the higher reactivity of the oxygen at the Ce-O-Ga interface and the capacity to form surface gallium hydride species, (iii) favors the formation of $\mathrm{CO}_{2}$ from acetate at lower temperature, and (iii) prevents the $\beta-\mathrm{CH}$ and $\mathrm{C}-\mathrm{O}$ breaking of $\mathrm{LD}$ ethoxy, hindering ethylene production and carbon deposits.

\section{Relationship between ethanol decomposition and the steam reforming reaction on $\mathrm{CeO}_{2}$ and $\mathrm{CeGaO}$}

By simple inspection of the non-normalized evolution curves of each gaseous compounds and acetate species on $\mathrm{CeO}_{2}$ and $\mathrm{CeGaO}_{\mathrm{x}}$ followed by the TPSR-MS and TPSR-IR experiments (Figure S11), we can conclude that gallium addition to ceria increased the $\mathrm{H}_{2}$ and $\mathrm{CO}_{2}$ production, and the amount of surface acetate, but decreased ethylene production. Those trends for gaseous products are consistent with those observed on Figure $1 \mathrm{~b}$ for the ethanol steam reforming reaction on pure $\mathrm{CeO}_{2}$ and $\mathrm{Ce}_{90} \mathrm{Ga}_{10} \mathrm{O}_{\mathrm{x}}$. If we assume that acetate species are involved in acetone productionunder ESR (ketonization reaction), which is the main hypothesis of several authors $[2,55-58]$, it is also possible to correlate the higher surface concentration of acetate on $\mathrm{CeGaO}_{\mathrm{x}}$ surface to the higher yield to acetone under ESR conditions (cf. Figure S11 and Figure 1b). Of course, under ESR conditions the role of water cannot be ignored. Some of us have studied by $\mathrm{H}_{2} \mathrm{O}$-TPO the reoxidation of ceria, and gallium-doped ceria $\left(\mathrm{Ce}_{75} \mathrm{Ga}_{25} \mathrm{O}_{\mathrm{x}}\right)$, by means of IR spectroscopy and time-resolved XRD [29]. On one hand, the evolution of $\mathrm{Ce}^{3+}$ IR signal showed a partial oxidation of $\mathrm{Ce}^{3+}$ to $\mathrm{Ce}^{4+}$ in both materials $(70$ and $45 \%$ of reoxidation on $\mathrm{CeO}_{2}$ and $\mathrm{Ce}_{75} \mathrm{Ga}_{25} \mathrm{O}_{\mathrm{x}}$ at $723 \mathrm{~K}$, respectively). On the other hand, the evolution of the lattice parameter obtained by XRD, showed a $50 \%$ of $\mathrm{Ce}^{3+}$ reoxidation by water, in close agreement with the IR spectroscopy results. Water activation was also studied on the water gas shift (WGS) platinum catalyst supported on ceria and $\mathrm{Ce}_{80} \mathrm{Ga}_{20} \mathrm{O}_{\mathrm{x}}$, showing that in the presence of the metallic function the oxygen vacancy filling by water is always fast enough in either $\mathrm{Pt} / \mathrm{CeO}_{2}$ or $\mathrm{Pt} / \mathrm{Ce}_{80} \mathrm{Ga}_{20} \mathrm{O}_{\mathrm{x}}$ [60]. Thus, it seems that the role of water under ESR conditions 
could be to quench oxygen vacancies and to populate the surface with $\mathrm{Ce}^{4+}$ cations. However, further studies would be necessary to explore the role of water during ESR reaction. Nonetheless, it appears that ethanol decomposition rules the product distribution under ESR conditions on the pure $\mathrm{CeO}_{2}$ and $\mathrm{CeGaO}_{\mathrm{x}}$ samples.

The metallic function is also crucial to run an effective steam reforming reaction, since the desired final products are $\mathrm{H}_{2}$ and $\mathrm{CO}_{2}$. Cobalt sites, for example, favor C-C sisson and water activation [61]. Then, increasing metal loadings (typically, $\sim 10 \mathrm{wt} . \%$ of Co is used) would lead to higher activity and selectivity towards ESR reaction. However, the effect of the support, and metal-support interface, which are also key factors to achieve active and stable catalysts, would be masked $[2,62]$. Thus, more significant insights were obtained after running the ESR reaction on cobalt supported on $\mathrm{CeO}_{2}$ and $\mathrm{Ce}_{90} \mathrm{Ga}_{10} \mathrm{O}_{\mathrm{x}}$, under the same experimental conditions described over the supports. In this case, to preserve "visible" the reactivity of the supports we chose a low Co loading ( 0.9 atom of $\mathrm{Co} / \mathrm{nm}^{2}$, that is, $0.5 \% \mathrm{w} / \mathrm{w} \mathrm{Co} / \mathrm{CeO}_{2}$ and $1.0 \% \mathrm{w} / \mathrm{w}$ $\left.\mathrm{Co} / \mathrm{Ce}_{90} \mathrm{Ga}_{10} \mathrm{O}_{\mathrm{x}}\right)$. The initial product distribution at $500{ }^{\circ} \mathrm{C}(\mathrm{t}=0 \mathrm{~h}, 100 \%$ of ethanol conversion), obtained under the same experimental conditions described for the supports, is shown in Figure S13. As expected, the Co-supported catalysts are more active and effective than the bare supports for the ESR reaction by decreasing the amount of carbonaceous byproducts such as ethylene and acetone, and increasing the amounts of $\mathrm{H}_{2}$ and $\mathrm{CO}_{2}$ (cf. Figures $1 \mathrm{~b}$ and S8). However, the main trends on product distribution mentioned above on the supports are still kept for our Co-supported catalysts at initial conditions: higher production of $\mathrm{H}_{2}, \mathrm{CO}_{2}$ and acetone, and lower ethylene formation are observed on $\mathrm{Co} / \mathrm{Ce}{ }_{90} \mathrm{Ga}_{10} \mathrm{O}_{\mathrm{x}}$ than on $\mathrm{Co} / \mathrm{CeO}{ }_{2}$. Furthermore, $12 \%$ less of carbon deposition, measured by TPO experiments (Figure S14 in $\mathrm{SI})$, was found on the gallium doped catalysts after $4 \mathrm{~h}$ on stream at $500{ }^{\circ} \mathrm{C}(1.60 \mathrm{vs} .1 .82 \mathrm{~g}$ $\mathrm{C} / \mathrm{g} \mathrm{Co} / \mathrm{h}$ for $1.0 \% \mathrm{Co} / \mathrm{Ce}_{90} \mathrm{Ga}_{10} \mathrm{O}_{\mathrm{x}}$ and $0.5 \% \mathrm{Co} / \mathrm{CeO}_{2}$, respectively), which suggests that gallium plays a role in avoiding coke formation, most likely by suppressing ethylene 
production. Then, future experimental (and theoretical) work involving specific IR studies under operando conditions will be required to discriminate intermediates from spectators and unravel de mechanism of ESR on our supports and Co catalysts.

\section{Conclusions}

Cerium oxide and cerium-gallium mixed oxides were evaluated as supports for the steam reforming of ethanol, showing that gallium increased the $\mathrm{H}_{2}$ yield and enhanced the $\mathrm{H}_{2}: \mathrm{CO}_{2}$ ratio at the reactor outlet. A noticeable change of the carbon-based product selectivity was also observed: ethanol was preferentially converted to ethylene on pure $\mathrm{CeO}_{2}$ and to carbon dioxide and acetone on $\mathrm{CeGaO}_{x}$. To understand these dissimilar behaviors we investigated the adsorption and decomposition of ethanol over the surface of the both kinds of oxides.

Ethanol adsorption and TPSR-IR studies on $\mathrm{CeO}_{2}$ and $\mathrm{CeGaO}_{\mathrm{x}}$ showed the formation of two types of ethoxy species, one being less reactive and another being less stable. DFT calculations of ethanol adsorption on the hydroxylated ceria(111) showed that the ethoxy species are adsorbed in monodentate coordination on a Ce atom, and two configurations are possible. In these two states, the alkyl chain is oriented parallel (ethoxy LD, "lying down") or perpendicular (ethoxy SU, "standing up") to the surface. In the case of the gallium-doped ceria surface, ethoxy can also dissociate on top of a Ga atom in a "lying-down" configuration.

The calculation of the vibrational frequencies of ethoxy species by DFT allowed us to assign the IR bands of ethoxy species found in the spectral region from 1200 to $800 \mathrm{~cm}^{-1}$. Based on the evolution of the surface species and gas phase products obtained by TPSR-IR and TPSRMS, we postulate a mechanism for ethanol adsorption and decomposition on the surface of the oxides studied in this work.

In the case of pure ceria, the ethoxy in SU configuration decomposes above $150^{\circ} \mathrm{C}$ to yield acetate species, which further decompose to $\mathrm{CO}_{2}$ and $\mathrm{CH}_{4}$ in the gas phase. Moreover, ethoxy 
LD begins to decompose above $200^{\circ} \mathrm{C}$, leading to $\mathrm{H}_{2}$ and $\mathrm{C}_{2} \mathrm{H}_{4}$. Ethylene can further polymerize resulting in the formation of carbon deposits on the surface of ceria. Surprisingly, ethylene was not detected at the outlet of the reactor on the mixed oxides. It is proposed that dehydrogenation and oxidation of ethoxy to acetate species at the Ce-O-Ga interface is assisted by the formation of Ga-H species. Thus, all of the ethoxy species adsorbed on the surface of the mixed oxides, including those in lying down configurations, rather take the acetate route than produce ethylene. Additionally, the more labile oxygen at the Ce-O-Ga interface likely assists the decomposition of acetate species to $\mathrm{CO}_{2}$ and $\mathrm{CH}_{4}$ at lower temperature. Thus, the absence of ethylene in the gas phase during TPSR-MS and the lower amounts of carbonaceous deposits, suggest that the cerium-gallium mixed oxides are more promising supports for ESR metal/oxide catalysts than pure ceria, that is, less coke formation might be anticipated.

\section{ASSOCIATED CONTENT}

\section{Appendix A. Supplementary data}

Supplementary material related to this article can be found, in the online version.

\section{Data availability}

The DFT data that support the findings of this study are available in Materials Cloud $\{$ https://www.materialscloud.org/home\} with the identifier doi:*****/materialscloud:2019.*****.

\section{AUTHOR INFORMATION}

\section{Corresponding Authors}

*Email: abonivar@santafe-conicet.gov.ar

*Email: $\underline{\text { lustemberg@,ifir-conicet.gov.ar }}$ 


\section{ACKNOWLEDGMENTS}

This work has been financed with the ANPCyT (PICT 2015-3651 and PICT-2016-2750) and UNL-CAID (PI 50420150100066LI) projects. S.M. and J.L. acknowledge support by the Deutsche Forschungsgemeinschaft (DFG, project number 214951840) and within the Excellence Cluster 'Engineering of Advanced Materials'. This project has received funding from the European Union's Horizon 2020 research and innovation program under the Marie Skłodowska-Curie grant agreement No 832121. M.V.G.-P. acknowledges the financial support of the Ministry of Economy and Competitiveness MINECO-Spain (grant Nr. CTQ2015-78823R) and of the Ministry of Science, Innovation and Universities MICINN-Spain (grant Nr. RTI2018-101604-B-I00). Computer time provided by the RES resources at Marenostrum and LaPalma nodes, the IFIR and CONICET at the Piluso and Tupac nodes, respectively. We acknowledge PRACE for awarding us access to Finisterrae (CESGA), Spain. The GENCICINES/IDRIS (Grants 2018- x2018082131 2019- x2019082131) and the CCRE-DSI of Sorbone Université, are thankfully acknowledged.

\section{REFERENCES}

[1] P.R. de la Piscina, N. Homs, Use of biofuels to produce hydrogen (reformation processes), Chem. Soc. Rev. 37 (2008) 2459-2467. https://doi.org/10.1039/b712181b.

[2] D. Zanchet, J.B.O. Santos, S. Damyanova, J.M.R. Gallo, J.M. C. Bueno, J.M.C. Bueno, Toward Understanding Metal-Catalyzed Ethanol Reforming, ACS Catal. 5 (2015) 3841-3863. https://doi.org/10.1021/cs5020755.

[3] L. V. Mattos, G. Jacobs, B.H. Davis, F.B. Noronha, Production of hydrogen from ethanol: Review of reaction mechanism and catalyst deactivation, Chem. Rev. 112 
(2012) 4094-4123. https://doi.org/10.1021/cr2000114.

[4] A. Ribeiro, S. Helena, C. Valentim, V. Briois, Operando monitoring of metal sites and coke evolution during non-oxidative and oxidative ethanol steam reforming over $\mathrm{Ni}$ and NiCu ex-hydrotalcite catalysts, Catal. Today. (2019) 1-9. https://doi.org/10.1016/j.cattod.2018.12.054.

[5] Y.C. Sharma, A. Kumar, R. Prasad, S. Nath, Ethanol steam reforming for hydrogen production : Latest and e ff ective catalyst modi fi cation strategies to minimize carbonaceous deactivation, Renew. Sustain. Energy Rev. 74 (2017) 89-103. https://doi.org/10.1016/j.rser.2017.02.049.

[6] A.L.M. Da Silva, J.P. Den Breejen, L. V. Mattos, J.H. Bitter, K.P. De Jong, F.B. Noronha, Cobalt particle size effects on catalytic performance for ethanol steam reforming - Smaller is better, J. Catal. 318 (2014) 67-74. https://doi.org/10.1016/j.jcat.2014.07.020.

[7] L1. Soler, A. Casanovas, J. Ryan, I. Angurell, C. Escudero, J. Llorca, Dynamic Reorganization of Bimetallic Nanoparticles under Reaction Depending on the Support Nanoshape : The Case of RhPd over Ceria Nanocubes and Nanorods under Ethanol Steam Reforming, (2019). https://doi.org/10.1021/acscatal.9b00463.

[8] E. V Matus, L.B. Okhlopkova, Effects of preparation mode and doping on the genesis and properties of $\mathrm{Ni} / \mathrm{Ce} 1-\mathrm{x} \mathrm{Mx} \mathrm{O} \mathrm{y} \mathrm{nanocrystallites} \mathrm{(} \mathrm{M}=\mathrm{Gd}, \mathrm{La}, \mathrm{Mg}$ ) for catalytic applications, J. Nanoparticle Res. 21:11 (2019) 1-17.

[9] A.E. M. Dömök, K. Baán, T. Kecskés, Promoting Mechanism of Potassium in the Reforming of Ethanol on Pt / Al 2 O 3 Catalyst, Catal. Letters. 126 (2008) 49-57. https://doi.org/10.1007/s10562-008-9616-0. 
[10] F. Frusteri, S. Freni, Bio-ethanol, a suitable fuel to produce hydrogen for a molten carbonate fuel cell, J. Power Sources. 173 (2007) 200-209.

https://doi.org/10.1016/j.jpowsour.2007.04.065.

[11] J. Llorca, N. Homs, J. Sales, J.G. Fierro, Effect of sodium addition on the performance of $\mathrm{Co}-\mathrm{ZnO}$-based catalysts for hydrogen production from bioethanol, J. Catal. 222 (2004) 470-480. https://doi.org/10.1016/j.jcat.2003.12.008.

[12] F. Frusteri, S. Freni, V. Chiodo, L. Spadaro, O. Di Blasi, G. Bonura, S. Cavallaro, Steam reforming of bio-ethanol on alkali-doped $\mathrm{Ni} / \mathrm{MgO}$ catalysts : hydrogen production for MC fuel cell, Appl. Catal. A Gen. 270 (2004) 1-7. https://doi.org/10.1016/j.apcata.2004.03.052.

[13] H. Song, U.S. Ozkan, Changing the oxygen mobility in $\mathrm{Co} / \mathrm{Ceria}$ catalysts by Ca incorporation: Implications for ethanol steam reforming, J. Phys. Chem. A. 114 (2010) 3796-3801. https://doi.org/10.1021/jp905608e.

[14] P. Biswas, D. Kunzru, Steam reforming of ethanol on Ni-CeO2-ZrO2 catalysts: Effect of doping with copper, cobalt and calcium, Catal. Letters. 118 (2007) 36-49. https://doi.org/10.1007/s10562-007-9133-6.

[15] A. Carrero, J.A. Calles, A.J. Vizcaíno, Effect of $\mathrm{Mg}$ and Ca addition on coke deposition over $\mathrm{Cu}-\mathrm{Ni}$ / SiO 2 catalysts for ethanol steam reforming, Chem. Eng. J. 163 (2010) 395-402. https://doi.org/10.1016/j.cej.2010.07.029.

[16] A.N. Fatsikostas, X.E. Verykios, Reaction network of steam reforming of ethanol over Ni-based catalysts, 225 (2004) 439-452. https://doi.org/10.1016/j.jcat.2004.04.034.

[17] J.W.C. Liberatori, R.U. Ribeiro, D. Zanchet, F.B. Noronha, J.M.C. Bueno, Steam reforming of ethanol on supported nickel catalysts, Appl. Catal. A Gen. 327 (2007) 
197-204. https://doi.org/10.1016/j.apcata.2007.05.010.

[18] R.M. Navarro, J.L.G. Fierro, Ethanol steam reforming over Ni / M x O y - Al 2 O 3 ( $\mathrm{M}=\mathrm{Ce}, \mathrm{La}, \mathrm{Zr}$ and $\mathrm{Mg}$ ) catalysts : Influence of support on the hydrogen production, Int. J. Hydrogen Energy. 32 (2007) 1462-1471.

https://doi.org/10.1016/j.ijhydene.2006.10.025.

[19] M.C. Sánchez-Sánchez, R.M. Navarro, J.L.G. Fierro, Ethanol steam reforming over Ni/La-A12O3 catalysts: Influence of lanthanum loading, Catal. Today. (2007). https://doi.org/10.1016/j.cattod.2006.10.013.

[20] F. Can, A. Le Valant, N. Bion, F. Epron, D. Duprez, New Active and Selective Rh REO x - Al 2 O 3 Catalysts for Ethanol Steam Reforming, Journa Phys. Chem. C. 112 (2008) 14145-14153.

[21] H. Sohn, U.S. Ozkan, Cobalt-Based Catalysts for Ethanol Steam Reforming: An Overview, Energy and Fuels. 30 (2016) 5309-5322. https://doi.org/10.1021/acs.energyfuels.6b00577.

[22] P. Li, X. Chen, Y. Li, J.W. Schwank, A review on oxygen storage capacity of CeO2based materials: Influence factors, measurement techniques, and applications in reactions related to catalytic automotive emissions control, Catal. Today. (2018) 90115. https://doi.org/10.1016/j.cattod.2018.05.059.

[23] H. Wang, L. Zhang, M. Yuan, T. Xu, Y. Liu, Steam reforming of ethanol over Ni/Ce0.7Pr0.3O2 catalyst, J. Rare Earths. 30 (2012) 670-675. https://doi.org/10.1016/S1002-0721(12)60110-0.

[24] P. Xiaojian, C. Yazhong, D.A.I. Ruiqi, C.U.I. Peng, Co / CeO 2 Catalysts Prepared Using Citric Acid Complexing for Ethanol Steam Reforming, Chinese J. Catal. 33 
(2012) 281-289. https://doi.org/10.1016/S1872-2067(11)60335-5.

[25] B. Noronha, R.C. Colman, B.L. Augusto, L.O.O. Costa, L. V Mattos, Ethanol reforming over $\mathrm{Ni}$ / CeGd catalysts with low Ni content, 7 (2012). https://doi.org/10.1016/j.ijhydene.2012.05.127.

[26] C. Liang, Z. Ma, H. Lin, L. Ding, J. Qiu, Template preparation of nanoscale Ce x Fe 1 À x O 2 solid solutions and their catalytic properties for ethanol steam reforming, J. Mater. Chem. 19 (2009) 1417-1424. https://doi.org/10.1039/b817942e.

[27] Z. Xiao, Y. Li, F. Hou, C. Wu, L. Pan, J. Zou, L. Wang, X. Zhang, G. Liu, G. Li, Engineering oxygen vacancies and nickel dispersion on $\mathrm{CeO} 2$ by $\mathrm{Pr}$ doping for highly stable ethanol steam reforming, Appl. Catal. B Environ. 258 (2019) 117940. https://doi.org/10.1016/j.apcatb.2019.117940.

[28] S. Collins, G. Finos, R. Alcántara, E. Del Rio, S. Bernal, a Bonivardi, Effect of gallia doping on the acid-base and redox properties of ceria, Appl. Catal. A Gen. 388 (2010) 202-210. https://doi.org/10.1016/j.apcata.2010.08.050.

[29] J. Vecchietti, S. Collins, W. Xu, L. Barrio, D. Stacchiola, M. Calatayud, F. Tielens, J.J. Delgado, A. Bonivardi, Surface Reduction Mechanism of Cerium-Gallium Mixed Oxides with Enhanced Redox Properties, J. Phys. Chem. C. 117 (2013) 8822-8831. https://doi.org/10.1021/jp400285b.

[30] J. Vecchietti, M.A. Baltanás, C. Gervais, S.E. Collins, G. Blanco, O. Matz, M. Calatayud, A. Bonivardi, Insights on hydride formation over cerium-gallium mixed oxides : A mechanistic study for efficient H 2 dissociation q, J. Catal. 345 (2017) 258269. https://doi.org/10.1016/j.jcat.2016.11.029.

[31] G. Vilé, P. Dähler, J. Vecchietti, M. Baltanás, S. Collins, M. Calatayud, A. Bonivardi, 
J. Pérez-Ramírez, Promoted ceria catalysts for alkyne semi-hydrogenation, J. Catal. 324 (2015) 69-78. https://doi.org/10.1016/j.jcat.2015.01.020.

[32] G. Kresse, Ab initio molecular dynamics for liquid metals, J. Non. Cryst. Solids. 192193 (1995) 222-229. https://doi.org/10.1016/0022-3093(95)00355-X.

[33] P.E. Blöchl, Projector augmented-wave method, Phys. Rev. B. 50 (1994) 1795317979. https://doi.org/10.1103/PhysRevB.50.17953.

[34] S. Dudarev, G. Botton, Electron-energy-loss spectra and the structural stability of nickel oxide: An LSDA+U study, Phys. Rev. B - Condens. Matter Mater. Phys. 57 (1998) 1505-1509. https://doi.org/10.1103/PhysRevB.57.1505.

[35] J.P. Perdew, K. Burke, M. Ernzerhof, Generalized gradient approximation made simple, Phys. Rev. Lett. 77 (1996) 3865-3868. https://doi.org/10.1103/PhysRevLett.77.3865.

[36] K. Lee, É.D. Murray, L. Kong, B.I. Lundqvist, D.C. Langreth, Higher-accuracy van der Waals density functional, Phys. Rev. B - Condens. Matter Mater. Phys. 82 (2010) 3-6. https://doi.org/10.1103/PhysRevB.82.081101.

[37] J. Klimeš, D.R. Bowler, A. Michaelides, Chemical accuracy for the van der Waals density functional, J. Phys. Condens. Matter. 22 (2010). https://doi.org/10.1088/0953$8984 / 22 / 2 / 022201$.

[38] J. Klime, D.R. Bowler, A. Michaelides, Van der Waals density functionals applied to solids, Phys. Rev. B - Condens. Matter Mater. Phys. 83 (2011) 1-13. https://doi.org/10.1103/PhysRevB.83.195131.

[39] G. Román-Pérez, J.M. Soler, Efficient implementation of a van der waals density 
functional: Application to double-wall carbon nanotubes, Phys. Rev. Lett. 103 (2009) 1-4. https://doi.org/10.1103/PhysRevLett.103.096102.

[40] J.P. Merrick, D. Moran, L. Radom, An evaluation of harmonic vibrational frequency scale factors, J. Phys. Chem. A. 111 (2007) 11683-11700. https://doi.org/10.1021/jp073974n.

[41] G. Finos, S. Collins, G. Blanco, E. del Rio, J.M. Cíes, S. Bernal, A. Bonivardi, Infrared spectroscopic study of carbon dioxide adsorption on the surface of ceriumgallium mixed oxides, Catal. Today. 180 (2012) 9-18. https://doi.org/10.1016/j.cattod.2011.04.054.

[42] Y. Suda, T. Morimoto, M. Nagao, Adsorption of Alcohols on Titanium Dioxide (Rutile) Surface, Langmuir. 3 (1987) 99-104. https://doi.org/10.1021/la00073a017.

[43] V.S. Lusvardi, M.A. Barteau, W.R. Dolinger, W.E. Farneth, Influence of surface hydroxyls on the adsorption and reaction of ethanol on polycrystalline titania, J. Phys. Chem. 100 (1996) 18183-18191. https://doi.org/10.1021/jp961372q.

[44] J. Lamotte, V. Moravek, M. Bensitel, J.C. Lavalley, React. Kinet. Catal. Lett., Vol. 36, No. i, 113-118 (1988), React. Kinet. Catal. Lett. 36 (1988) 113-118.

[45] E. Collins, L.E. Briand, L.A. Gambaro, M.A. Baltana, A.L. Bonivardi, Adsorption and Decomposition of Methanol on Gallium Oxide Polymorphs, (2008) 14988-15000.

[46] A. Yee, S.J. Morrison, H. Idriss, A Study of the Reactions of Ethanol on $\mathrm{CeO} 2$ and $\mathrm{Pd} / \mathrm{CeO} 2$ by Steady State Reactions, Temperature Programmed Desorption, and In Situ FT-IR, J. Catal. 186 (1999) 279-295. https://doi.org/10.1006/jcat.1999.2563.

[47] M. Li, Z. Wu, S.H. Overbury, Surface structure dependence of selective oxidation of 
ethanol on faceted CeO2nanocrystals, J. Catal. 306 (2013) 164-176.

https://doi.org/10.1016/j.jcat.2013.06.019.

[48] A. Beste, S.H. Overbury, Pathways for ethanol dehydrogenation and dehydration catalyzed by ceria (111) and (100) surfaces, J. Phys. Chem. C. 119 (2015) 2447-2455. https://doi.org/10.1021/jp509686f.

[49] P.G. Lustemberg, M. V. Bosco, A. Bonivardi, H.F. Busnengo, M. V. GandugliaPirovano, Insights into the Nature of Formate Species in the Decomposition and Reaction of Methanol over Cerium Oxide Surfaces: A Combined Infrared Spectroscopy and Density Functional Theory Study, J. Phys. Chem. C. 119 (2015) 21452-21464. https://doi.org/10.1021/acs.jpcc.5b05070.

[50] C. Binet, A. Badri, J. Lavalley, Spectroscopic Characterization of the Reduction of Ceria from Electronic Transitions of Intrinsic Point Defects, J. Phys. Chem. 98 (1994) $6392-6398$.

[51] A. Borodziński, G.C. Bond, Selective hydrogenation of ethyne in ethene-rich streams on palladium catalysts, Part 2: Steady-state kinetics and effects of palladium particle size, carbon monoxide, and promoters, 2008. https://doi.org/10.1080/01614940802142102.

[52] P. Galli, The breakthrough in catalysis and processes for olefin polymerization: Innovative structures and a strategy in the materials area for the twenty-first century, Prog. Polym. Sci. 19 (1994) 959-974.

[53] B.K. Vu, S.M. Bok, I.Y. Ahn, E.W. Shin, Oxidation of coke formed over Pt-A12O3 and Pt-SBA-15 in propane dehydrogenation, Catal. Letters. 133 (2009) 376-381. https://doi.org/10.1007/s10562-009-0196-4. 
[54] A. Remiro, B. Valle, B. Aramburu, A.T. Aguayo, J. Bilbao, A.G. Gayubo, Steam reforming of the bio-oil aqueous fraction in a fluidized bed reactor with in situ $\mathrm{CO} 2$ capture, Ind. Eng. Chem. Res. 52 (2013) 17087-17098. https://doi.org/10.1021/ie4021705.

[55] E.I. Kauppi, R.K. Kaila, J.A. Linnekoski, A.O.I. Krause, M.K. Veringa Niemelä, Temperature-programmed oxidation of coked noble metal catalysts after autothermal reforming of n-hexadecane, Int. J. Hydrogen Energy. 35 (2010) 7759-7767. https://doi.org/10.1016/j.ijhydene.2010.05.046.

[56] M. Virginie, M. Araque, A.C. Roger, J.C. Vargas, A. Kiennemann, Comparative study of $\mathrm{H} 2$ production by ethanol steam reforming on $\mathrm{Ce} 2 \mathrm{Zr} 1.5 \mathrm{Co} 0.5 \mathrm{O} 8-\delta$ and $\mathrm{Ce} 2 \mathrm{Zr} 1.5 \mathrm{Co} 0.47 \mathrm{Rh} 0.07 \mathrm{O} 8-\delta$ : Evidence of the $\mathrm{Rh}$ role on the deactivation process, Catal. Today. 138 (2008) 21-27. https://doi.org/10.1016/j.cattod.2008.04.047.

[57] M. Greluk, M. Rotko, S. Turczyniak-Surdacka, Comparison of catalytic performance and coking resistant behaviors of cobalt- and nickel based catalyst with different Co/Ce and Ni/Ce molar ratio under SRE conditions, Appl. Catal. A Gen. 590 (2020) 117334. https://doi.org/10.1016/j.apcata.2019.117334.

[58] E. Varga, Z. Ferencz, A. Oszkó, A. Erdohelyi, J. Kiss, Oxidation states of active catalytic centers in ethanol steam reforming reaction on ceria based $\mathrm{Rh}$ promoted Co catalysts: An XPS study, J. Mol. Catal. A Chem. 397 (2015) 127-133. https://doi.org/10.1016/j.molcata.2014.11.010.

[59] G. Jacobs, R. Keogh, B. Davis, Steam reforming of ethanol over Pt/ceria with co-fed hydrogen, J. Catal. 245 (2007) 326-337. https://doi.org/10.1016/j.jcat.2006.10.018.

[60] J. Vecchietti, A. Bonivardi, W. Xu, D. Stacchiola, J.J. Delgado, M. Calatayud, S.E. 
Collins, Understanding the role of oxygen vacancies in the water gas shift reaction on ceria-supported platinum catalysts, ACS Catal. 4 (2014) 2088-2096. https://doi.org/10.1021/cs500323u.

[61] S. Ogo, Y. Sekine, Recent progress in ethanol steam reforming using non-noble transition metal catalysts: A review, Fuel Process. Technol. 199 (2020) 106238. https://doi.org/10.1016/j.fuproc.2019.106238.

[62] H. Song, X. Bao, C.M. Hadad, U.S. Ozkan, Adsorption/desorption behavior of ethanol steam reforming reactants and intermediates over supported cobalt catalysts, Catal. Letters. 141 (2011) 43-54. https://doi.org/10.1007/s10562-010-0476-z. 


\section{Supporting Information}

\section{Controlled selectivity for ethanol steam}

\section{reforming reaction over doped $\mathrm{CeO}_{2}$ surfaces:}

\section{The role of gallium}

Julia Vecchietti ${ }^{1}$, Pablo Lustemberg ${ }^{2,3^{*}}$, Esteban L. Fornero ${ }^{1}$, Mónica Calatayud ${ }^{4}$,

Sebastián E. Collins ${ }^{1}$; Susanne Mohr ${ }^{5}$, M. Verónica Ganduglia-Pirovano ${ }^{3}$, Jörg

Libuda ${ }^{5}$,Adrian L. Bonivardi ${ }^{1,6^{*}}$

${ }^{1}$ Instituto de Desarrollo Tecnológico para la Industria Química, UNL-CONICET, 3000

Santa Fe, Argentina.

${ }^{2}$ Instituto de Física Rosario (IFIR), CONICET-UNR, Bv. 27 de Febrero 210bis, S2000EZP Rosario, Santa Fe, Argentina.

${ }^{3}$ Instituto de Catálisis y Petroleoquímica, CSIC, C/Marie Curie 2, 28049 Madrid, Spain.

${ }^{4}$ Sorbonne Université, CNRS, Laboratoire de Chimie Théorique, LCT, F. 75005 Paris, France

${ }^{5}$ Interface Research and Catalysis, ECRC, Friedrich-Alexander-Universität ErlangenNürnberg, Egerlandstraße 3, D-91058 Erlangen, Germany.

${ }^{6}$ Facultad de Ingeniería Química, Universidad Nacional del Litoral, Santiago del Estero 2829, 3000 Santa Fe, Argentina. 


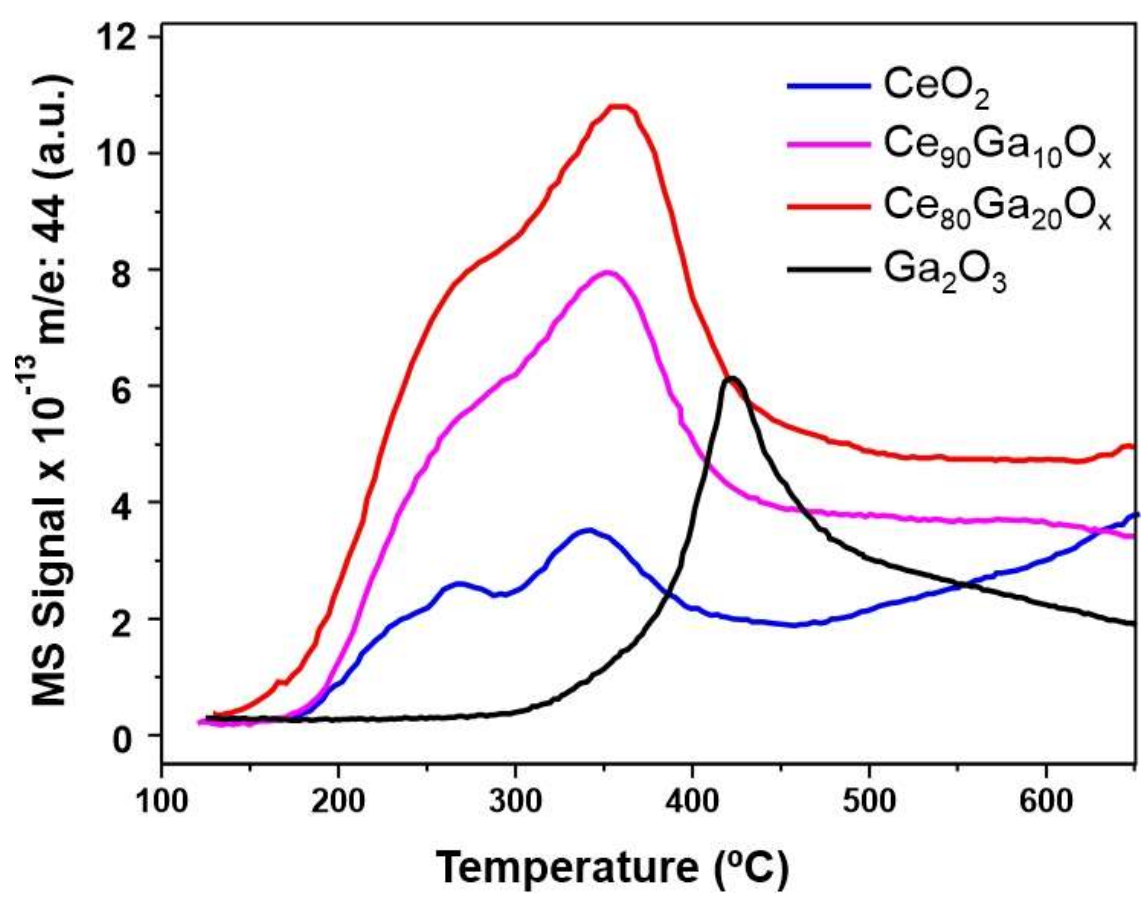

Figures S1. CO-TPSR profiles of the Ga-promoted ceria and the pure oxides.

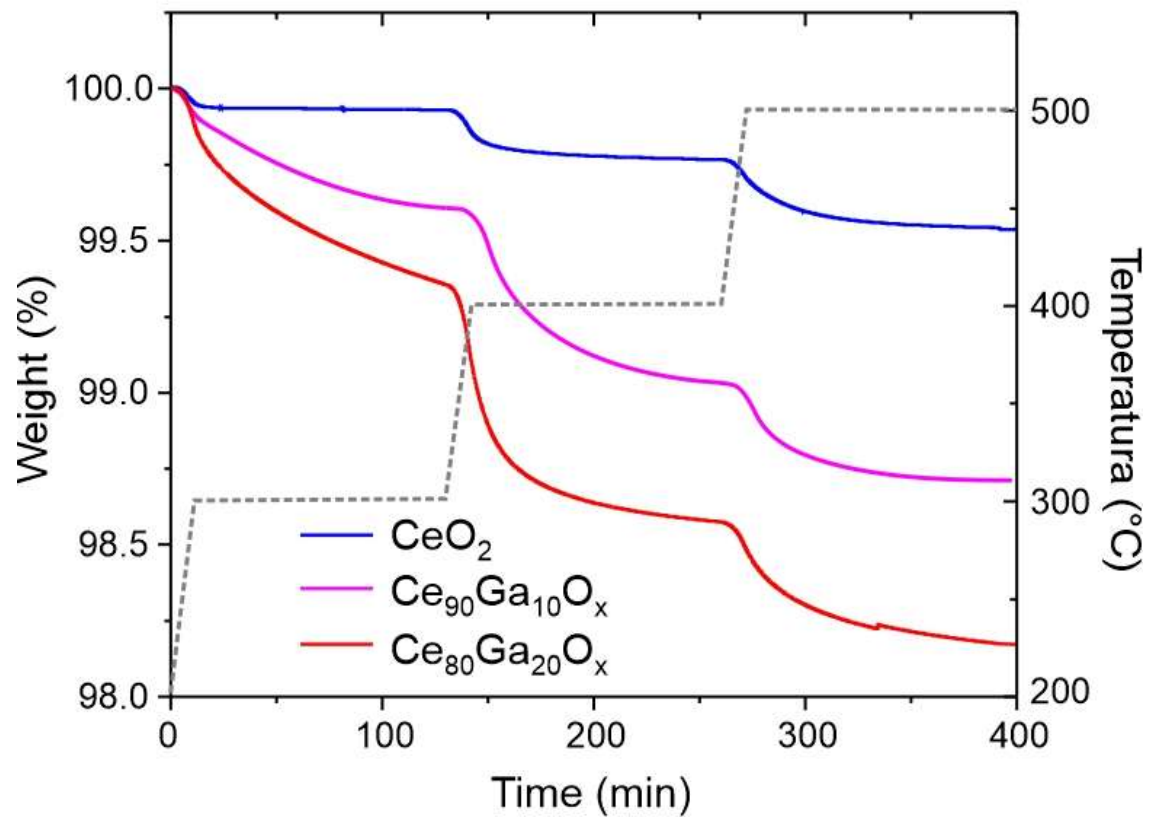

Figure S2. Weight loss measured by TGA during OSC measurents under reduction with $\mathrm{H}_{2}$ at 300 , 400 y $500^{\circ} \mathrm{C}$. 

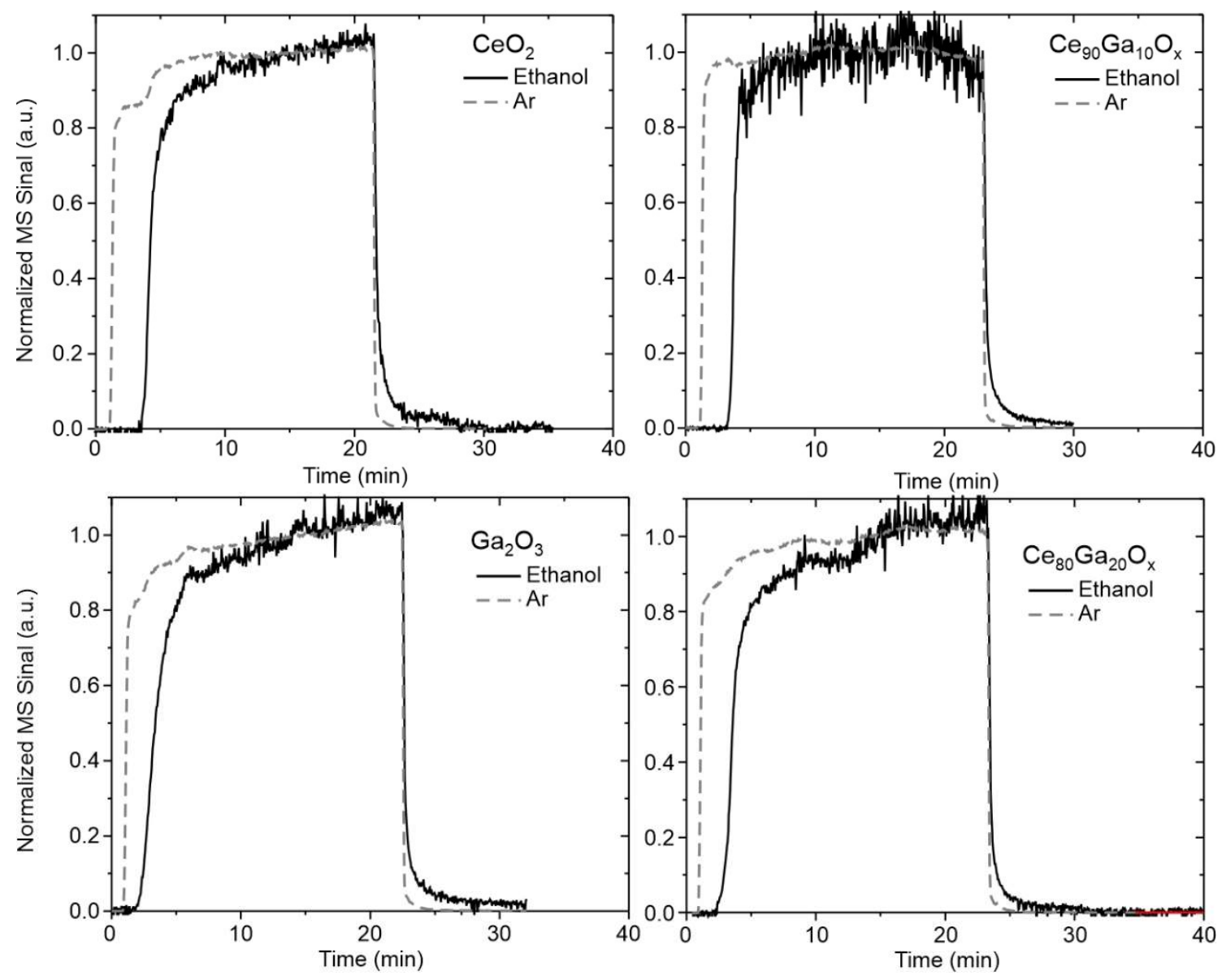

Figure S3. Evolution of the Ar and ethanol MS signals collected during ethanol adsorption at $100^{\circ} \mathrm{C}$, over $\mathrm{CeO}_{2}, \mathrm{Ga}_{2} \mathrm{O}_{3}$ and $\mathrm{CeGaO}_{x}$ samples, right before the TPSR-MS experiments. 


\section{Conversion and yield definitions to evaluate the catalytic performance}

Conversion of ethanol $\left(X_{\mathrm{C}_{2} \mathrm{H}_{5} \mathrm{OH}}\right), \%$ :

$$
X_{C_{2} \mathrm{H}_{5} \mathrm{OH}}=\frac{\left(m_{C_{2} \mathrm{H}_{5} \mathrm{OH}}^{\text {in }}-m_{C_{2} \mathrm{H}_{5} \mathrm{OH}}^{\text {out }}\right)}{m_{\mathrm{C}_{2} \mathrm{H}_{5} \mathrm{OH}}^{\text {in }}} * 100
$$

Yield to hydrogen $\left(\right.$ Yield $\left._{\mathrm{H}_{2}}\right)$, \%:

$$
\text { Yield }_{\mathrm{H}_{2}}=\frac{m_{\mathrm{H}_{2}}^{\text {out }}}{6 * m_{\mathrm{C}_{2} \mathrm{H}_{5} \mathrm{OH}}^{\text {in }}} * 100
$$

Yield to carbon-containing compounds $\left(\right.$ Yield $\left._{i}\right), \%$ :

$$
\text { Yield }_{i}=\frac{n_{C_{i}} * m_{i}^{\text {out }}}{2 * m_{C_{2} \mathrm{H}_{5} \mathrm{OH}}^{\text {in }}} * 100
$$

$m_{\mathrm{C}_{2} \mathrm{H}_{5} \mathrm{OH}}^{\text {in }}$ : moles of ethanol at the inlet of the reactor

$m_{\mathrm{C}_{2} \mathrm{H}_{5} \mathrm{OH}}^{\text {out }}$ : moles of ethanol at the reactor outlet

$m_{\mathrm{H}_{2}}^{\text {out }}$ : moles of $\mathrm{H}_{2}$ at the reactor outlet

$n_{C_{i}}:$ number of carbon atoms of the $i$-product

$m_{i}^{\text {out }}$ : moles of the $i$-product at the reactor outlet

Table S1: Adsorption energy of dissociatively adsorbed ethanol on: the clean ceria surface $\left(\mathrm{Ce}_{18} \mathrm{O}_{36}\right)$, hydroxylated ceria $\left(\mathrm{Ce}_{18} \mathrm{O}_{37} \mathrm{H}_{2}\right)$ and hydroxylated gallium-doped ceria $\left(\mathrm{Ce}_{17} \mathrm{GaO}_{37} \mathrm{H}_{3}\right)$ surfaces. In the case of gallium-doped ceria the subscript $\mathrm{Ga}(\mathrm{Ce})$ means that the ethoxy is adsorbed on a $\mathrm{Ga}(\mathrm{Ce})$ atom. The numbers in parenthesis correspond to calculations employing a three $\mathrm{O}-\mathrm{Ce}-\mathrm{O}$ trilayers slab.

\begin{tabular}{|c|c|c|c|}
\hline \multirow{2}{*}{ State/Catalyst } & \multicolumn{3}{|c|}{ Adsorption Energy $(\mathrm{eV})$} \\
\cline { 2 - 4 } & $\mathrm{C}_{18} \mathrm{O}_{36}$ & $\mathrm{Ce}_{18} \mathrm{O}_{37} \mathrm{H}_{2}$ & $\mathrm{Ce}_{17} \mathrm{GaO}_{37} \mathrm{H}_{3}$ \\
\hline $\mathrm{SU}$ & -0.93 & $-1.08(-1.12)$ & $-1.51_{\mathrm{Ga}} /-0.777_{\mathrm{Ce}}$ \\
\hline LD & -0.92 & $-1.12(-1.15)$ & $-1.68_{\mathrm{Ga}}\left(-1,71_{\mathrm{Ga}}\right) /-0.82_{\mathrm{Ce}}$ \\
\hline SU.Tridentate & +0.02 & -- & -- \\
\hline
\end{tabular}


Table S2: Calculated scaled frequencies with two and three O-Ce-O trilayers slabs, i.e. 2TL and $3 T L$, respectively.

\begin{tabular}{|c|c|c|c|c|c|c|}
\hline & \multicolumn{2}{|c|}{$\mathrm{C}_{2} \mathrm{H}_{5} \mathrm{O}_{\text {LD.H,Ce }}$} & \multicolumn{2}{c|}{$\mathrm{C}_{2} \mathrm{H}_{5} \mathrm{O}_{\text {SU.H,Ce }}$} & \multicolumn{2}{c|}{$\mathrm{C}_{2} \mathrm{H}_{5} \mathrm{O}_{\text {LD.H,Ga }}$} \\
\hline & $3 \mathrm{TL}\left(\mathrm{cm}^{-1}\right)$ & $2 \mathrm{TL}\left(\mathrm{cm}^{-1}\right)$ & $3 \mathrm{TL}\left(\mathrm{cm}^{-1}\right)$ & $2 \mathrm{TL}_{\left(\mathrm{cm}^{-1}\right)}$ & $3 \mathrm{TL}_{\left(\mathrm{cm}^{-1}\right)}$ & $2 \mathrm{TL}_{\left(\mathrm{cm}^{-1}\right)}$ \\
\hline$\tau(\mathrm{CCO})$ & 1148 & 1146 & 1158 & 1163 & 1160 & 1158 \\
\hline$v(\mathrm{CO})$ & 1106 & 1105 & 1114 & 1114 & 1105 & 1103 \\
\hline$v_{\mathrm{as}}(\mathrm{CCO})$ & 1048 & 1051 & 1054 & 1058 & 1050 & 1050 \\
\hline$v_{\mathrm{s}}(\mathrm{CCO})$ & 896 & 896 & 912 & 914 & 878 & 874 \\
\hline
\end{tabular}

Table S3: Experimental and calculated frequencies of ethanol in gas phase in the $800-1200 \mathrm{~cm}^{-1}$ range. These values were used to find the scale factor $\lambda$.

\begin{tabular}{c|cc}
$\begin{array}{c}\text { Vibrational } \\
\text { mode }\end{array}$ & $\begin{array}{c}\text { Experimental } \\
\left(\mathbf{c m}^{-\mathbf{1}}\right)\end{array}$ & $\begin{array}{c}\text { Calculated } \\
\left(\mathbf{c m}^{-\mathbf{1}}\right)\end{array}$ \\
\hline$\tau(\mathrm{CCO})$ & 1161 & 1144.23 \\
\hline$\nu(\mathrm{CO})$ & 1091 & 1064.21 \\
\hline$\nu_{\mathrm{as}}(\mathrm{CCO})$ & 1028 & 1000.44 \\
\hline$v_{\mathrm{s}}(\mathrm{CCO})$ & 888 & 871.88 \\
\hline
\end{tabular}

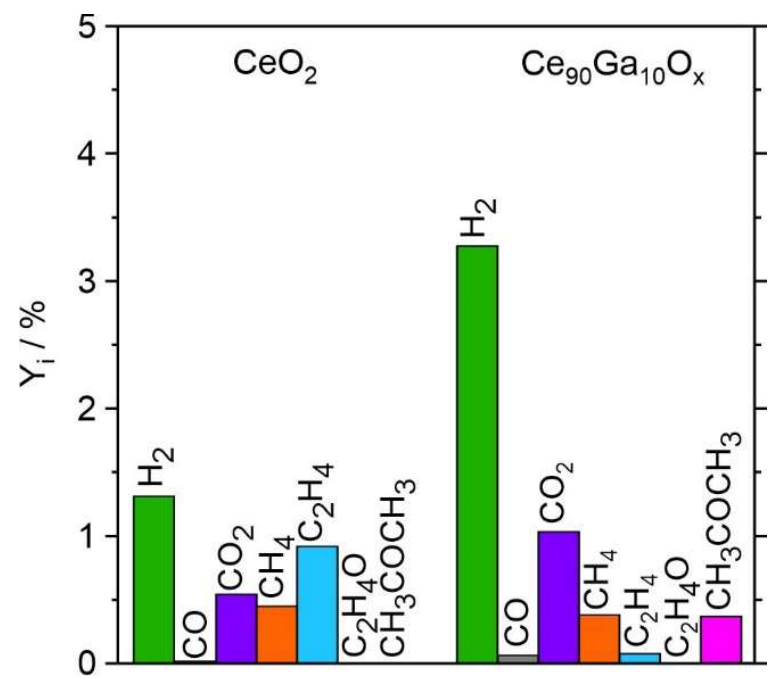

Figure S4. Product molar fraction at $500{ }^{\circ} \mathrm{C}$ under ESR conditions $\left(\mathrm{H}_{2} \mathrm{O} / \mathrm{C}_{2} \mathrm{H}_{5} \mathrm{OH}=6 / 1,1550\right.$ $\left.\mathrm{m}^{2} . \mathrm{h} / \mathrm{mol}_{\mathrm{C} 2 \mathrm{H} 5 \mathrm{OH}}\right)$ for $\mathrm{CeO}_{2}$ and $\mathrm{Ce}_{90} \mathrm{Ga}_{10} \mathrm{O}_{\mathrm{x}}$. 


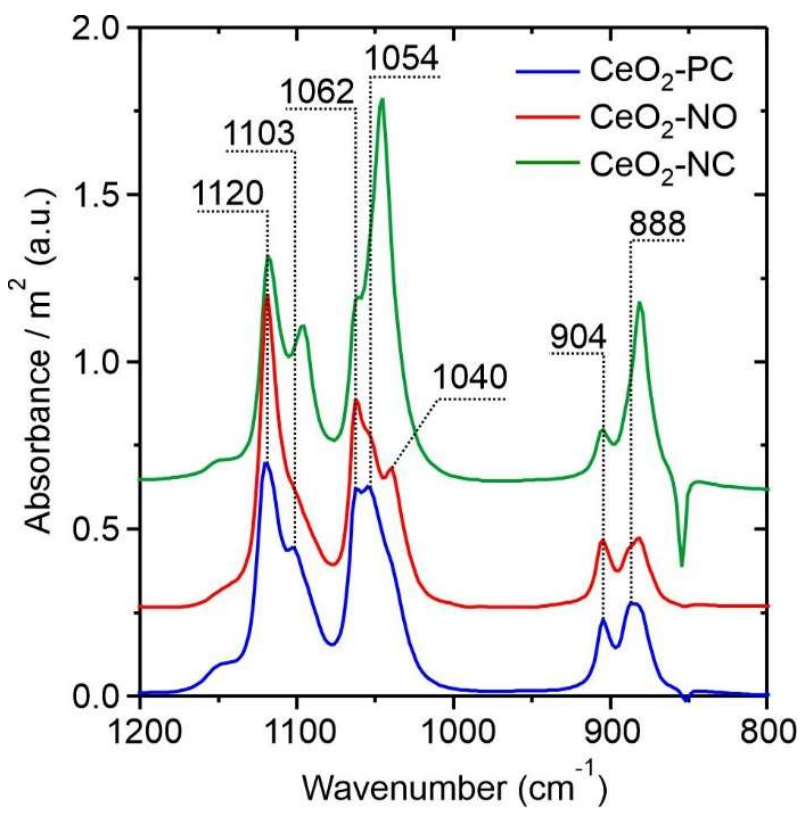

Figure S5. Normalized DRIFT spectra for $\mathrm{CeO}_{2}-\mathrm{PC}$ (polycrystalline), $\mathrm{CeO}_{2}-\mathrm{NO}$ (nanooctahedra) and $\mathrm{CeO}_{2}-\mathrm{NC}$ (nanocubes) after ethanol adsorption at $100^{\circ} \mathrm{C}$ and purging with $\mathrm{He}$. The spectrum of the clean oxide right before the adsorption was subtracted. The $\mathrm{CeO}_{2}-\mathrm{NO}_{\text {y }} \mathrm{CeO}_{2}-\mathrm{NC}$ were synthesized according to the methods described in references [1] and [2].

\section{Ethanol adsorption and vibrational frequencies of ethoxy species on the clean $\mathrm{CeO}_{2}(111)$ surface}

Here, we examine the dissociative adsorption of ethanol on the clean (non-doped and nonhydroxylated) $\mathrm{CeO}_{2}(111)$ surface $\left(\mathrm{Ce}_{18} \mathrm{O}_{36}\right.$ slab) and specifically consider monodentate, bidentate and tridentate ethoxy species with different adsorption sites for the hydrogen atom resulting from the $\mathrm{O}-\mathrm{H}$ bond cleavage of ethanol. The $\mathrm{DFT}+\mathrm{U}+\mathrm{DF} 2$ results indicate that stable ethoxy species are adsorbed on a Ce atom, that is, in a monodentate form (Figures $\mathrm{S} 3 \mathrm{a}$ and b), where the oxygen of the $\mathrm{C}_{2} \mathrm{H}_{5} \mathrm{O}$ group is interacting by hydrogen bonding with the adsorbed hydrogen on a neighboring surface lattice oxygen atom. In agreement with Li et al. [3] two types of monodentate states were found since the alkyl chain can be parallel or perpendicular to the surface normal. We name these ethoxy states as "standing-up" (SU), $\mathrm{C}_{2} \mathrm{H}_{5} \mathrm{O}_{s u}$, and "lying-down" (LD), $\mathrm{C}_{2} \mathrm{H}_{5} \mathrm{O}_{L D}$, respectively. These two states have very similar chemisorption energies, about $-1 \mathrm{eV}\left(-0.92\right.$ and $-0.93 \mathrm{eV}$ for the $\mathrm{C}_{2} \mathrm{H}_{5} \mathrm{O}_{\llcorner\mathrm{D}}$ and $\mathrm{C}_{2} \mathrm{H}_{5} \mathrm{O}_{\text {su }}$ species, respectively). The higher binding of the $\mathrm{C}_{2} \mathrm{H}_{5} \mathrm{O}_{\text {su }}$ state with respect to that reported by Beste et al. [4] $(-0.62 \mathrm{eV})$ is likely due to 
the inclusion of dispersion terms to the PBE functional (optB88-vdW+U) in the present work. All other considered states do not bind to the surface, out of which the one with the lowest adsorption energy is a tridentate ethoxy (Figure 4c) with an adsorption energy of $+0.02 \mathrm{eV}$ with respect to ethanol in the gas phase. It was also considered that ethanol could dissociate by the $\mathrm{C}-\mathrm{O}$ bond, generating a $\mathrm{C}_{2} \mathrm{H}_{5}$ species adsorbed on a surface oxygen atom and a $\mathrm{OH}$ species adsorbed on a Ce atom, but the energy of such a state is $-0.57 \mathrm{eV}$, i.e., $0.36 \mathrm{eV}$ more unstable that the stable SU monodentate ethoxy species.

Moreover, according to the findings in this study, the (scaled) vibrational frequencies were calculated for the more stable $\mathrm{C}_{2} \mathrm{H}_{5} \mathrm{O}_{L D}$ and $\mathrm{C}_{2} \mathrm{H}_{5} \mathrm{O}_{\text {su }}$ species, see Table $\mathrm{S} 2$. In the $1200-800 \mathrm{~cm}^{-}$ ${ }^{1}$ range, four vibrational modes were found, a CCO twist mode $(\tau)$ around $1150-1160 \mathrm{~cm}^{-1}$, three stretching modes $(v)$ CO mode between $1120-1100 \mathrm{~cm}^{-1}$, an asymmetric CCO mode $\left(v_{\text {as }}\right)$ at $1060-1050 \mathrm{~cm}^{-1}$, and a symmetric CCO mode $\left(\nu_{\mathrm{s}}\right)$ in the $900-880 \mathrm{~cm}^{-1}$ range. The calculated scaled frequencies for the $\mathrm{C}_{2} \mathrm{H}_{5} \mathrm{O}_{L D}$ state are: $1152,1119,1055$ and $925 \mathrm{~cm}^{-1}$, whereas those for the $\mathrm{C}_{2} \mathrm{H}_{5} \mathrm{O}_{\text {su }}$ state are: $1159,1108,1061$ and $907 \mathrm{~cm}^{-1}$ (see Table $\mathrm{S} 2$ for the as calculated values). As mentioned in the main text, two sets of bands that could result from the existence of two types of ethoxy species [type 1 and 2 , with $v(\mathrm{j} \text {-mode })_{1}<v(\mathrm{j} \text {-mode })_{2}$, respectively] are experimentally observed, and the intensities of the bands at 1103,1054 and $888 \mathrm{~cm}^{-1}[v(\mathrm{j}-$ mode) ${ }_{1}$ ] decrease slower with increasing temperature than those of the 1120, 1062 and $904 \mathrm{~cm}^{-}$ ${ }^{1}\left[v(\mathrm{j} \text {-mode })_{2}\right]$ bands (see also Section 2$)$. If we tentatively assign the type 1 and type 2 species to $\mathrm{C}_{2} \mathrm{H}_{5} \mathrm{O}_{L D}$ and $\mathrm{C}_{2} \mathrm{H}_{5} \mathrm{O}_{\text {su, }}$, respectively, we observe that the $v(\mathrm{j} \text {-mode })_{1}<v(\mathrm{j} \text {-mode })_{2}$ order is not fully reproduced, namely, $v(\mathrm{CO})_{\llcorner D} 1119 \mathrm{~cm}^{-1}>v(\mathrm{CO})_{\mathrm{SU}} 1108 \mathrm{~cm}^{-1}, v_{\text {as }}(\mathrm{CCO})_{\llcorner\mathrm{D}} 1055 \mathrm{~cm}^{-1}<$ $v_{\text {as }}(\mathrm{CCO})_{\text {su }} 1061 \mathrm{~cm}^{-1}$, and $v_{\mathrm{s}}(\mathrm{CCO})_{\text {LD }} 925 \mathrm{~cm}^{-1}>v_{\mathrm{s}}(\mathrm{CCO})_{\mathrm{su}} 907 \mathrm{~cm}^{-1}$ (Figure S4). 

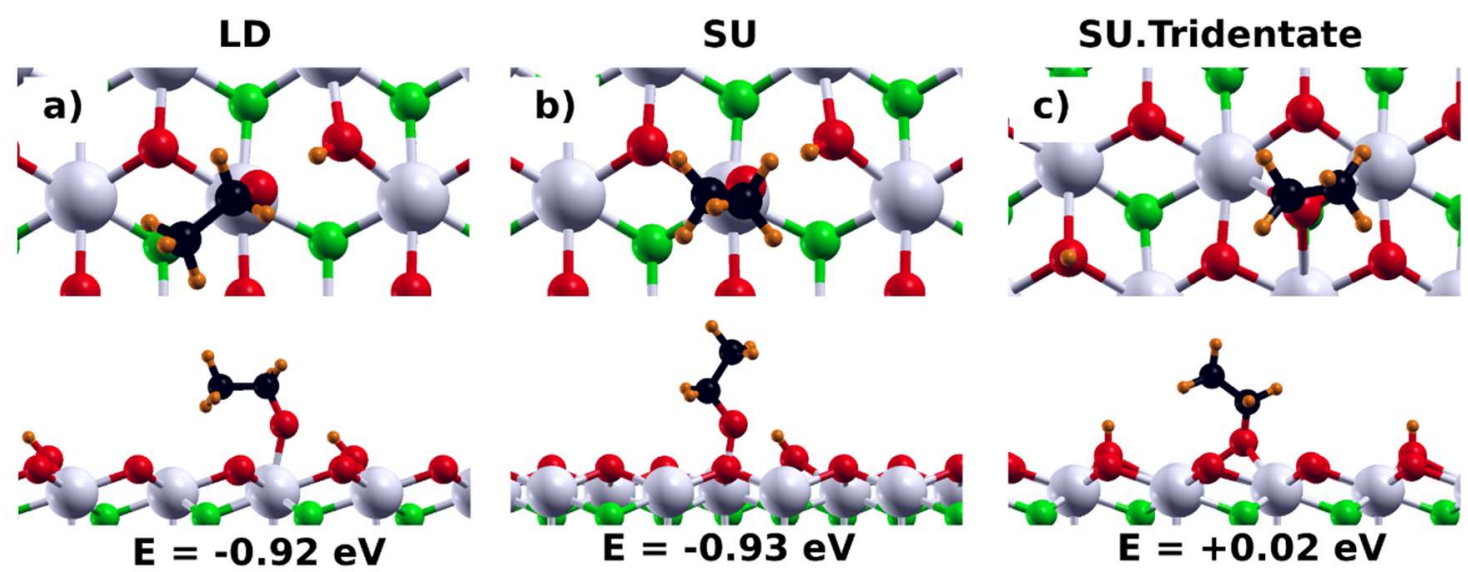

Figure S6. Top and side views of adsorbed ethoxy species with a co-adsorbed dissociated water molecule on $\mathrm{CeO}_{2}(111)\left(\mathrm{Ce}_{18} \mathrm{O}_{36}\right.$ slab): a) monodentate $\mathrm{C}_{2} \mathrm{H}_{5} \mathrm{O}_{L \mathrm{~L}}$, b) monodentate $\mathrm{C}_{2} \mathrm{H}_{5} \mathrm{O}_{\text {su }}$, c) tridentate $\mathrm{C}_{2} \mathrm{H}_{5} \mathrm{O}_{\text {su }}$. Color code: $\mathrm{Ce}$ atoms, white; $\mathrm{O}$ atoms of the first $\mathrm{CeO}_{2}$ layer and belonging to the ethoxy species, red; $\mathrm{O}$ atoms of the second $\mathrm{CeO}_{2}$ layer, green; $\mathrm{C}$ atoms, black, and $\mathrm{H}$ atoms, orange. The ethanol adsorption energies are calculated with respect to ethanol in the gas-phase and the clean surface, i.e, $E_{\text {ads }}=E\left[\left(\mathrm{CH}_{3} \mathrm{O}+\mathrm{H}\right) / \mathrm{Ce}_{18} \mathrm{O}_{36}\right]-E\left[\mathrm{Ce}_{18} \mathrm{O}_{36}\right]-E\left[\mathrm{CH}_{3} \mathrm{OH}_{\text {gas }}\right]$, where $\mathrm{E}\left[\left(\mathrm{CH}_{3} \mathrm{O}+\mathrm{H}\right) / \mathrm{Ce}_{18} \mathrm{O}_{36}\right]$ is he total energy of the ethoxy species and hydrogen co-adsorbed on the surface, $E\left[\mathrm{Ce}_{18} \mathrm{O}_{36}\right]$ isthe total energy of the surface without the adsorbate, and $E\left[\mathrm{CH}_{3} \mathrm{OH}_{\text {gas }}\right]$ is the energy of the gas phase ethanol molecule (cf. Eq 1 in the main text).

Table S4: Calculated and scaled frequencies of the most important ethoxy adsorbed states.

\begin{tabular}{|c|c|c|c|c|c|c|c|c|c|c|}
\hline \multirow{3}{*}{$\begin{array}{l}\text { Vibrational } \\
\text { mode }\end{array}$} & \multicolumn{10}{|c|}{ States } \\
\hline & \multicolumn{2}{|c|}{ LD,Ce } & \multicolumn{2}{|c|}{$\mathrm{SU}, \mathrm{Ce}$} & \multicolumn{2}{|c|}{ LD. $\mathrm{H}, \mathrm{Ce}$} & \multicolumn{2}{|c|}{ SU.H,Ce } & \multicolumn{2}{|c|}{ LD.H,Ga } \\
\hline & Calc. & Scaled & Calc. & Scaled & Calc. & Scaled & Calc. & Scaled & Calc. & Scaled \\
\hline$\tau(\mathrm{CCO})$ & 1128 & 1152 & 1135 & 1159 & 1123 & 1146 & 1139 & 1163 & 1134 & 1158 \\
\hline$v(\mathrm{CO})$ & 1096 & 1119 & 1085 & 1108 & 1082 & 1105 & 1091 & 1114 & 1080 & 1103 \\
\hline$v_{\mathrm{as}}(\mathrm{CCO})$ & 1033 & 1055 & 1039 & 1061 & 1030 & 1051 & 1036 & 1058 & 1028 & 1050 \\
\hline$v_{s}(\mathrm{CCO})$ & 906 & 925 & 889 & 907 & 878 & 896 & 895 & 914 & 856 & 874 \\
\hline
\end{tabular}




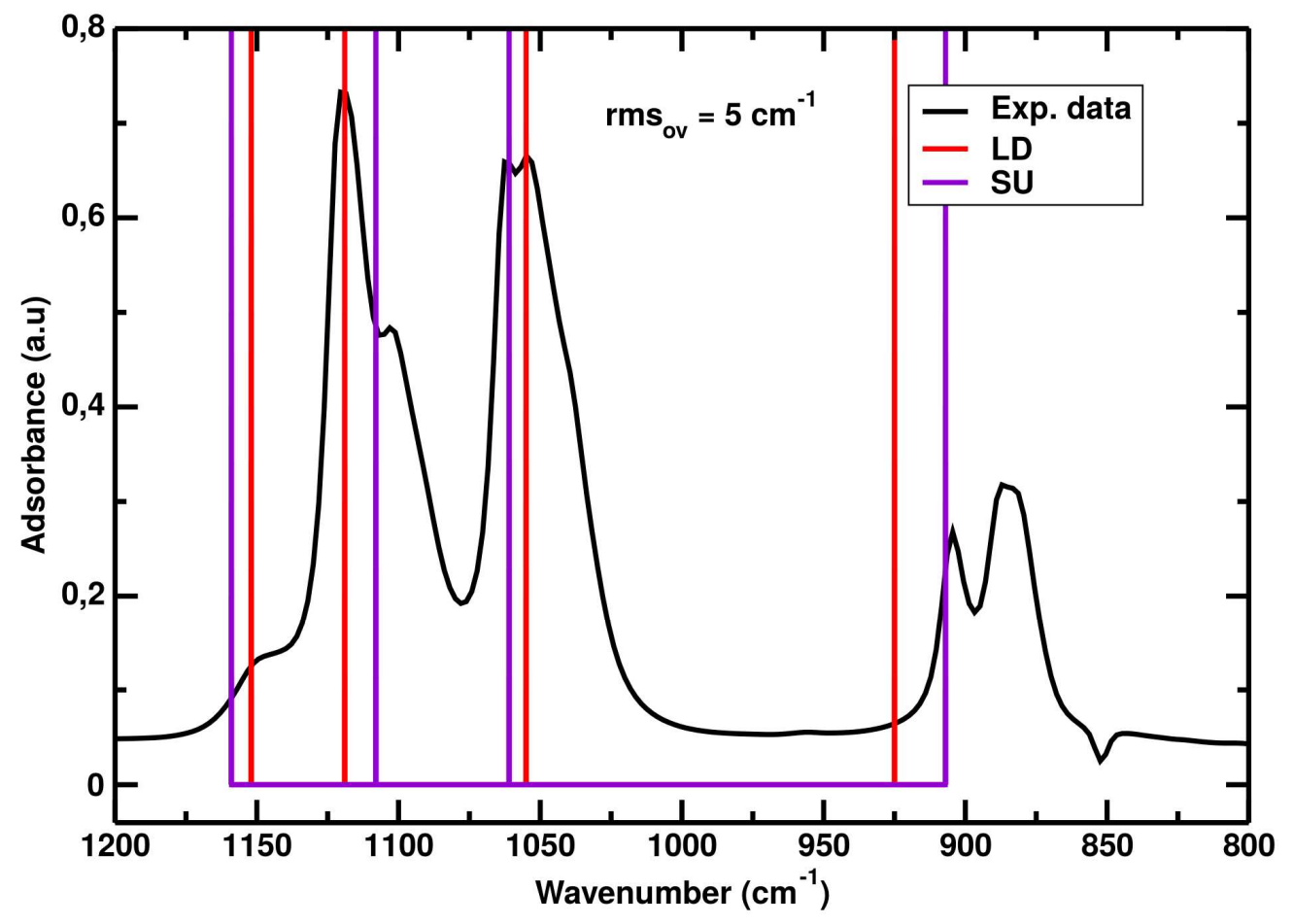

Figure S7: The calculated scaled frequencies for $\mathrm{C}_{2} \mathrm{H}_{5} \mathrm{O}_{L D}$ (red lines) and $\mathrm{C}_{2} \mathrm{H}_{5} \mathrm{O}_{s u}$ (violet lines) in the $1200-800 \mathrm{~cm}^{-1}$ range for the on the non-hydroxylated $\mathrm{CeO}_{2}$ surface model are

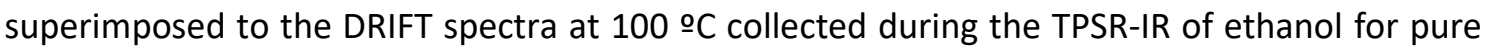
$\mathrm{CeO}_{2}$ (black curve).

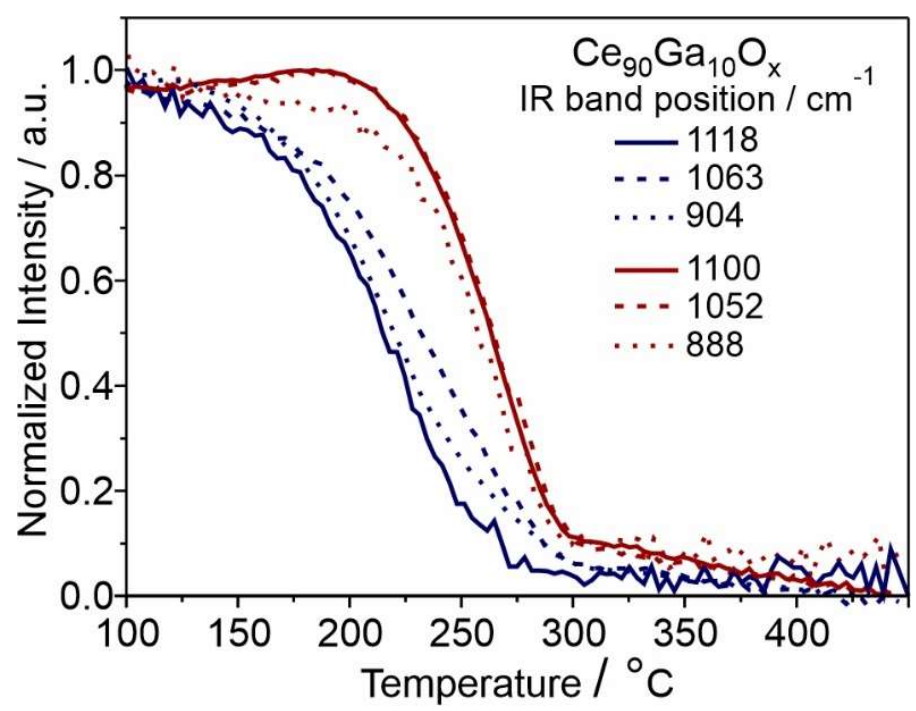

Figure S8. Normalized integrated intensity of the ethoxy DRIFT signals detected in the $1200-$ $800 \mathrm{~cm}^{-1}$ region of the spectra during the TPSR-IR for $\mathrm{Ce}_{90} \mathrm{Ga}_{10} \mathrm{O}_{x}$. 

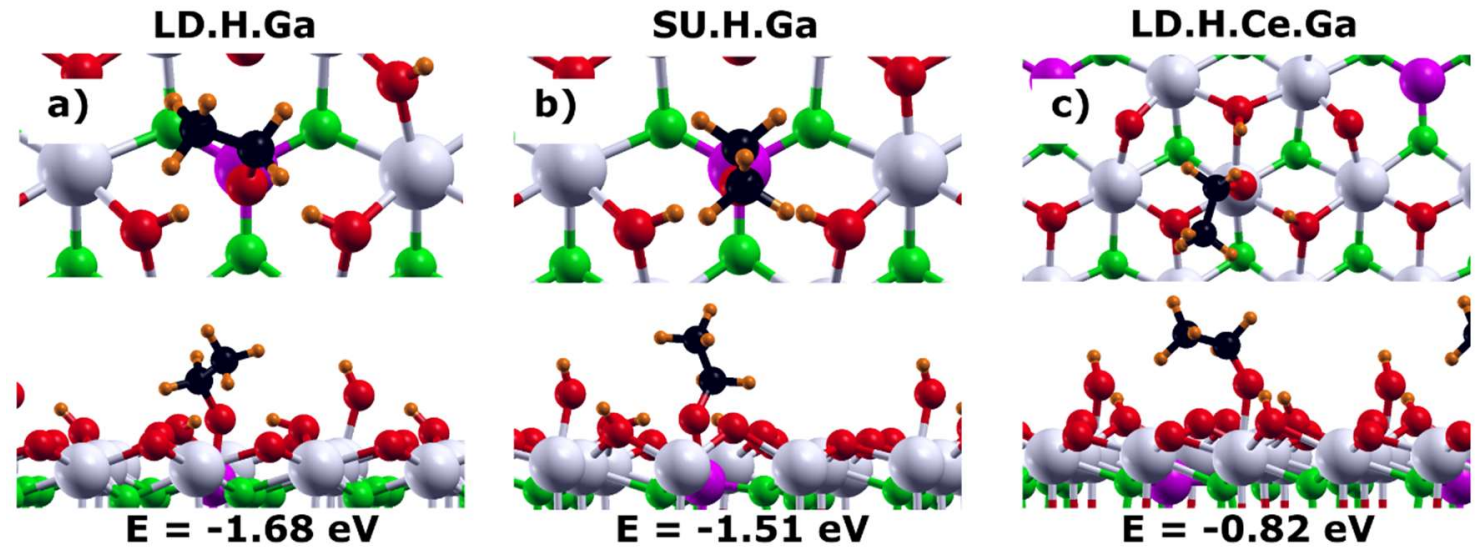

Figure 59: Top and side views of dissociatively adsorbed ethanol (ethoxy+H) on the hydroxylated $\mathrm{Ce}(\mathrm{Ga}) \mathrm{O}_{x}$ surface model. a) monodentate $\mathrm{C}_{2} \mathrm{H}_{5} \mathrm{O}_{S U . H, G a}$, b) monodentate $\mathrm{C}_{2} \mathrm{H}_{5} \mathrm{O}_{L D . H, G a}$ and $\mathrm{c}$ ) monodentate lying down ethoxy adsorbed on a $\mathrm{Ce}$ atom at the $\mathrm{CeGaO}_{2}$ surface. Color code: $\mathrm{Ce}$ atoms, white; $\mathrm{O}$ atoms of the first $\mathrm{CeO}_{2}$ layer and belonging to the ethoxy species, red; $\mathrm{O}$ atoms of the second $\mathrm{CeO}_{2}$ layer, green; $\mathrm{C}$ atoms, black, $\mathrm{H}$ atoms, orange; $\mathrm{Ga}$ atom, purple. 

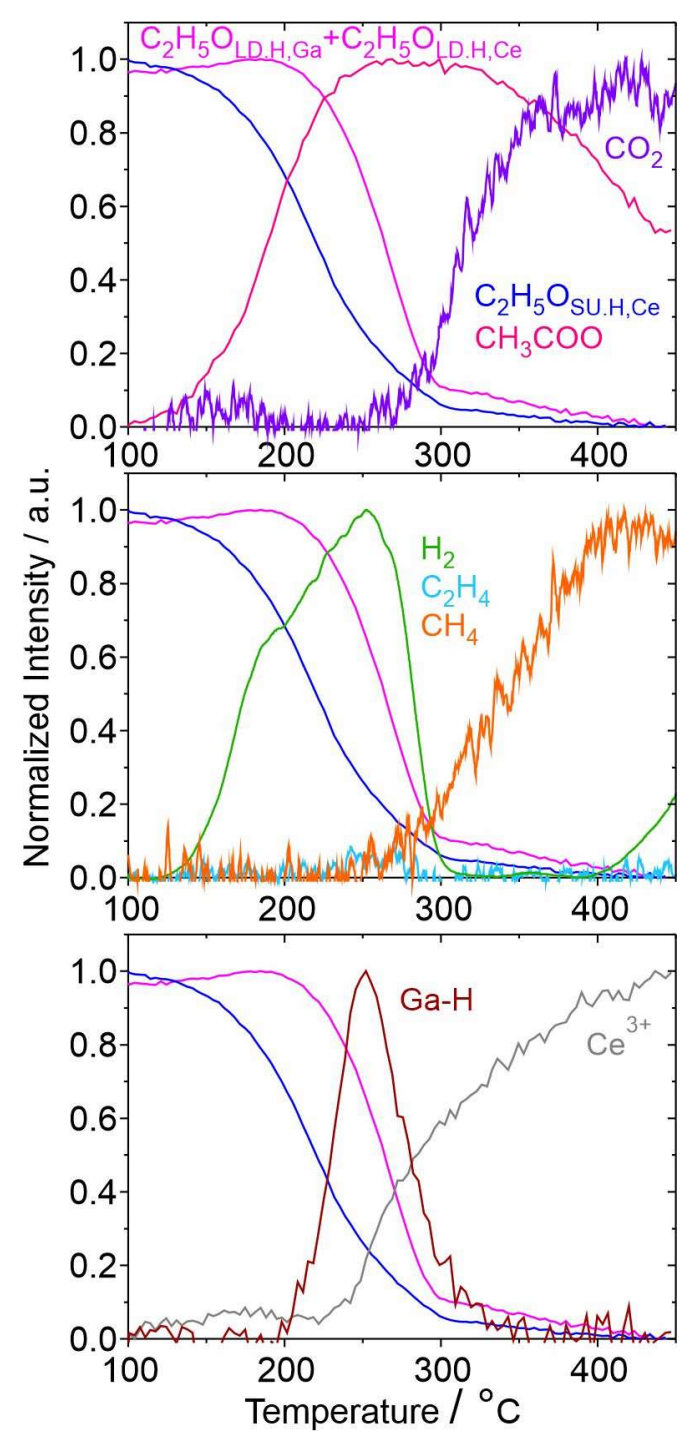

Figure S10. Normalized integrated intensity of the most important DRIFT signals detected during the TPSR-IR (left axis) and normalized intensity of the gaseous products detected during the TPSR-MS (right axis) of $\mathrm{Ce}_{90} \mathrm{Ga}_{10} \mathrm{O}_{x}$ sample. 


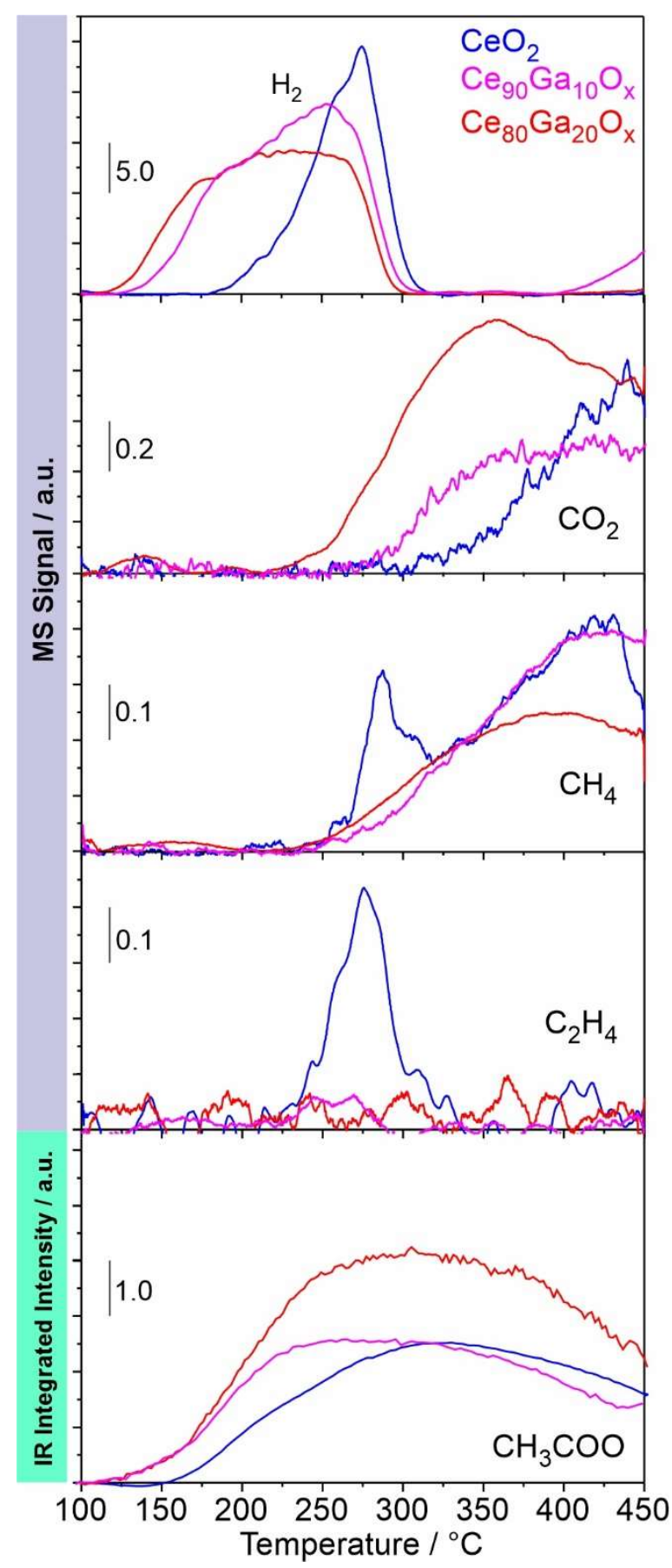

Figure S11. Traces of $\mathrm{H}_{2}, \mathrm{CO}_{2}, \mathrm{CH}_{4}$ and $\mathrm{C}_{2} \mathrm{H}_{4}$ obtained during the TPSR-MS and integrated intensity of the $1550 \mathrm{~cm}^{-1}$ IR signal of acetate species obtained during TPSR-IR, for $\mathrm{CeO}_{2}$ and $\mathrm{CeGaO}_{x}$ samples. 


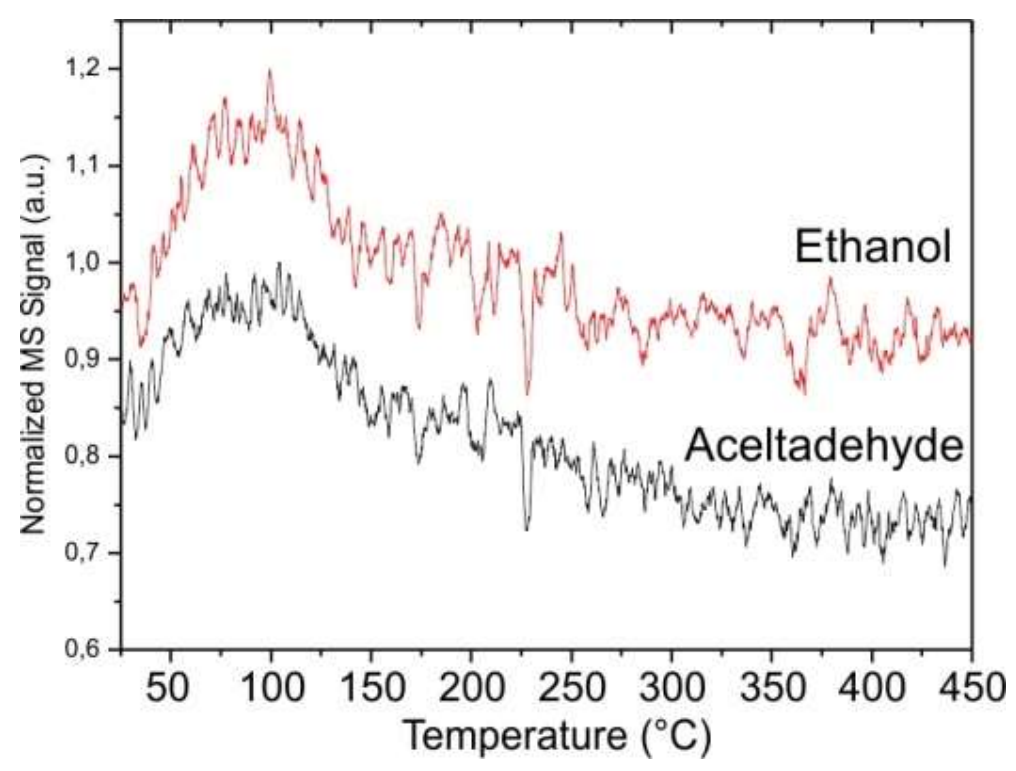

Figure S12. Normalized intensity of the ethanol and acetaldehyde detected during the TPSR-MS of $\mathrm{CeO}_{2}$ sample after adsorption of ethanol at room temperature.

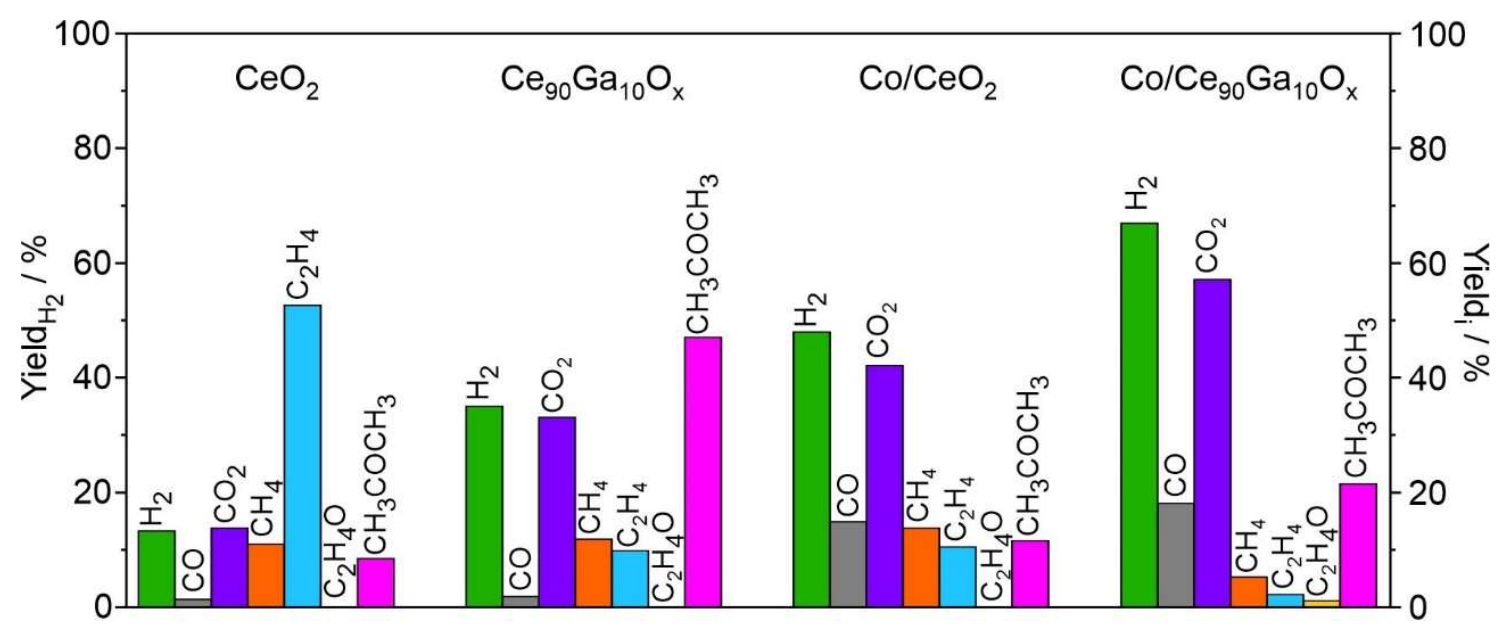

Figure S13. Initial product yield ( $\mathrm{t}=0 \mathrm{~h}$ ) at $500{ }^{\circ} \mathrm{C}$ under ESR conditions for $\mathrm{CeO}_{2}, \mathrm{Ce}_{90} \mathrm{Ga}_{10} \mathrm{O}_{\mathrm{x}}$, $\mathrm{Co} / \mathrm{CeO}_{2}$ and $\mathrm{Co} / \mathrm{Ce}_{90} \mathrm{Ga}_{10} \mathrm{O}_{x}$ after pretreatment with pure $\mathrm{H}_{2}$ at $450^{\circ} \mathrm{C}$ for $1 \mathrm{~h}$. Experimental conditions: 1) $\mathrm{H}_{2} \mathrm{O}: \mathrm{C}_{2} \mathrm{H}_{5} \mathrm{OH}=6: 1-\mathrm{Ar}$ diluted-, 2) Residence time $=1550 \mathrm{~m}^{2} . \mathrm{h} / \mathrm{mol}_{\mathrm{C} 2 \mathrm{H} 5 \mathrm{OH}}$ or 0.14 $\mathrm{gco} . \mathrm{h} / \mathrm{mol}_{\mathrm{C2}} \mathrm{HOH}$. Carbon balance: for $\mathrm{CeO}_{2}=90 \%$ and for $\mathrm{Ce}_{90} \mathrm{Ga}_{10} \mathrm{O}_{\mathrm{x}}=103 \%, 0.5 \% \mathrm{Co} / \mathrm{CeO}_{2}=$ $93 \%$ and for $1 \% \mathrm{Co} / \mathrm{Ce}_{90} \mathrm{Ga}_{10} \mathrm{O}_{x}=105 \%$ at $500 \stackrel{\circ}{ } \mathrm{C}$. 


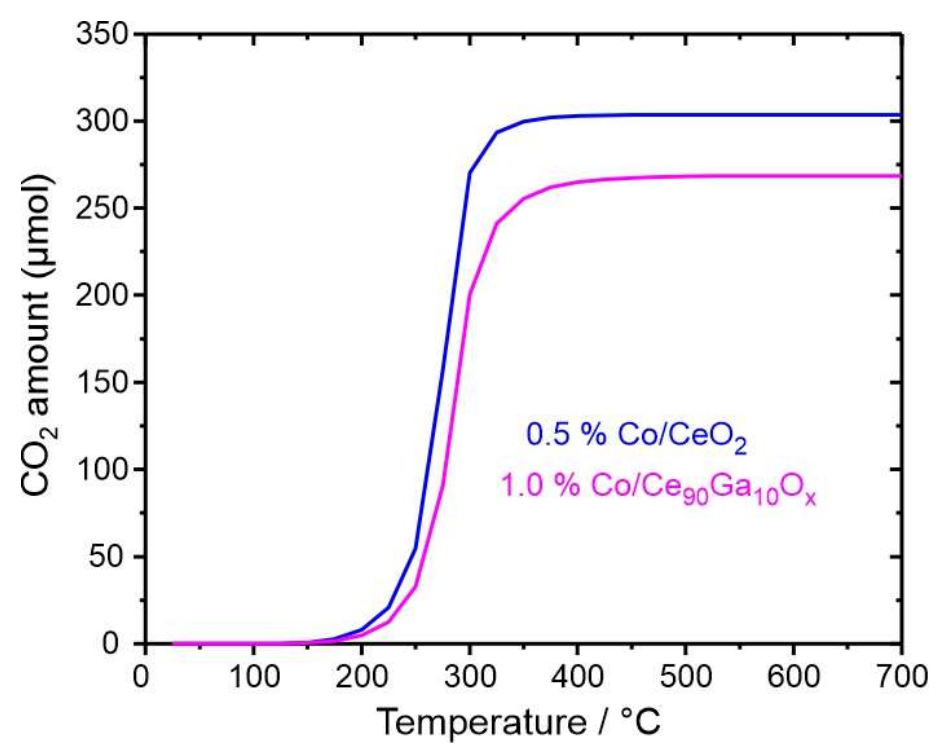

Figure S14. Cumulative amount of $\mathrm{CO} 2$ during TPO experiment performed on the Co catalysts after ESR reaction.

\section{References}

[1] L. Yan, R. Yu, J. Chen, X. Xing, Template-free hydrothermal synthesis of $\mathrm{CeO}_{2}$ nanooctahedrons and nanorods: Investigation of the morphology evolution, Cryst. Growth Des. 8 (2008) 1474-1477. https://doi.org/10.1021/cg800117v.

[2] H.X. Mai, L.D. Sun, Y.W. Zhang, R. Si, W. Feng, H.P. Zhang, H.C. Liu, C.H. Yan, Shapeselective synthesis and oxygen storage behavior of ceria nanopolyhedra, nanorods, and nanocubes, J. Phys. Chem. B. 109 (2005) 24380-24385.

https://doi.org/10.1021/jp055584b.

[3] M. Li, Z. Wu, S.H. Overbury, Surface structure dependence of selective oxidation of ethanol on faceted $\mathrm{CeO}_{2}$ nanocrystals, J. Catal. 306 (2013) 164-176. https://doi.org/10.1016/j.jcat.2013.06.019.

[4] A. Beste, S.H. Overbury, Pathways for ethanol dehydrogenation and dehydration catalyzed by ceria (111) and (100) surfaces, J. Phys. Chem. C. 119 (2015) 2447-2455. https://doi.org/10.1021/jp509686f. 
